Longitudinal studies of executive and cognitive development after preterm birth

Aiko Lundequist

Doctoral thesis in Psychology, Stockholm University, 2012 



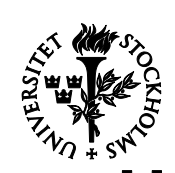

Stockholm

University

\section{Longitudinal studies of executive and cognitive development after preterm birth}

Aiko Lundequist 
(C)Aiko Lundequist, Stockholm 2012

ISBN 987-91-7447-550-0

Printed in Sweden by US-AB, Stockholm 2012

Distributor: Department of Psychology, Stockholm University 
To Tomas, Mikaela and Erika 



\section{Abstract}

The population of survivors after preterm birth is increasing, and, in conjunction with this, there is growing concern about their long-term development. Stockholm Neonatal Project (SNP) is a longitudinal population-based study of children born prematurely in 1988-93, with a very low birth weight $(<1500 \mathrm{~g})$, who have been followed prospectively from birth through adolescence. A matched control group was recruited at age $51 / 2$ years. The overall aim of this thesis was to investigate the long-term development of preterm children compared to controls, paying particular attention to their executive functions (EF) in relation to the degree of prematurity, birth weight and medical risks. Study I, utilizing Bender drawings and other data obtained at age 5 $1 / 2$ years, showed a disadvantage in visuo-motor development in preterm children, especially among the boys. Visuo-motor skills were highly related to performance IQ (PIQ) in both groups, and also to EF in the preterm group. In Study II, data from the NEPSY test battery administered at age $51 / 2$ was used, and neuropsychological profiles typical of preterm children and term born children respectively, were identified through cluster analysis. The general level of performance corresponded well with intelligence, motor functions and parental education in both groups, but preterm children had overall lower results and exhibited greater variability across domains. Study III showed that extremely preterm birth (w. 23-27) per se poses a risk for cognitive outcome at age 18 , particularly for $\mathrm{EF}$, and that perinatal medical complications add to the risk. By contrast, adolescents born very preterm (w. 28-31) performed just as well as term-born controls in all cognitive domains. However, adolescents who had been born moderately preterm (w. 32-36) and small for gestational age, showed general cognitive deficits. Study IV found that cognitive development was highly stable over time, with parental education and $\mathrm{EF}$ at $51 / 2$ years being significant predictors for cognitive outcome at age 18, in both groups. In the preterm group, perinatal medical risks and being small for gestational age continued to significantly influence development from $51 / 2$ to 18 years. Study $V$ demonstrated that neuropsychological scoring of Bender drawings, which was developed in study I, predicted general cognitive outcome as well as EF in adolescence. This indicates that developmental screening using Bender drawings with neuropsychological scoring may be useful around school entry.

In summary, the results illustrate that cognitive outcome after preterm birth is highly diverse and influenced by biological and environmental factors. No 
single factor can explain or predict children's development, but we conclude that extreme prematurity presents a particular risk for EF dysfunction. Developmental screening is recommended to identify children who may benefit from special educational interventions.

Key words

Preterm birth, low birth-weight, degree of prematurity, medical risks, general intelligence, executive functions, parental education, gender, development. 


\section{List of studies}

Böhm, B., Lundequist, A., Smedler, A-C. (2010) Visualmotor and executive functions in children born preterm: The Bender Visual Motor Gestalt Test revisited. Scandinavian Journal of Psychology, 51, 376-384.

II

Lundequist, A., Böhm, B., Smedler, A-C. (2012) Individual neuropsychological profiles at age $51 / 2$ years in children born preterm in relation to medical risk factors. Child Neuropsychology, iFirst, 1-19.

III

Lundequist, A., Böhm, B., Forssberg, H., Smedler, A-C (manuscript in prep. for submission for publication) Stockholm Neonatal Project: Cognitive and executive functioning in adolescents born preterm.

IV Lundequist, A., Böhm, B., Forssberg, H., Smedler, A-C (manuscript in prep. for submission for publication) Stockholm Neonatal Project: Stability and predictors of cognitive outcome from preschool through adolescence in children born preterm.

V Lundequist, A., Böhm, B., Smedler, A-C (submitted). Screening for executive dysfunction before school start. Concurrent and predictive validity of the Bender test.

Study I is reprinted from Scandinavian Journal of Psychology, with permission from the publisher.

Study II is reprinted from Child Neuropsychology, with permission from the publisher. 


\section{Contents}

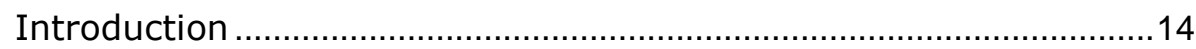

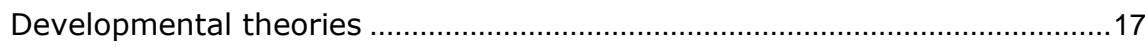

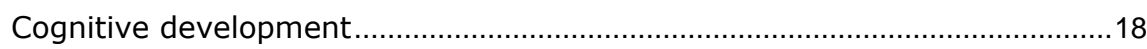

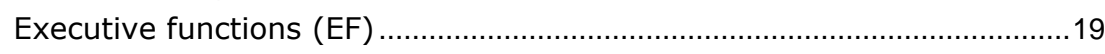

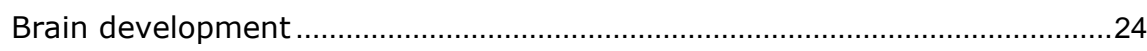

Perinatal medical complications associated with preterm birth ......................26

Preterm children's development ...................................................................2

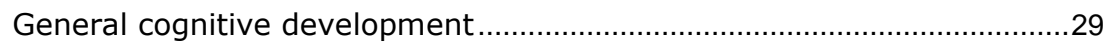

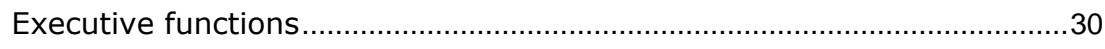

Other neuropsychological functions ................................................................3

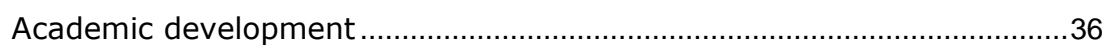

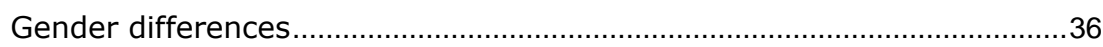

Socio-emotional development ....................................................................37

Socioeconomic factors, parental education ....................................................38

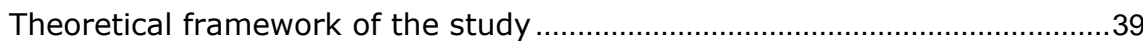

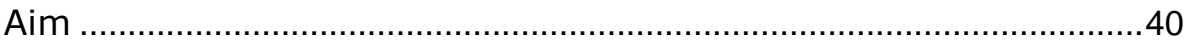

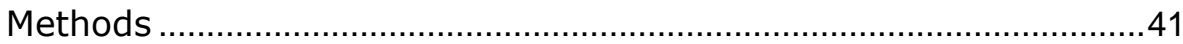

Participants and procedure at $51 / 2$ years of age............................................41

Participants and procedure at 18 years of age ............................................. 42

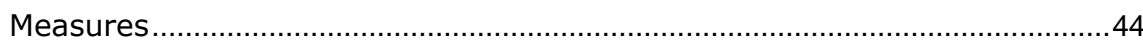

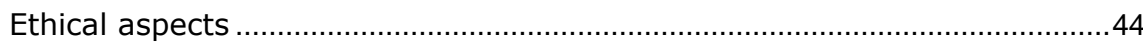

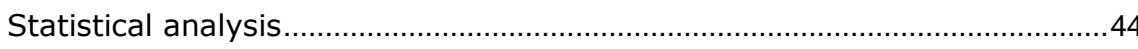

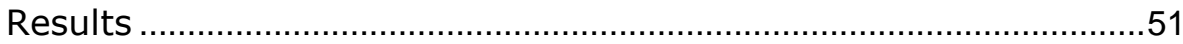

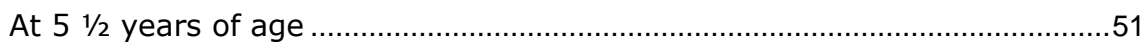

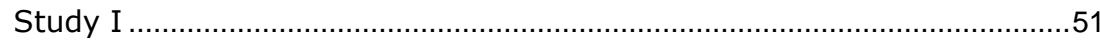

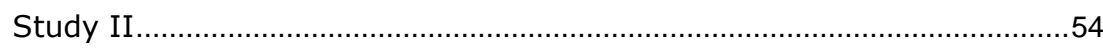

At 18 years of age ........................................................................................

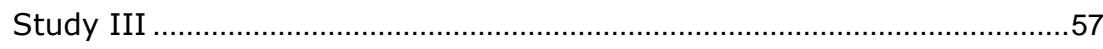

Predicting the developmental outcome from $5 \frac{1 / 2}{2}$ to 18 years of age ..........61

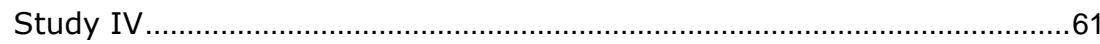

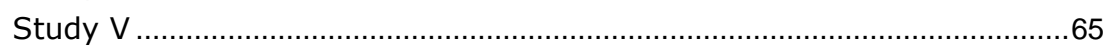

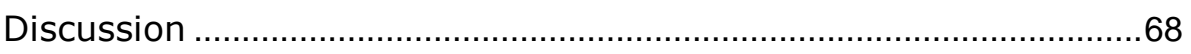

Group differences: preterm vs term ..........................................................6 


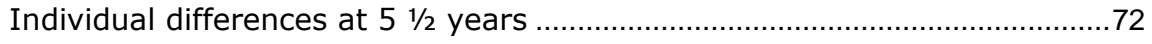

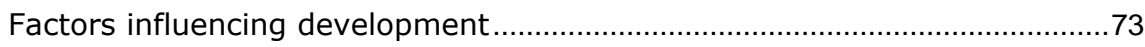

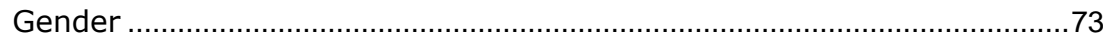

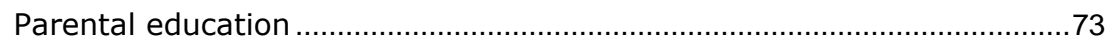

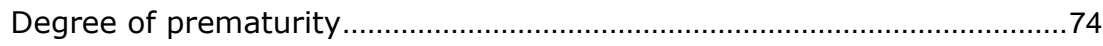

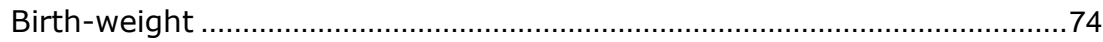

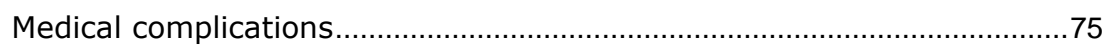

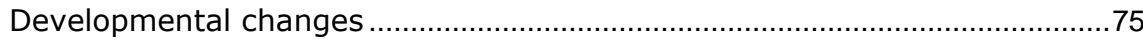

Summary of the present state of knowledge ............................................ 77

Methodological strengths and challenges ................................................... 78

Suggestions for further research ............................................................... 79

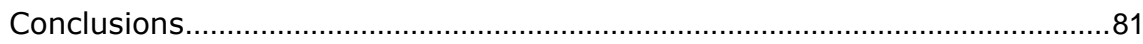

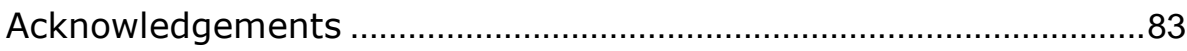

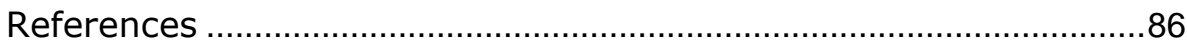




\section{Abbreviations and definitions}

\begin{tabular}{ll} 
ADHD & Attention-Deficit /Hyperactivity Disorder \\
ANOVA & Analysis of variance \\
Bender & Bender Visual Motor Gestalt test \\
BW & Birth-weight \\
CLD & Chronic lung disease \\
CNS & Central nervous system \\
D-KEFS & Delis-Kaplan Executive Function Systems \\
EF & Executive functions \\
FIQ & Full scale intelligence quotient \\
ELBW & Extremely low-birth weight \\
EPT & Extremely preterm \\
fMRI & Functional magnetic resonance imaging \\
GA & Gestational age \\
IQ & Intelligence quotient \\
IUGR & Intrauterine growth retardation \\
IVH & Intraventricular hemorrhage \\
MRI & Magnetic resonance imaging \\
NEPSY & NEuroPSYchological assessment battery \\
PIQ & Performance (non-verbal) intelligence quotient \\
PVL & Periventricular leukomalacia \\
ROP & Retinopathy of prematurity \\
SD & Standard deviation \\
SGA & Small for gestational age \\
SNP & Stockholm Neonatal Project \\
The Movement ABC & The Movement Assessment Battery for Children \\
VLBW & Very low birth-weight \\
VPT & Very preterm \\
WISC-III & Wechsler Intelligence Scale for Children third edi- \\
& tion \\
WPPSI-R & Wechsler-Preschool and Primary Scale of intelli- \\
& gence- Revised \\
\hline
\end{tabular}


Preterm birth is defined as delivery before 37 weeks. Definition of preterm from the World Health Organization (WHO):

Definitions based on gestational age: moderately (GA 32-36 weeks), very (GA 28-31 weeks) or extremely (GA $\leq 27$ weeks) preterm.

Definitions based on birth-weight: Low $(<2500 \mathrm{~g})$, Very low $(<1500 \mathrm{~g})$ and extremely low ( $<1000 \mathrm{~g})$ birth-weight 


\section{Introduction}

In high income countries, at least five percent of children are born preterm and the survival rates for preterm infants have improved dramatically in the past three decades, thanks to advances in perinatal medical care. As a consequence, the population of survivors of preterm birth is increasing, however, less is known about the long-term consequences of being born significantly early. Concern for preterm children and their families as well as what supports society needs to provide during the neonatal period and beyond make an understanding of the long-term consequences of importance. The challenge is to identify if preterm children have special needs, and if so, to determine what kind of support might alleviate these needs, as well as determining when such measures should be implemented and for how long.

Population based studies from Norway and Canada recently reported that, on a group level, young adults who were born preterm attained lower educational levels, had lower incomes and a higher proportion were in receipt of Social Security benefits (Dall'oglio et al., 2010; Goddeeris et al., 2010; Moster, Lie, \& Markestad, 2008). A Swedish national cohort study reported similar results and demonstrated that preventive programs in perinatal health could result in economic gains for society of about 65 million Euros in one year alone, in terms of the increased revenue from taxes and the decreased cost of having to pay social security benefits (Lindström, Winbladh, Haglund, \& Hjern, 2007). This illustrates the importance of conducting clinical follow-up studies.

The cause of preterm birth is still unknown, however, there are several factors that are known to be associated with preterm birth. For instance, maternal age (both high and low), smoking, infections, inflammation and stress have all been confirmed to be risk factors (Andrews, Hauth, \& Goldenberg, 2000; Copper et al., 1996; Hoffman et al., 2007; Kyrklund-Blomberg \& Cnattingius, 1998; Olausson, Cnattingius, \& Haglund, 1999). Twin pregnancy can also lead to preterm birth (Blondel, Macfarlane, Gissler, Breart, \& Zeitlin, 2006).

The improved survival rates have been particularly striking in the most immature and smallest infants, corresponding to those with extremely low birth weights (ELBW; <1000 g). According to a British single-center cohort study 
of extremely preterm children, overall survival rates rose from 32 to 71 percent between 1981-2000 (Riley, Roth, Sellwood, \& Wyatt, 2008) and similar figures have been reported by others (Arpino et al., 2010; Hintz, Kendrick, Vohr, Poole, \& Higgins, 2005; Lemons et al., 2001; Stephens \& Vohr, 2009). In Sweden, the incidence of extreme prematurity was 3.3 per 1000 births in 2004 to 2007, and the overall one-year survival of infants born alive at 22-26 weeks of gestation was 70 percent, ranging from 10 percent at 22 weeks to 85 percent at 26 weeks (Fellman et al., 2009).

Many studies report that, the more prematurely a child is born, the higher the risk of neurodevelopmental impairment (Hintz, Kendrick, Vohr, et al., 2005; Leversen et al., 2011; Washburn et al., 2007; Wilson-Costello, Friedman, Minich, Fanaroff, \& Hack, 2005). It is a matter of debate whether or not the improvements in survival among extremely preterm infants have also increased the risk of neurodevelopmental impairment among survivors. Some argue that this concern is unfounded, and claim that such impairments have in fact decreased (Washburn et al., 2007), whereas others have found that improved survival rates are accompanied by a higher incidence of neurodevelopmental problems (Wilson-Costello et al., 2005). Yet other studies report that overall neurodevelopmental outcomes have largely remained unchanged (Colvin, McGuire, \& Fowlie, 2004; Hintz et al., 2011; Hintz, Kendrick, Vohr, et al., 2005). In spite of these conflicting results, researchers agree that preterm and in particular extremely preterm birth poses an increased risk for the future development of the child.

Differences in results could, in part, be explained by population samples. Many studies have investigated differences in development between children born preterm and those born at term. However, the vast majority of studies have focused on cognitive and emotional outcome on group levels. The diversity of preterm children's cognitive development in relation to multiple factors such as gestational age, birth-weight, medical complications, gender, and environmental influence is still unclear. To identify mechanisms underlying individual variations in preterm children's cognitive outcome, behavior and mental health is important in order to develop appropriate intervention services that are also well-timed.

The Stockholm Neonatal Project (SNP) is a longitudinal and population based study involving a large cohort of children who have been followed prospectively since birth. In this context, a "preterm child" is any child that was born preterm and who has lived to grow up into childhood, regardless of his or her present age. The longitudinal design of the SNP allows us to investigate individual developmental aspects that cannot be addressed in registerbased or crossover studies. The SNP data base contains extensive medical data from the perinatal period of all preterm children, as well as a standard- 
ized developmental assessment conducted at 10 months of age, corrected for prematurity. At age $51 / 2$ years, a comprehensive neuropsychological assessment was administered, of the preterm cohort and of a matched control group born at term. A long-term follow-up assessment of both groups at age 18 involved neuropsychological tests as well as self-report measures concerning health and psycho-social adjustment, interpersonal relations, school performance, interests and quality of life. As a complement, and to provide a family perspective, parents were asked to complete a rating scale of their child's health, adjustment and educational record, as well as to self-report measures relating to their own health, well-being and possible parental stress. The overall aim of SNP is to investigate how the development of preterm children is related to perinatal medical history and how cognitive development, as well as biological (DNA and MRI), psychological and social factors interact in a long-term perspective. In the present thesis, part of the data accumulated from the SNP was utilized to investigate preterm children's executive and general cognitive development, and determinants thereof. 


\section{Developmental theories}

Human development can be described as dynamic interactions between genes (biological growth) and various environmental factors, which can be common to the species or specific to individuals (Johnson, 2005). Genetic factors influence individual development, and environmental factors can influence genes and gene expression/biological growth, such as brain development.

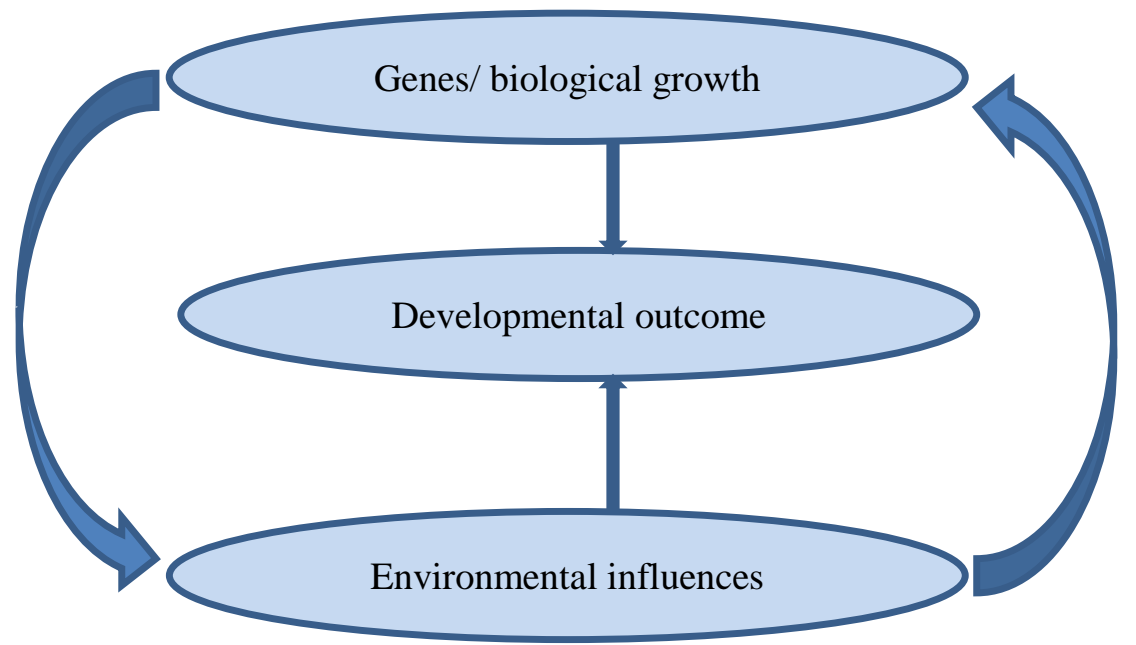

Figure 1 The central principle of developmental psychology (Harris \& Butterworth, 2002).

A large number of developmental theories relating to aspects throughout the life span in a typically developing population have been presented, and it is now widely accepted that no single theory is likely to sufficiently explain complex human development. We can approach human development by, for instance, adopting a psychoanalytic perspective (Freud, 1973), or applying psychosocial theory (E. H. Erikson, 1950), sociocultural theory (Vygotsky, 1978) or cognitive development theory (Piaget, 1971). This study has focused on cognitive aspects of child development, and therefore tends to prioritize the work of Piaget and his successors; however, in the modern spirit, a broad perspective of development and the influences is adopted. Nevertheless, the emphasis is on cognitive development, and I will proceed with a broad outline of the relevant theoretical background and findings. 


\section{Cognitive development}

Cognitive development is the process by which a child acquires the ability to reason, solve problems and to think consciously. In other words, it is the process of gaining and organizing knowledge required to understand and interact with the world. Optimal cognitive development is considered to be a key to success in school achievement, as well as to establishing relationships and making friends. Jean Piaget developed one of the earliest and most frequently used cognitive developmental theories, which illustrated how the development of human intelligence interacts with the environment.

Piaget described acquisition of knowledge as analogous to a biological process. According to Piaget's cognitive-developmental theory, children actively construct schemas, or knowledge, as they manipulate and explore their world. Central to his theory is the biological concept of adaptation, and the processes of assimilation, by which new information is added to an existing schema, or accommodation, by which the schema is modified to incorporate new experiences (Piaget, 1971). Through these processes, children expand their knowledge and revise their incorrect ideas about the world to achieve "equilibrium", meaning that there is balance between their internal schemas and the information they encounter in their everyday life. According to the theory, children's experiences expand as they grow and are transformed as they move through four broad developmental stages: the sensory-motor stage (from birth to 2 years), the preoperational stage (from 2-7 years), the concrete operational stage (from 7-11 years) and the formal operational stage (from 11 years and onwards). About the time that children reach the concrete operational stage, their ability to think logically about a situation without having to try it out in the real world develops rapidly. This ability is a part of what is known as the executive functions.

Piaget's theory has been both influential and criticized. Empirical studies have shown that developmental stages are neither as discrete nor as invariant as postulated by the theory. Rather, cognitive structures evolve gradually. Likewise, cognitive development is not critically dependent on sensory motor activity, as described by Piaget, since children with severe motor impairment may still develop age-appropriate cognitive skills. However, Piaget's hypothesized timing for transition between cognitive stages has strong relations to growth spurts within the CNS (V. Anderson, Jacobs, \& Anderson, 2010). Therefore the theory is still useful in developmental neuropsychology. 


\section{Executive functions (EF)}

Executive functions (EF) are defined as a set of complex, cognitive processes (V. Anderson, Jacobs, \& Anderson, 2008) required to control and regulate other abilities in real-life situations (Lezak, 1995). There are many models that seek to explain the constructs involved in EF. However, no model has been uniformly accepted. Although there are differences in the constructs, most researchers agree that the EF are higher-order control processes involving the regulation of thought and action that evolve in situations that require planning and organized goal-directed behavior. Early on, EF were considered to be a single construct, but most recent studies show that they may be better understood as a multidimensional psychological construct ( $\mathrm{P}$. Anderson, 2002). This also means that multiple factors contribute to the effective EF development. Researchers are not in agreement on which constructs play the most central roles, and a number of theoretical models of the EF have been proposed (Brocki, 2007). The models differ in their understanding of how the multidimensional constructs interact and are integrated with one another. Essentially, the theoretical EF models differ regarding which constructs are included, which constructs play the central roles and how the constructs interact with one another.

Some theories claim that EF constructs are integrated supervisory or control systems (Baddeley, 2000; Stuss \& Alexander, 2000) and other theories advocate that all constructs are inter-related or inter-dependent (P. Anderson, 2002); still others claim that there is a common underlying mechanism (Miyake et al., 2000).

One of the first truly influential theories of EF was Baddeley's working memory model, according to which the working memory consists of three components. One component, called the central executive, controls two components which are known as the phonological loop and the visuo-spatial sketch-pad. Without delving into details of the model, it can be said that the working memory is a system for the temporary maintenance of information that is necessary for the performance of higher cognitive abilities such as learning, comprehension of language and problem solving. In other words, the working memory plays a significant role in complex activities in general (Baddeley, 2000; Baddeley \& Hitch, 1974). However, this model does not include motivational factors and self-regulation. By contrast, Barkley claims that the self-regulation and inhibitory mechanisms are key components of $\mathrm{EF}$, necessary for goal-directed behavior, devising plans to achieve futureoriented goals, the utilization of self-directed speech, rules, plans and impulse control. In his model, Barkley claims that inhibition plays a central role in EF (Barkley, 1996), and his theory is widely used for studies of Attention- Deficit/Hyperactivity Disorder (ADHD). 
Miyake and colleagues (2000) introduced a model of the EF consisting of three components: Shifting involves moving backwards and forwards between multiple tasks, Updating involves monitoring and coding incoming information, and Inhibition involves inhibiting dominant, automatic or prepotent responses. All three of these can be distinguished from one another, but there is a common working memory factor or mechanism underlying these components.

Luria's (1902-1977) empirical work on patients with frontal lobe damage has greatly influenced the theories of EF in neuropsychology. Luria found that patients with prefrontal cortex damage had severe problems controlling and regulating their behavior in daily life and concluded that the prefrontal lobe area is critical for programming, monitoring and regulating behavior (Luria, 1973). Until two decades ago, it was believed that this was the case for children as well (Brocki, 2007), However, with the help of advanced techniques of brain imaging, it became obvious that children with prefrontal lesions do not exhibit the same symptoms as adults (V. Anderson, Northam, Hendy, \& Wrennal, 2001). This result indicated the importance of empirical studies of developmental aspects of executive functions. EF emerge early in life and continue to develop along with structural maturation of the frontal cortex (Pascanu \& Jaeger, 2011). Based on factorial analysis and developmental neuropsychology, Anderson (2002) proposed a model of the executive control system. According to this model, executive function is an overall control system that consists of four domains: attention control, cognitive flexibility, goal setting and information processing (see figure 2). These domains are independent, but they interact and have a bidirectional relationship. The level of input from each domain is determined by the requirement of the task under consideration. These functions are assumed to be associated with a selective prefrontal network (V. Anderson, 2002). This model is of interest in clinical research as it can be used to investigate if individuals display global, or specific, executive dysfunction. 


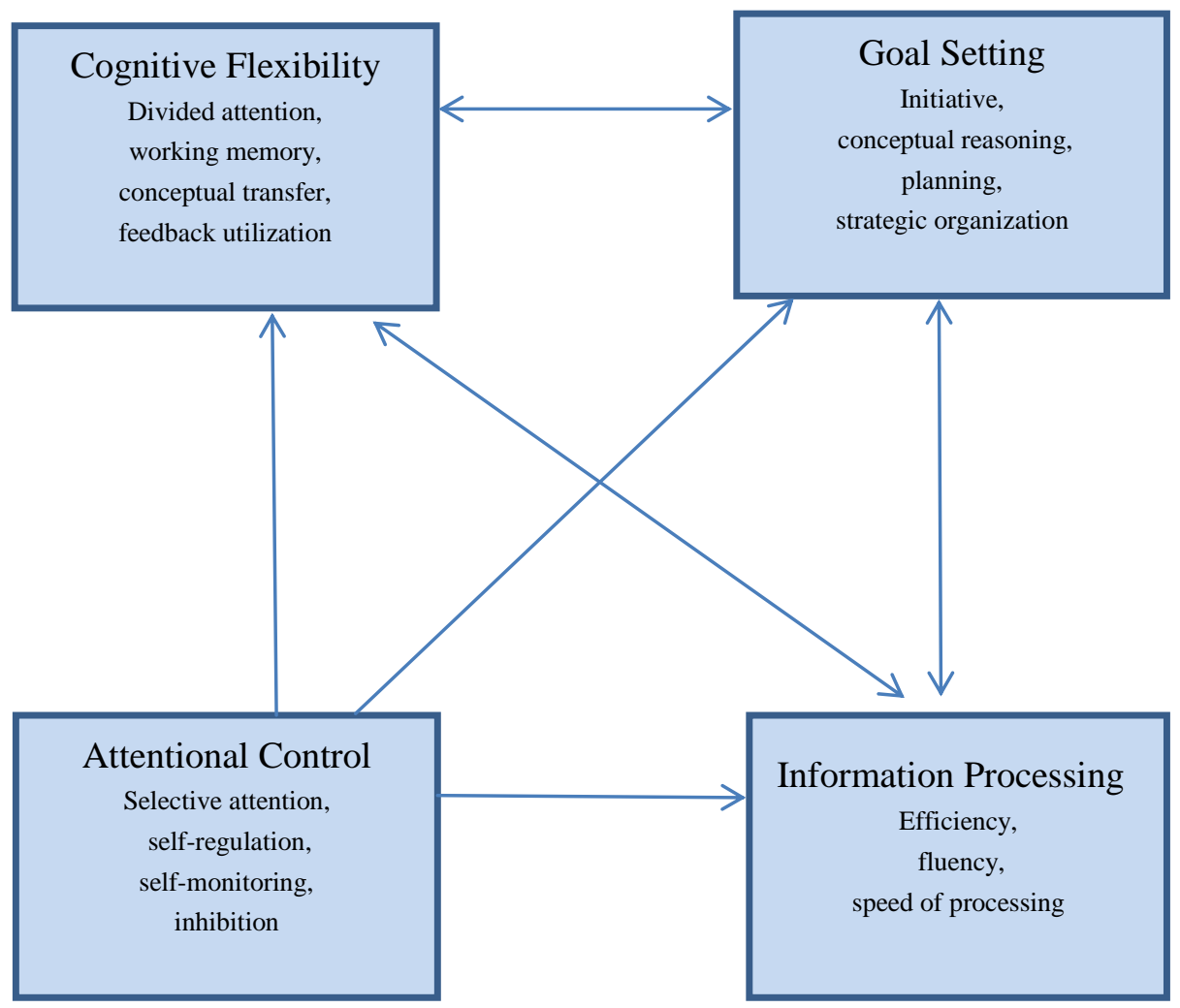

Figure 2. The executive control system. Adopted from "Assessment and development of executive functions (EF) during childhood" by P. Anderson (2002), Child Neuropsychology, 8 (2), p.71. 


\section{EF development}

Although the existing theories are not in complete agreement, it is known that EF have been associated with functioning of the prefrontal cortex in infants, children and adults. However, children's EF are under development, a claim supported by evidence that activation and the anatomical localization of cortical networks become greater with increasing age (V. Anderson, Spencer-Smith, \& Wood, 2011). Furthermore, EF development does not occur linearly, but is quite rapid in early childhood, and slower when approaching adulthood (P. Anderson, 2002). In addition to this, EF development is age-related, meaning that it takes place in stages, with different abilities and strategies evolving at different ages (De Luca \& Leventer, 2008). As pointed out by Brocki, any attempt to use a single test to investigate developmental change in executive functions would run a high risk of being task dependent (Brocki, 2007).

\section{From Infancy to Pre-school}

EF emerge as early as infancy (Diamond \& Goldman-Rakic, 1989), but significant changes are associated with the progressive myelination of the frontal lobes (V. Anderson et al., 2001). The assessment of executive functions is particularly challenging since children's capacity to engage in tasks requiring attention, memory and verbal comprehension is limited, particularly at a very young age. Nevertheless, by the age of three, children are generally able to state the rules of a game that requires executive control (inhibition and sustained attention), but this capacity is easily disturbed by automatic response to an environmental stimulus. Inhibition improves with age, and at about 4 to 5 years of age, children show an increased ability to hold and manipulate complex material in their minds (which is known as mental flexibility). A study reported that, by age 7, children have already reached adult levels of performance in a simple working memory task of the Cambridge Neuropsychological Test Automated Battery (Luciana \& Nelson, 2002). According to Espy (2004), "preschoolers do not suffer from a lack of abilities, but rather from the ability to deploy these abilities in particular contexts, that is, they lack basic meta-cognitive awareness of when and how to apply their knowledge and to deploy particular strategies effectively." (Espy, 2004, p.380). 


\section{Adolescence}

Grey matter volumes slowly decline from the early adolescent years to young adulthood, a maturational process which optimizes frontal lobe circuitry (Paus, Keshavan, \& Giedd, 2008). Working memory improves significantly during the period from 9-12 years, while strategic thinking and goaldirected behavior increase around 12 years of age (V. Anderson et al., 2001; Brocki \& Bohlin, 2004; Luciana \& Nelson, 2002). Inhibition control improves steadily during adolescence (Leon-Carrion, Garcia-Orza, \& PerezSantamaria, 2004), and attentional control and processing speed develop rapidly around 15 years of age and continue steadily to do so through late adolescence and beyond (V. Anderson et al., 2001) . Through this development, adolescents can process information faster, can have logical, abstract flexible thinking and improve their ability to make decisions. Luna and Sweeney describe the period of adolescence as a "transition to efficient brain collaboration" (p. 305) meaning that the EF become more efficient and effective (Luna \& Sweeney, 2004). 


\section{Brain development}

Cerebral development is ongoing throughout gestation to adulthood. The central nervous system (CNS) begins to develop around day 40 of embryonic life, and the brain is recognizable around 100 days post conception (V. Anderson et al., 2001). The fastest rate of brain growth occurs during the prenatal period, and during the $10^{\text {th }}$ through $20^{\text {th }}$ week of gestation as many as 250,000 brain cells are formed every minute (Papalia \& Olds, 1992).

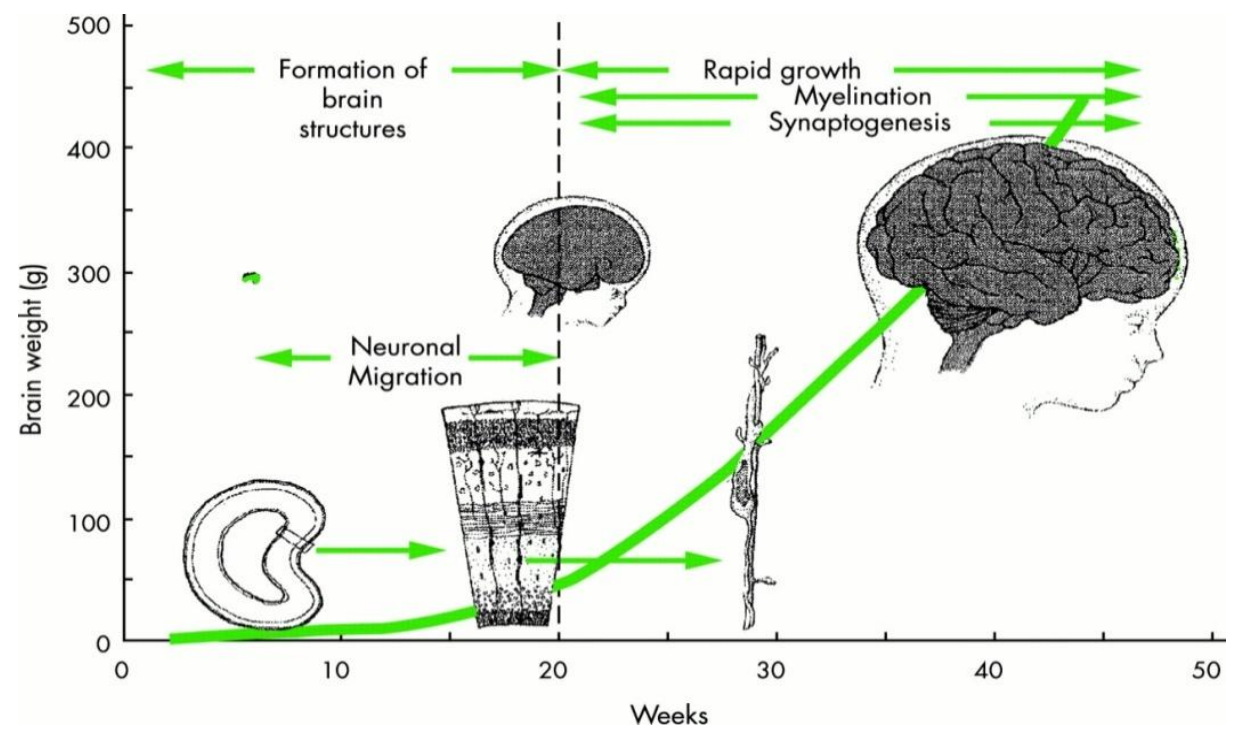

Figure 3. Illustration courtesy of Dr. Marian Squire in Stanley, Blair and Alberman (2000) Cerebral palsies: epidemiology \& causal pathways. Clinics in Developmental Medicine No 151. Mac Keith Press. Distributed by Cambridge University Press.

When an infant is born preterm, the birth occurs during the stage of sustained rapid growth of the brain, when myelination and synaptogenesis occur. The immature brain of the infant who is born preterm is exposed to an environment that it is not prepared for. The need for rapid development translates to a heightened vulnerability to damage from both the internal 
(e.g., ischemia, inflammation, free-radical attack) and external (e.g., hormones, drugs, poor nutrition, etc.) environments (Volpe, 2008). Very and extremely preterm born individuals also run a high risk of sustaining brain injury in the perinatal period as a result of adverse medical influences, such as sepsis, under-nutrition and hypoxia-ischemia (Allin et al., 2004). Infants with a gestational age of less than 28 weeks are the most vulnerable, owing to their immature and fragile organs. Aside from the obvious medical risks, the developing brain is vulnerable to excessive stimulation from noise, light, touch and pain (Philbin, Ballweg, \& Gray, 1994; Westrup, Kleberg, von Eichwald, Stjernqvist, \& Lagercrantz, 2000).

A recent meta-analysis of very preterm children's brain development after birth showed that, compared to term children, preterm children have smaller total brain volumes throughout childhood to adolescence, with approximately equal reductions in white matter and gray matter. These effects present themselves, irrespective of age at assessment. Results also show that the cerebellum, hippocampus and corpus callosum of preterm children are significantly smaller compared to term children. Moreover, the reduction of brain volume is associated with lower general cognitive development (de Kieviet, Zoetebier, Van Elburg, Vermeulen, \& Oosterlaan, 2012). One of the 15 studies included in the cited meta-analysis presented MRI-data from the SNP-cohort, collected at an average age of 14.6 years. Structural brain development of our cohort followed the same overall pattern as in the other studies, with a large effect size for preterm birth, on white and grey matter volumes alike (Nagy et al., 2009).

A previous SNP study revealed that a subgroup of children who had displayed early attention deficits $(\mathrm{n}=10)$, had remaining white matter disturbances as shown by diffusion tensor imaging at the age of 11 years. This study concluded that differences in white matter fiber track between preterm and term children may be related to impaired myelination, a restricted growth in axon diameters, a reduction in the number of axons, or a combination of these factors (Nagy et al., 2003). 


\section{Perinatal medical complications associated with preterm birth}

According to a recent study of extremely preterm children in Sweden, major perinatal complications have decreased, but are still high for the EPT infants (EXPRESS, 2010). Brain lesions, such as intraventricular hemorrhage (IVH) and periventricular leukomalacia (PVL) are frequently seen after preterm birth, especially in extremely preterm infants (Volpe, 2008). An abrupt increase in the arterial blood pressure increases the cerebral blood flow and plays an important role in the development of IVH. IVH is the most common type of neonatal intracranial hemorrhage, and it occurs mainly in preterm infants (Volpe, 2008). PVL is the predominant form of brain injury and is the leading known cause of cerebral palsy and cognitive deficits in premature infants (Deng, Pleasure, \& Pleasure, 2008). The physical explanation for this is that the periventricular white matter is located between the central and peripheral vascular territories in the foetus or neonate of less than 35 weeks of gestation, and therefore is particularly vulnerable to vascular insult (Takashima \& Tanaka, 1978). In addition, maternal inflammation and infection are associated with preterm birth and the development of PVL (Wharton et al., 2004). PVL and IVH can occur without clinical signs and, presumably owing to the reserve capacity of the developing brain, only about 10 percent of children with such brain lesions have retarded physical, motor and mental development at the age of two years (Chen et al., 2009).

Visual impairment can frequently be seen among children who were born preterm as they grow up. Retinopathy of prematurity (ROP) is an eye disease that can lead to myopia and, in the worst case, to blindness. Both oxygen toxicity and relative hypoxia can contribute to the development of ROP. Many children born preterm with visual impairment or visual dysfunction have been found to have brain lesions, usually periventricular leukomalacia, either as the primary cause of visual impairment or as a concomitant finding in severe retinopathy of prematurity (Jacobson, Lundin, Flodmark, \& Ellstrom, 1998). Visual deficits among preterm children are not only caused by retinal disease, but can also be attributable to damage to the posterior visual pathways (Cioni et al., 1997).

Respiratory distress and unstable oxygen levels arising from the immaturity of the lungs can lead to chronic lung disease (CLD), also called bronchopulmonary dysplasia (BPD). There is evidence that the increased incidence of neurological deviations in preterm infants with CLD may be linked to severe brain damage such as PVL and IVH, rather than to CLD per se (Katz-Salamon, Gerner, Jonsson, \& Lagercrantz, 2000). Still, from a clin- 
ical point of view, it is of interest that the prevalence of neuropsychological sequelae among preterm children with severe CLD is significantly higher than among preterm children with a lower grade of CLD (Böhm, KatzSalamon, Smedler, Lagercrantz, \& Forssberg, 2002). Likewise, Vohr and colleagues reported that prolonged ventilator treatment, necessitated by poor lung function, was associated with a worse developmental outcome (Vohr et al., 2004). Prematurely born infants who have been treated with postnatal glucocorticoids to mature the lungs have also shown an increased risk of developmental problems, mediated by stress effects on the developing brain (Yeh et al., 2004). However, antenatal glucocorticoid treatment has been demonstrated to reduce neurodevelopmental impairments caused by lung problems (Vohr, Wright, Poole, \& McDonald, 2005).

Severe perinatal infections such as sepsis, necrotizing enterocolitis, and intestinal perforation, are all associated with a higher risk of subsequent developmental problems (Mikkola et al., 2005; Shah et al., 2008; Stoll et al., 2004).

Children with VLBW who are small for their gestational age (SGA) as a result of intrauterine growth failure are at elevated risk of perinatal morbidity and of suffering chronic disease in later life, such as heart disease, high blood pressure, disordered cholesterol metabolism and insulin resistance (Barker, 1995).

SGA children are also considered to be at high risk of suboptimal cognitive development, and of developing psychiatric disorders (Boyle et al., 2011; Hutton, Pharoah, Cooke, \& Stevenson, 1997). However, available research is by no means conclusive regarding the impact of being SGA. According to some reports, adults who were born SGA tend to display poor academic achievement and professional attainment, but otherwise normal social adjustment (R. Strauss, 2000; Viggedal, Lundalv, Carlsson, \& Kjellmer, 2004). On the other hand, other studies of adults report that VLBW as such is associated with lower cognitive outcome, irrespective of the intra uterine growth pattern (Pyhala et al., 2011).

An American study showed that SGA children are at risk of neurodevelopmental problems but the effect can be moderated by factors in the postnatal environment, such as socio-economic status (Drews-Botsch, Schieve, Kable, \& Coles, 2011).

A study on behavioral aspects of children who were born at full term but SGA showed no increased risk for emotional and behavior problems later in development (Cornforth et al., 2011). This finding is, however, contradicted by yet another study which showed that SGA babies born at term run an 
increased risk for mild to moderate school problems, which may persist into late puberty, and that growth hormone treatment did not improve these adverse neurodevelopmental consequences (van Wassenaer, 2005) .

In this dissertation, I have investigated the medical complications of PVL, IVH, CLD, ROP and SGA and their relation to cognitive outcome. In the following I will refer to these complications as "medical risks". 


\section{Preterm children's development}

Although preterm babies have an increased risk of having medical complications, the risk of having a major disability such as cerebral palsy (CP), mental retardation (IQ< 70), blindness and deafness is limited to about 5-9 percent. In contrast to a major handicap, which is normally diagnosed in early infancy, deficits in higher cognitive functions only become obvious later in childhood; such deficits have been found to range from 20-45\% (Brodd, 2011).

Preterm children's developmental outcome and predictors thereof have been the focus of a large number of studies. According to some reports preterm birth is associated with general intellectual impairment rather than with specific dysfunctions (Hoff Esbjørn, Hansen, Greisen, \& Mortensen, 2006), whereas other studies report on specific impairments despite normal overall cognitive levels (Bayless \& Stevenson, 2007; Böhm, Smedler, \& Forssberg, 2004; Lind et al., 2011).

\section{General cognitive development}

General cognitive development is usually assessed using standardized intelligence tests, which allow for comparison of individual test results to a statistical norm based on a representative sample of test-takers. As such, the Wechsler scales have a strong standing among clinicians and researchers in applied psychology. The scales, which appear in a preschool, a school-age and an adult version, are comprised of 10-15 subtests, covering verbal as well as visuo-spatial functions, attention, and processing speed. Individual subtest results can be subject to norm comparison, but may also be summarized to broader indices of cognitive function. The broadest is the intelligence quotient, IQ, which is normally distributed with a population mean of 100 and a standard deviation of 15 , and generally accepted as a valid index of overall cognitive functioning.

Most of the children born preterm perform within normal limits on IQ tests $(>85)$, but as a group, preterm children's IQ scores are significantly lower than those of the population born at full term, indicating that although the average values could be similar for the two groups, the distribution is negatively skewed for children born preterm. Such a skewed population demonstrates higher rates of sub-average IQ $(<85)$ among pre-term born children than in the full-term population (Bhutta, Cleves, Casey, Cradock, \& Anand, 2002; Böhm et al., 2002). This tendency seems to persist into adulthood 
(Hack et al., 2002). Deficits in IQ have been found to be associated with perinatal medical complications (Hack \& Taylor, 2000) in the population as a whole, however an in-depth discussion of this topic is beyond the scope of this thesis. Finally, before moving on to discuss specific aspects of neuropsychological development after preterm birth it should be noted that, although IQ tests are useful for assessing children's general development, they have limited capacity to identify weaknesses and strengths in specific cognitive domains.

\section{Executive functions}

Executive functions are often reported as a specific weakness among children born preterm (Böhm et al., 2004; Howard, Anderson, \& Taylor, 2008; H. G. Taylor, Minich, Bangert, Filipek, \& Hack, 2004). However, it is still uncertain whether preterm children exhibit a global or specific impairment in executive functioning ( Nosarti, Murray, \& Hack, 2010). Studies have shown that difficulties in executive functions can be related to early cerebral insults (V. Anderson, Jacobs, Spencer-Smith, et al., 2010; V. Anderson, SpencerSmith, et al., 2010), and preterm birth is a risk factor for that (Lagercrantz, Katz-Salamon, \& Forssberg, 1997). Cerebral insults acquired before two years of age can be expected to impact on the brain as a whole and give rise to impairment in general functioning (V. Anderson, Jacobs, Spencer-Smith, et al., 2010). Owing to the fact that the brain is still in the process of being formed, the damage affects the general level of functioning rather than specific functions because these have yet to be developed and mature. As a result, specific impairments, such as aphasia and apraxia, are less common in children and generalized disturbances of information processing and executive functions are more frequently reported (V. Anderson et al., 2001; Eslinger, Biddle, Pennington, \& Page, 1999; Garth, Anderson, \& Wrennall, 1997). 


\section{Brain correlates}

Norsati and colleagues reported that very preterm birth is associated with abnormal cortical development and neurodevelopmental sequelae (Nosarti, Giouroukou, Healy, et al., 2007). Abnormalities in both gray and white matter distributions can be consequences of perinatal brain injuries and ongoing neurodevelopmental processes, in interaction (Allin et al., 2004), and may serve as identifiers of those individuals who are at risk of exhibiting executive dysfunction. Nosarti and colleagues found that gray matter and white matter volumes in the brain stem, frontal temporal and limbic region mediate the relation between preterm birth and adolescents' cognitive impairment (Nosarti et al., 2008). Furthermore, Woodward and colleagues reported that EF performance is associated with neonatal brain volumes and, specifically, the dorsolateral prefrontal, premotor, sensorimotor and parieto-occipital lobes (Woodward, Edgin, Thompson, \& Inder, 2005). In an earlier report, Rushe and colleagues had reported that correlations between structural abnormalities in the brain and executive functioning are minor (Rushe et al., 2001).

Skrarnes and colleagues report that impairments in executive function in VLBW children may be influenced not only by structural differences, but also by disturbed connectivity between posterior brain regions and the prefrontal cortex (Skranes et al., 2009).

In our sample, anatomic MRI data revealed that the adolescents who had been born preterm had 8.8 percent less grey matter volume than their agematched peers, and that the difference was attributable to the temporal lobes, prefrontal, orbitofrontal and parietal lobes, as well as the caudeate nucleus, hippocampus and thalamus; a lower cortical thickness was found in all lobes. In addition, the white matter volume of the preterm group was $9.4 \%$ smaller than that of the term group, primarily attributable to the posterior corpus callosum, fornix and external capsules (Nagy et al., 2009). 


\section{Executive functional development at preschool and junior school age}

Anderson and Doyle (2004) claim that executive deficits are important determinants for school-related difficulties, and that such difficulties are often reported in children who were born preterm. Already at preschool age, though, deficits in executive functions, such as attention, planning, task initiation and goal setting are commonly reported by parents and teachers of children born very preterm (P. Anderson \& Doyle, 2004). A previous study from the Stockholm Neonatal Project reported that preterm children displayed a specific weakness in their executive functions, and that this was evident even when general intelligence had been taken into account (Böhm et al., 2004).

Based on a comprehensive review of the research literature, Howard and colleagues concluded that preterm children are at risk of exhibiting specific impairment in most aspects of executive functioning, and, in particular, that they have a reduced working memory capacity and demonstrate cognitive inflexibility. Deficits in sustained attention were observed even in low-risk preterm children, while cognitive inflexibility at a preschool age seems to be strongly associated with brain pathology (Howard et al., 2008). Indeed, in early childhood (5-12 years), the population comprised of VPT/ VLBW infants exhibits at least subtle deficits across all executive domains, indicating a rather global dysfunction. The severity of the executive dysfunctions may be increased by the presence of medical complications (V. Anderson et al., 2001).

\section{Executive functions in adolescence}

Relatively few studies have investigated executive functions in adolescents who were born preterm, but most of those that do exist report that they are still at risk of exhibiting executive dysfunctions (H. G. Taylor et al., 2004). A recent Canadian study showed that VPT young adults perform worse than controls on tasks involving selective aspects of executive processing, such as mental flexibility and response inhibition (Luu, Ment, Allan, Schneider, \& Vohr, 2011). On the other hand, others have reported that working memory 
deficits observed in childhood may improve with age (Saavalainen et al., 2007; H. G. Taylor et al., 2004). Indeed, Hack and colleagues reported that early cognitive skills are only weakly related to later cognitive outcome (Hack et al., 2005). It is important to note that the development of EF is agerelated, meaning that some early problems might be resolved, while other problems might emerge over time. Differences in individual outcomes need to be investigated further.

\section{Other neuropsychological functions}

Neurocognitive development in children manifests itself in behaviors that can be systematically observed with the aid of validated neuropsychological tests. In order to assess intra-individual variability and to explore correlates of various functions, an increasing number of follow-up studies of children born preterm are including neuropsychological assessment. According to the theory of A .R. Luria $(1973 ; 1980)$, the major functional domains are attention, memory, sensory-motor, visuo-spatial and verbal functions (Korkman, 1990). In this context, attention is largely synonymous to executive functions, which have been discussed above. Here follows brief summaries of what is known regarding sensory-motor, visuo-spatial, verbal and memory development in children who were born preterm.

\section{Sensory-motor functions}

Medical complications, low birth-weight and low gestational age influence sensory-motor and psychomotor development in an unfavorable manner (Grunau et al., 2009; Heineman et al., 2010). The quality of spontaneous movement of preterm infants is a strong predictor of neurological and intellectual outcome (Butcher et al., 2009). Infants who showed deviant performance on early sensory-motor measures had significantly lower cognitive test scores, from infancy through early childhood (Wallace, Rose, McCarton, Kurtzberg, \& Vaughan, 1995). In an early report from the Stockholm Neonatal Project, preterm birth without additional medical risks had no significant effect on development at the age of 10 months, with the exception of a delay in eye-hand coordination (Gerner, Katz-Salamon, Hesser, Soderman, \& Forssberg, 1997). At $5 \frac{1}{2} 2$ years, the majority of the preterm children in the same cohort performed within the normal range on motor tasks, although they were not quite on a par with the control group. However, the motor performance of preterm children who had suffered medical complications was clearly inferior to that of control children (C. Erikson, Allert, Carlberg, \& Katz-Salamon, 2003). A recent Norwegian study of extremely preterm children showed that motor functions were positively related to gestational 
age and negatively related to being small for gestational age, of male gender and having retinopathy of prematurity (Leversen et al., 2011). The same study reported that moderate to severe disability in sensory-motor outcome was more common in children born at 25 weeks of gestation or less; however, gestational age had a limited association with outcome for extremely preterm children without severe disability (Leversen et al., 2011). Deficits in sensory motor skills have been reported in young adults who were born preterm. Allin and colleagues showed that neurological signs, such as deficits in sensory-motor skills and interhemispheric integration are higher in VPT adults compared to term-born controls, and they are strongly associated with reduced neuropsychological function (Allin et al., 2006).

\section{Visuo-spatial functions}

Already as a newborn, the healthy infant is actively interacting with the immediate environment, and the sensory modality of vision is a primary means by which this is accomplished. The gain of smooth pursuit in infant eye movement was significantly lower at 2 and 4 months in children born preterm in comparison to term born children (Strand-Brodd et al., 2011). Visuospatial and visuo-motor deficits from infancy and through later childhood have also been frequently reported (Cioni et al., 1997; Groen, de Blecourt, Postema, \& Hadders-Algra, 2005; Ornstein, Ohlsson, Edmonds, \& Asztalos, 1991; Saigal \& O'Brodovich, 1987) and a higher gestational age has been associated with better visuo-motor skills in VLBW children (Lind et al., 2011). Deficits in visual-motor integration often remain at school age, and preterm children with such deficits and poor motor competence are at risk of developing writing and mathematics-related learning disabilities (Chaudhari, Otiv, Chitale, Pandit, \& Hoge, 2004).

Skranes and colleagues found that the thinning of the entorhinal cortex is associated with reduced visuo-motor, cognitive and executive skills in VLBW adolescents, but not in controls (Skranes et al., 2012).

\section{Verbal functions}

Verbal ability has been reported to be an area of strength in preterm children, with and without structural brain abnormalities (Schafer et al., 2009). A few studies have reported problems in language acquisition in the early childhood period among children born preterm (Foster-Cohen, Edgin, Champion, \& Woodward, 2007). However, delays in expressive language in the preschool years (which means up to the age of 6 in Sweden) have been associated with lower general cognitive ability (IQ) and there is no evidence of any specific language problems after controlling for IQ (Wolke \& Meyer, 1999). In adults who were born preterm, verbal deficits and language impairment 
appear mostly in verbal fluency tests, which are strongly related to executive functions (Nosarti, Giouroukou, Micali, et al., 2007). Archibald and Gathercole suggested that language problems are influenced by phonological working memory, and that early identification of working memory problems and subsequent intervention may support language development (Archibald $\&$ Gathercole, 2006).

An fMRI connectivity analysis suggested that preterm children rely upon different neural pathways for lexical semantic processing than do term controls. Plasticity in network connections may provide the substrate for improving language skills in the prematurely born child as he/she develops (Schafer et al., 2009). However, there is also MRI evidence for children born preterm revealing that severe brain pathology at 5 years of age may be associated with poor verbal memory (Lind et al., 2011).

In summary, very few studies have reported on specific verbal deficits associated with preterm birth. It has been suggested that the dominant hemisphere, with its critical role for language skills, has adequate reserve capacity to compensate for the risks involved with preterm birth (Satz, 1993).

\section{Memory}

Retention and episodic memory deficits have been reported and associated with significantly slower information processing in preterm infants (Rose \& Feldman, 1996; Rose, Feldman, \& Jankowski, 2009). On the other hand, Wilcox (1996) reported that uncomplicated premature birth had no obvious effect on the development of location-related memory and related attention abilities during the first 6.5 months of life post full term, i.e. the age corrected for prematurity (Wilcox, Nadel, \& Rosser, 1996). Moreover, an extensive developmental study, including preterm as well as control children, found that everyday memory problems were not a general feature of children born prematurely. At five years of age, memory performance was closely linked to receptive language ability, but not general cognitive ability, in both groups (Briscoe, Gathercole, \& Marlow, 2001). According to a recent Finnish study, memory functions were not associated with gestational age in VLBW children born in the 2000s (Lind et al., 2011). However, deficits in visuo-spatial and phonological working memory have been reported in other studies (Alloway, Gathercole, \& Pickering, 2006; Gathercole, Pickering, Ambridge, \& Wearing, 2004), but this may also be understood as EF deficits. Furthermore, it should be mentioned that Luu and collaborators (2011) reported that adolescents born preterm had an increased risk of having deficits in memory and executive functions, even after exclusion of preterm subjects with significant disabilities (Luu et al., 2011). 


\section{Academic development}

As presented above, a large body of research conducted on school-age children showed that premature birth is associated with below average performance on sensory-motor and cognitive tasks. The IQ scores of very preterm children have been found both to be overrepresented in the lower end of the normal range, and significantly lower than their full-term peers (P. Anderson \& Doyle, 2008).

Moreover, preterm children with normal intelligence may still face significant school difficulties. (Saigal, Hoult, Streiner, Stoskopf, \& Rosenbaum, 2000). A study of school readiness in 5 year-old children showed that preterm groups had lower school readiness, irrespective of social risks (Roberts, Lim, Doyle, \& Anderson, 2011). Other studies have shown that this tendency persists into adolescence (Hallin, Hellstrom-Westas, \& Stjernqvist, 2010a).

According to a large French study, only 5 percent of VPT children need to be in a specialized school or class, and the majority of VPT children are educated in mainstream schools (Larroque et al., 2011). The numbers are similar in Sweden (Stjernqvist \& Svenningsen, 1999). Although the expressive language of VPT children is as good as that of their term born peers (Pritchard et al., 2009), parents and teachers still report significant difficulties in reading, spelling and especially in mathematics (Bowen, Gibson, \& Hand, 2002; Pritchard et al., 2009). There are many studies reporting school difficulties among preterm children in the primary grades. Some studies suggest that school performance may decline over time, as is evidenced by a higher need for special education and by lower school grade achievement in the higher grades. In contrast, however, there are studies that have shown a relative improvement of language skills over time (Norsarti et al, 2010). The factors underpinning negative and positive development in school need to be studied further.

\section{Gender differences}

Compared to girls, preterm boys have a significantly increased risk of neonatal death, or of a poor neurodevelopmental outcome. Hence, infant mortality as well as morbidity after preterm birth is higher in males (Cartlidge \& Stewart, 1997; Ingemarsson, 2003). Neuroanatomical studies of typically developing children have shown that cortical development follows different pathways in males and females, largely due to hormonal factors, with the female brain developing more rapidly during early childhood (Kolb \& Wishaw, 1996). Likewise, fMRI studies have reported gender specific pat- 
terns of cerebral activation, with males showing greater lateralization of functions and females showing more bilateral activation in adulthood (Shaywitz et al., 1995). It has been suggested that females show a greater capacity for functional transfer, since female brains are more diffusely organized, and there may be greater potential for plasticity and reorganization of function (E. Strauss, Wada, \& Hunter, 1992). These structural gender differences might contribute to the better recovery from the impact of early lesions in females than in males (V. Anderson et al., 2001).

Several studies report that boys born preterm are at a higher risk of exhibiting learning problems in school than are girls (Kesler et al., 2008; Reiss et al., 2004). Long-term follow-up studies of young adults who were born preterm have reported that there is a female advantage when it comes to overall health and educational attainment (Goddeeris et al., 2010; Hack et al., 2002).

\section{Socio-emotional development}

According to a meta- analysis performed by Bhutta and colleagues, most studies have found evidence for an increased risk of attention deficits, and internalizing as well as externalizing problems among preterm children throughout their lives (Bhutta et al., 2002). Some studies claimed that preterm toddlers with a high level of medical complications display difficulties in socio-communicative skills (De Groote, Roeyers, \& Warreyn, 2006), whereas others have reported difficulties in initiating social interaction, regardless of their medical histories (Landry, Densen, \& Swank, 1997). At school age, some teachers report that preterm children display more attention-related problems and depression, and that they exhibit less adaptability and lower social skills than their peers (Johansson \& Cnattigius, 2010), and in adolescence preterm individuals report having less social interaction (Hallin \& Stjernqvist, 2011b).

This could be partly explained by difficulties in executive functions, especially as self-regulation is known to negatively affect peer relationships (Lezak, 1995). With increasing age, children develop social skills and independence that match the demands from society. However, there are reports that adolescents born preterm have less independence and have remained more emotionally vulnerable than controls (Botting, Powls, Cooke, \& Marlow, 1998; Indredavik et al., 2004). Hack and colleagues found that female adolescents who were born preterm are significantly more withdrawn and experience more internalizing problems, including anxiety and depression, and that these problems correlate with attention problems (Hack et al., 2002). The other side of the coin is that preterm born adolescents demonstrate less risk-taking behavior than their peers (Hack et al., 2002; Saigal, Pinelli, Hoult, Kim, \& Boyle, 2003). 


\section{Socioeconomic factors, parental education}

In studies of typically developing children, parents' educational expectations and the opportunities that they provide for their children to engage in learning-related activities have been related to children's cognitive and academic development (L. C. Taylor, Clayton, \& Rowley, 2004). Parents with higher levels of education engage their children in more learning-related activities at the home, such as reading books, and providing additional learning activities, such as music or art lessons (Davis-Kean, 2005). A previous study from the Stockholm Neonatal Project showed that parental education was the single most important predictor of intelligence at age $5 \frac{1}{2}$ years, and that this was also the case for children who had been born preterm (Böhm et al., 2002); other studies support this finding (Gisselmann, Koupil, \& De Stavola, 2010; McNeal, 2001). An early follow-up study of the impact of socioeconomic status and preterm birth on development, showed that preterm birth per se had a significant effect on children's intellectual skills, but the combination of preterm birth and low socioeconomic status had a dramatic negative impact on intellectual development (Drillien, Thomson, \& Burgoyne, 1980). 


\section{Theoretical framework of the study}

Harris and Butterworth (2002; see Figure 1) formulated a model in which human development is described as the result of dynamic interactions between biological and environmental factors. However, preterm born individuals have an additional set of factors associated with the preterm birth as such, factors that also reciprocally interact with biological as well as environmental factors. In the present thesis, the effects of preterm birth, biological as well as environmental factors on cognitive development were investigated by comparing developmental changes in preterm and term born children. The overall conceptual framework is illustrated in Figure 4.

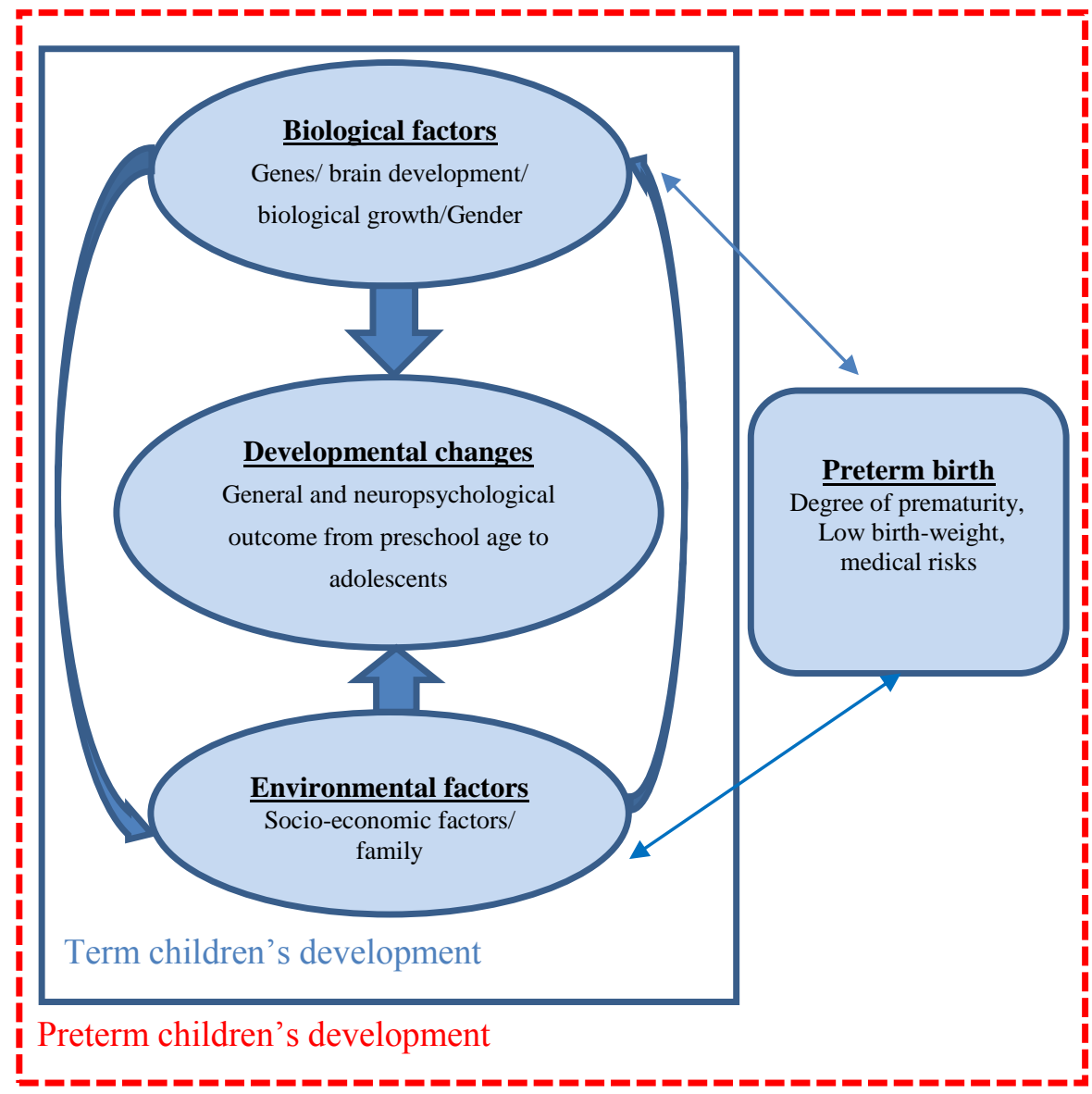

Figure 4. The theoretical framework of the studies. 


\section{Aim}

The overall aim was to investigate the long-term outcome of preterm children's development in relation to their degree of prematurity, birth-weight and medical risks, with a special focus on executive functions.

The specific aims were to

- compare their developmental outcome to that of children born at term

- identify individual neuropsychological profiles

- investigate the influence of medical risks and gender (biological factors) as well as parental education (an environmental factor) on their neuropsychological development

- examine developmental stability from preschool age to adolescence.

- evaluate the Bender Visual Motor Gestalt test as a tool in developmental screening for deficits in executive functions in 5 to 6-year-old children. 


\section{Methods}

The Stockholm Neonatal Project (SNP) is a longitudinal population-based study of children born prematurely in 1988-93, with very low birth weight $(<1500 \mathrm{~g}, \mathrm{VLBW})$. In the initial recruitment process, all children who met these inclusion criteria and were born between September, 1988 and March, 1993 at Karolinska Hospital and at Löwenströmska Hospital in Stockholm, Sweden, were invited through their parents to participate at birth and onwards. In addition, all children from the entire county of Stockholm with a birth weight of $1000 \mathrm{~g}$ or less who were in need of neonatal intensive care at Karolinska Hospital were invited to participate. A total of 291 newborns were invited, of which 8 percent declined to participate, and another 18 percent died neonatally, after which 213 children remained. Extensive perinatal medical data was obtained from the participants, and a standardized developmental assessment was conducted at 10 months of age, corrected for prematurity. A subgroup of preterm children $(n=20)$ and their parents were subject to an observational study of early emotional interaction (Gerner,1999).

\section{Participants and procedure at $5 \frac{1}{2} 2$ years of age}

The 213 children originally included were invited for a follow-up at $51 / 2$ years. At that time, 19 families had moved away from the area and 12 declined to participate, leaving 182 children born preterm available for assessment. Six preterm children were unable to complete the assessment owing to a disability, such as visual impairment (1) spastic diplegia (2), mental retardation not due to prematurity (2) and pronounced hyperactivity (1). A control group of 125 children born at term was recruited and assessed during the same period. The controls were children born on the same day and at the same hospital as the VLBW children. Further inclusion criteria for controls were a gestational age of at least 37 weeks, a birth weight of at least $2500 \mathrm{~g}$, and a classification as a healthy baby at birth. The preterm and control groups did not differ in terms of socio-demographic parameters. Both groups had the same mean values for maternal education, the mother's age at the time of the birth of the child (mean 30 years), percentage of children living with both parents (86 percent) and in bilingual families (21 percent) (Böhm et al., 2002; Lagercrantz et al., 1997). The assessment of each child took place at Astrid Lindgren's Children's Hospital at the age of 5 1/2 years $( \pm 2$ 
weeks), corrected for prematurity. Subjects were assessed in the mornings of two consecutive days, all by the same child neuropsychologist (Birgitta Böhm). They all started with the NEPSY test battery and were given the WPPSI-R test on the second day (Böhm et al., 2002).

\section{Participants and procedure at 18 years of age}

All VLBW children $(n=181)$ and matched controls born at term $(n=125)$ who participated in the previous follow-up at the age of $5 \frac{1 / 2}{2}$ years (Böhm et al., 2002) were invited to a psychological assessment at the age of 18 . Of the 306 invited, 229 i.e. close to 75 percent, participated in the assessment. Twelve families had moved and their address could not be identified, 23 declined to participate. In addition, 42 failed to reply. One preterm male was unable to complete the test protocol owing to mental retardation. Hence, 134 18-year olds, who had been VLBW babies, and 94 controls completed the assessment involving neuropsychological tests as well as self-reported measures of health and adjustment. According to our drop-out analysis performed on the data from the follow-up study at $51 / 2$ years, the dropouts at age 18 did not differ from the participants in cognitive abilities, motor skills or father's educational levels. However, mother's educational level was lower among dropouts in the preterm group $(\mathrm{p}=.001)$ and the same tendency was seen in the term group $(\mathrm{p}=.09)$. The participants were individually assessed at Astrid Lindgren's Children's Hospital at age 18 years ( \pm 3 weeks). Subjects were tested for $3.5-4$ hours, and the tests were always administered in the same order, starting with WISC-III. Fifteen master level students who were in their last year of the clinical psychology program at Stockholm university, and the present author (AL) were especially trained to conduct the assessments under the supervision of SNP senior psychologists. Each examiner tested around 15 subjects, drawn from both the preterm and control groups, and the examiners were blind as to which group the subjects belonged. No systematic examiner effects were detected. All protocols were double checked for scoring by the present author.

Figure 5 presents a flow chart of SNP participants and data collection points. 
3,18 and 24 months

291 VLBW infants $(<1500 g)$

with a gestational age of $<37$ weeks, were invited.

After 51 neonatal deaths,

4 sudden infant deaths and 23

dropouts, the study started with

213 VLBW infants

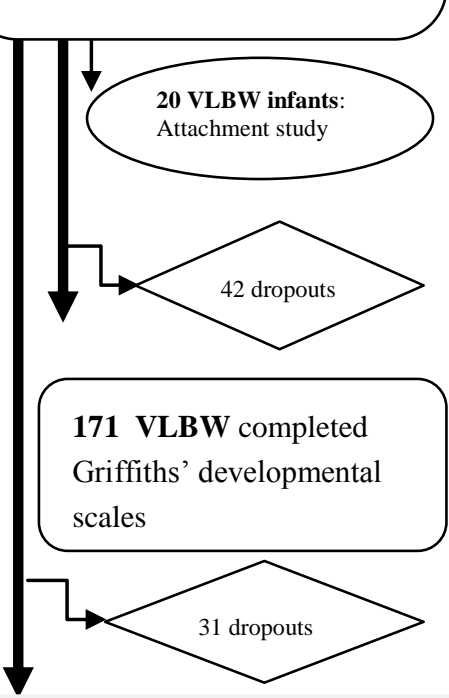

$5 \frac{1}{2}$ years

12-19 years

18 years

Ongoing data collection
181 VLBW completed

WPPSI-R, NEPSY, Bender,

Movement ABC

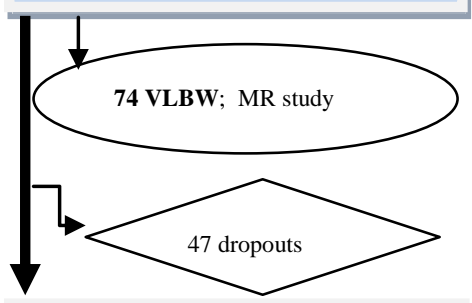

135 VLBW completed

WISC- III, D-KEFS, RAVL,

VMI, SDQ, YSR, IPPA

(+parental questionnaires)

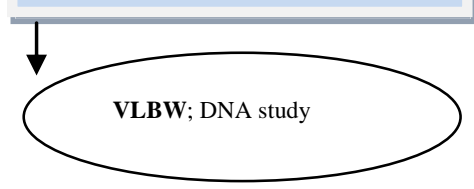

20 controls:

Attachment study

35 controls completed

Griffiths' developmental scales
125 controls completed

WPPSI-R, NEPSY, Bender,

Movement ABC

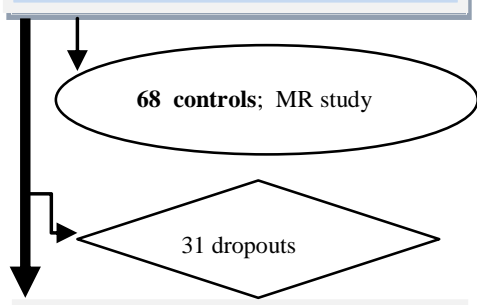

94 controls completed

WISC -III, D-KEFS, RAVL,

VMI, SDQ, YSR, IPPA

(+parental questionnaires)

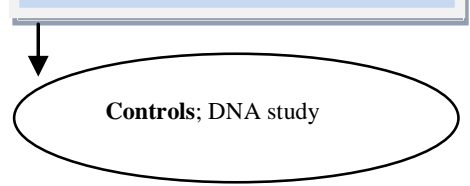

Figure 5. SNP participants and data collection points. 


\section{Measures}

The variables used in the present thesis are presented in Table 1. General cognitive outcome was measured at $51 / 2$ and 18 years by the Swedish versions of the Wechsler-Preschool and Primary scale of Intelligence-Revised (WPPSI-R) and Wechsler Intelligence Scale for Children, $3^{\text {rd }}$ edition (WISCIII), respectively. At age $51 / 2$ specific neuropsychological functions were assessed by the NEuroPSYchological assessment battery (NEPSY), covering the domains of Attention, Memory, Sensory-motor, Verbal and Visuo-spatial functions. The neuropsychological test battery at age 18 was dominated by EF tests from the Delis-Kaplan Executive Function System (D-KEFS), complemented by specific measures of episodic memory, verbal and visuomotor functions.

\section{Ethical aspects}

The study at $5 \frac{1}{2}$ years of age was approved by the Ethics Committee of Karolinska Hospital, as described elsewhere (Böhm, Katz-Salamonson, Smedler, Lagecrantz \& Forssberg, 2002). Throughout SNPs lifetime, participation has been based on informed consent, obtained explicitly for each data collection. The continued data collection and analysis at 18 years of age was approved by the Regional Ethics Board of Stockholm (2007/46-31/3).

\section{Statistical analysis}

Normality of distribution for all variables was checked by descriptive analysis.

The level of significance was set to $p<0.05$, and cases with missing data were excluded from the respective analyses. The statistical methods applied are described in the respective articles. 
Table 1. Overview of variables used in the present thesis.

\begin{tabular}{|c|c|c|c|c|}
\hline Variables & Age & Measurement & Description & Reference \\
\hline \multicolumn{5}{|l|}{ Study I } \\
\hline \multirow[t]{2}{*}{$\begin{array}{l}\text { Visuo-motor } \\
\text { function }\end{array}$} & $5^{1 / 2}$ & $\begin{array}{l}\text { Bender Visual Motor } \\
\text { Gestalt Test. }\end{array}$ & $\begin{array}{l}\text { The Bender draw- } \\
\text { ings were analysed } \\
\text { according to three } \\
\text { different scoring } \\
\text { systems. }\end{array}$ & $\begin{array}{l}\text { (Brannigan \& Decker, } \\
\text { 2003; Böhm, } \\
\text { Lundequist, \& } \\
\text { Smedler, 2010; } \\
\text { Koppitz, 1964, 1975). }\end{array}$ \\
\hline & $51 / 2$ & $\begin{array}{l}\text { The developmental test } \\
\text { of Visual-Motor Integra- } \\
\text { tion (VMI). }\end{array}$ & $\begin{array}{l}\text { Copy designs of } \\
\text { increasing complex- } \\
\text { ity. }\end{array}$ & (Beery \& Berry, 2004). \\
\hline $\begin{array}{l}\text { General Intel- } \\
\text { ligence (IQ) }\end{array}$ & $5 \frac{1}{2}$ & $\begin{array}{l}\text { The Swedish version of } \\
\text { the Wechsler-Preschool } \\
\text { and Primary Scale of } \\
\text { Intelligence - Revised } \\
\text { (WPPSI-R). }\end{array}$ & $\begin{array}{l}\text { The test provides } \\
\text { three IQ measures: } \\
\text { full scale (FIQ), } \\
\text { verbal (VIQ) and } \\
\text { performance (PIQ) } \\
\text { scores. }\end{array}$ & (Wechsler, 1999). \\
\hline $\begin{array}{l}\text { NEPSY } 4 \\
\text { executive } \\
\text { measures } \\
\text { (NEPSY-4) }\end{array}$ & $51 / 2$ & $\begin{array}{l}\text { Composite measure of } \mathrm{z} \text { - } \\
\text { score from the verbal } \\
\text { fluency, color-form, } \\
\text { selective attention and } \\
\text { naming changing objects } \\
\text { in NEPSY. }\end{array}$ & $\begin{array}{l}\text { Four sub-tests of the } \\
\text { NEPSY test battery } \\
\text { (see study II). }\end{array}$ & (Korkman, 1990)- \\
\hline
\end{tabular}


Table 1. (Continued)

\begin{tabular}{|c|c|c|c|c|}
\hline Variables & Age & Measurement & Description & Reference \\
\hline \multicolumn{5}{|l|}{ Study II } \\
\hline $\begin{array}{l}\text { Neuropsychological } \\
\text { outcome }\end{array}$ & $51 / 2$ & $\begin{array}{l}\text { The NEPSY test battery, } \\
\text { standardized in Sweden for } \\
\text { children from } 4 \text { to } 7 \text { years } \\
\text { of age. }\end{array}$ & $\begin{array}{l}\text { Test battery covering } \\
\text { five domains: Atten- } \\
\text { tion, Memory, Senso- } \\
\text { ry-motor, Verbal, and } \\
\text { Visuo- spatial func- } \\
\text { tions. }\end{array}$ & (Korkman, 1990) . \\
\hline $\begin{array}{l}\text { General Intelligence } \\
\text { (IQ) }\end{array}$ & $51 / 2$ & WPPSI-R. & See study I. & (Wechsler, 1999). \\
\hline Motor functions & $51 / 2$ & $\begin{array}{l}\text { The Movement Assess- } \\
\text { ment Battery for Children } \\
\text { (Movement ABC). }\end{array}$ & $\begin{array}{l}\text { General motor func- } \\
\text { tioning: Fine motor } \\
\text { skills and Dynamic } \\
\text { and static balance. } \\
\text { Items are scored 0-5, } \\
\text { where } 0 \text { indicates } \\
\text { optimal performance. }\end{array}$ & $\begin{array}{l}\text { (Henderson, } \\
\text { 1992). }\end{array}$ \\
\hline Maternal education & $51 / 2$ & $\begin{array}{l}\text { Mother's attained educa- } \\
\text { tional level was graded } \\
\text { according to Statistics } \\
\text { Sweden standards. }\end{array}$ & $\begin{array}{l}0=\text { no formal educa- } \\
\text { tion, } 1=\text { did not finish } \\
\text { elementary school, } 2= \\
\text { graduated from junior } \\
\text { high school, } 3= \\
\text { completed two years } \\
\text { of high school, } 4= \\
\text { completed three years } \\
\text { of high school, } 5= \\
\text { Bachelor's degree, } 6= \\
\text { Master's degree, } 7= \\
\text { Doctoral degree. }\end{array}$ & $\begin{array}{l}\text { Swedish statistic } \\
\text { bureau. } \\
\text { www.scb.se/defau } \\
\text { t_2154.aspx. }\end{array}$ \\
\hline Medical risks & $\begin{array}{l}\text { At } \\
\text { birth }\end{array}$ & $\begin{array}{l}\text { A perinatal medical com- } \\
\text { plication associated with } \\
\text { an elevated risk of a poor } \\
\text { outcome. The number of } \\
\text { high risks that a child had } \\
\text { experienced was summed, } \\
\text { and ranged from } 0 \text { (for the } \\
\text { majority) to } 3 \text { (one case). }\end{array}$ & $\begin{array}{l}\text { Intraventricular hem- } \\
\text { orrhage (IVH) } \\
\text { grade III-IV, } \\
\text { periventricular } \\
\text { leukomalacia, (PVL) } \\
\text { grade III-IV, chronic } \\
\text { lung disease (CLD) } \\
\text { and retinopathy of } \\
\text { prematurity (ROP) } \\
\text { grade 3+. }\end{array}$ & $\begin{array}{l}\text { (Böhm et al., } \\
\text { 2002) }\end{array}$ \\
\hline
\end{tabular}




\begin{tabular}{|c|c|c|c|c|}
\hline Variables & Age & Measurement & Description & Reference \\
\hline \multicolumn{5}{|l|}{ Study III } \\
\hline $\begin{array}{l}\text { General intelli- } \\
\text { gence (IQ) }\end{array}$ & 18 & $\begin{array}{l}\text { The Wechsler Intel- } \\
\text { ligence Scale for } \\
\text { Children third edi- } \\
\text { tion (WISC-III), } \\
\text { Swedish version. } \\
\text { Short form. }\end{array}$ & $\begin{array}{l}\text { The test provides three IQ } \\
\text { measures: full scale IQ } \\
\text { (FIQ), verbal IQ (VIQ) } \\
\text { and performance IQ } \\
\text { (PIQ), plus index scores } \\
\text { for, Verbal comprehen- } \\
\text { sion (VCI), Perceptual } \\
\text { organization, (POI), } \\
\text { Attention and Speed. }\end{array}$ & $\begin{array}{l}\text { (Donders, 2001; } \\
\text { Wechsler, 1991). }\end{array}$ \\
\hline $\begin{array}{l}\text { Executive func- } \\
\text { tions }(\mathrm{EF})\end{array}$ & 18 & & $\begin{array}{l}(\mathrm{D})=\mathrm{D}-\mathrm{KEFS} \\
(\mathrm{W})=\text { WISC-III; } \\
\text { (WA) = Wechsler Adult }\end{array}$ & $\begin{array}{l}\text { (Delis, Kaplan, \& } \\
\text { Kramer, 2001; } \\
\text { Donders, 1997; }\end{array}$ \\
\hline $\begin{array}{l}\text {-Attention and } \\
\text { Speed }\end{array}$ & & $\begin{array}{l}\text { Coding }(\mathrm{W}), \text { Sym- } \\
\text { bol search }(\mathrm{W}) \text {, } \\
\text { TMT } 1 \text { (D). }\end{array}$ & $\begin{array}{l}\text { Intelligence Scale Revised } \\
\text { (WAIS-R). }\end{array}$ & $\begin{array}{l}\text { Wechsler, 1991; } \\
\text { 1997). }\end{array}$ \\
\hline $\begin{array}{l}\text {-Working } \\
\text { memory }\end{array}$ & & $\begin{array}{l}\text { Digit span }(\mathrm{W}) \text {, } \\
\text { Block repetition } \\
(\mathrm{WA})\end{array}$ & $\begin{array}{l}\text { TMT = Trail Making } \\
\text { VF = Verbal fluency } \\
\text { DF = Design fluency } \\
\text { CW = Color-Word }\end{array}$ & \\
\hline $\begin{array}{l}\text {-Cognitive } \\
\text { flexibility }\end{array}$ & & $\begin{array}{l}\text { TMT } 3 \text { (D), VF (D), } \\
\text { DF (D), CW } 3 \text { (D). }\end{array}$ & $\begin{array}{l}\text { All D-KEFS subtests } \\
\text { yield a scaled score with a } \\
\text { mean of } 10 \pm 3 \text {. }\end{array}$ & \\
\hline -Complex task & & $\begin{array}{l}\text { Sorting (D), CW } 4 \\
\text { (D). }\end{array}$ & & \\
\hline \multicolumn{5}{|l|}{ Episodic } \\
\hline Memory & & & & \\
\hline -visuo-spatial & 18 & Face recognition. & $\begin{array}{l}\text { Examiner presented } 24 \\
\text { pictures, } 3 \text { secs each. } \\
\text { After } 30 \text { minutes subjects } \\
\text { were presented the same } \\
24 \text { faces, randomly mixed } \\
\text { with } 24 \text { new faces. Each } \\
\text { face was shown for } 5 \\
\text { secs, and subjects com- } \\
\text { pleted a yes-no recogni- } \\
\text { tion task. }\end{array}$ & $\begin{array}{l}\text { (Rey, 1964; } \\
\text { Schmidt, 1996). }\end{array}$ \\
\hline
\end{tabular}




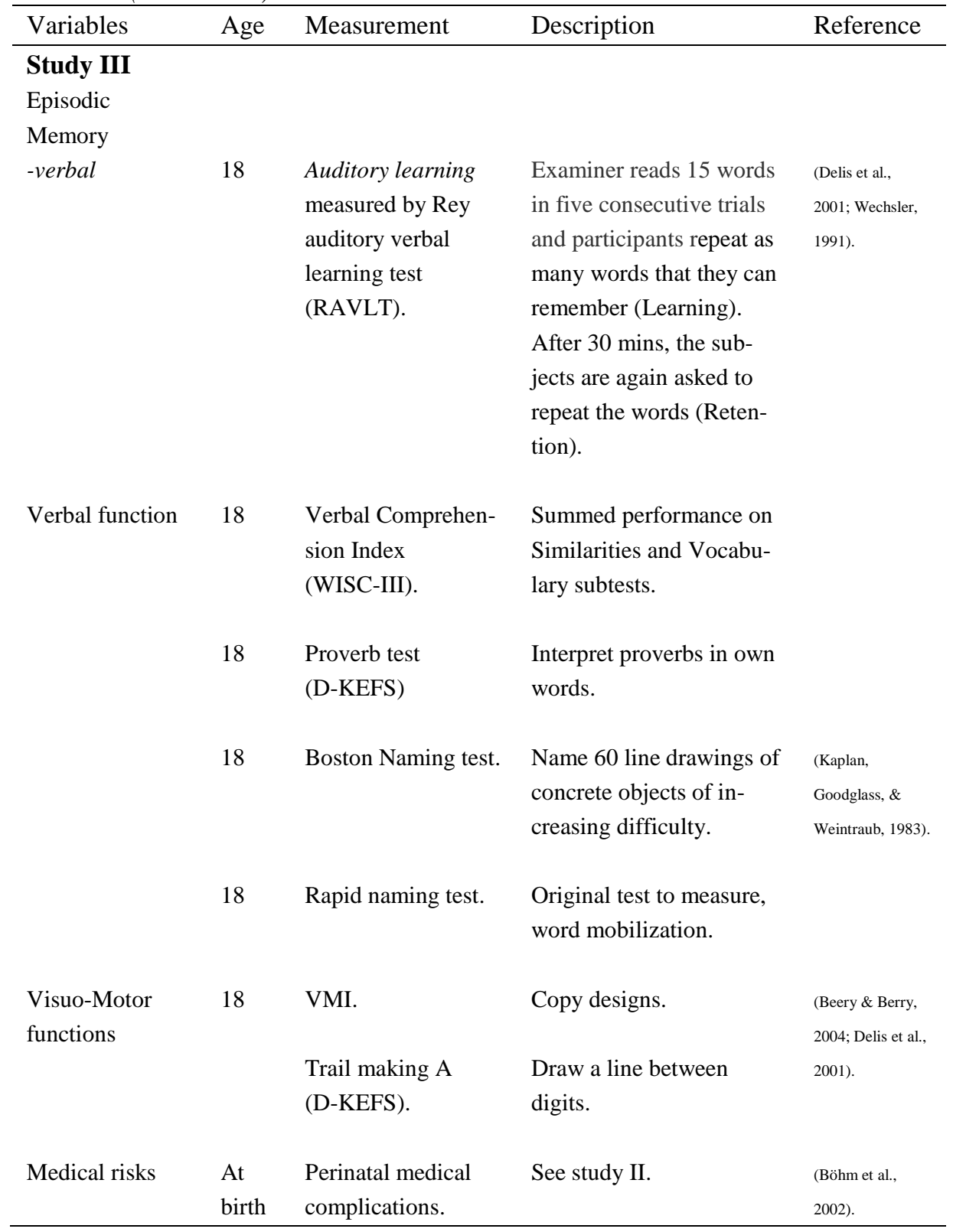




\begin{tabular}{|c|c|c|c|c|}
\hline Variables & Age & Measurement & Description & Reference \\
\hline Study IV & & & & \\
\hline $\begin{array}{l}\text { General intelli- } \\
\text { gence (IQ } 5 \text { 1⁄2 ) }\end{array}$ & $51 / 2$ & WPPSI-R. & See study I. & (Wechsler, 1999). \\
\hline $\begin{array}{l}\text { Executive func- } \\
\text { tions (EF } 51 / 2 \text { ) }\end{array}$ & $51 / 2$ & $\begin{array}{l}\text { Composite measure of the z- } \\
\text { score from NEPSY Impulse } \\
\text { Control, three items, Selective } \\
\text { Attention, Verbal Fluency, } \\
\text { Color/Form Test, Naming } \\
\text { Changing Objects, as well as } \\
\text { the WPPSI-R Arithmetic and } \\
\text { Animal Pegs Test. }\end{array}$ & & $\begin{array}{l}\text { (Korkman, 1990; } \\
\text { Wechsler, 1999). }\end{array}$ \\
\hline $\begin{array}{l}\text { General Intelli- } \\
\text { gence (IQ 18) }\end{array}$ & 18 & WISC-III. & See study III. & (Wechsler, 1991). \\
\hline $\begin{array}{l}\text { Executive func- } \\
\text { tions (EF 18) }\end{array}$ & 18 & $\begin{array}{l}\text { Composite measure of z- scores } \\
\text { from D-KEFS Color Word } \\
\text { (CF), Trail Making Test (TMT), } \\
\text { Verbal Fluency (VF), Design } \\
\text { Fluency (DF), Sorting, as well } \\
\text { as the WISC-III Digit-span, } \\
\text { WAIS-R Block repetition. }\end{array}$ & & $\begin{array}{l}\text { (Delis et al., 2001; } \\
\text { Wechsler, } \\
\text { 1991;1997) }\end{array}$ \\
\hline $\begin{array}{l}\text { Parental } \\
\text { education }\end{array}$ & $51 / 2$ & $\begin{array}{l}\text { The parents' attained educa- } \\
\text { tional level was graded accord- } \\
\text { ing to Statistics Sweden stand- } \\
\text { ards. The mean value of moth- } \\
\text { er's and father's educational } \\
\text { level was used. }\end{array}$ & See study II. & $\begin{array}{l}\text { Statistic Sweden, } \\
\text { www.scb.se/de } \\
\underline{\text { fault } 2154 . a s p} \\
\underline{x}\end{array}$ \\
\hline Medical risks & $\begin{array}{l}\text { At } \\
\text { birth }\end{array}$ & $\begin{array}{l}\text { Perinatal medical complica- } \\
\text { tions. }\end{array}$ & See study II. & \\
\hline Birth-weight ratio & $\begin{array}{l}\text { At } \\
\text { birth }\end{array}$ & $\begin{array}{l}\text { Birth-weight ratio was calculat- } \\
\text { ed in each case as birth weight } \\
\text { divided by mean birth-weight } \\
\text { relative to the norm for gesta- } \\
\text { tional age. }\end{array}$ & $\begin{array}{l}\text { A ratio of } 1.0 \\
\text { means normal } \\
\text { weight. }\end{array}$ & \\
\hline
\end{tabular}


Table 1. (Continued)

\begin{tabular}{|c|c|c|c|c|}
\hline Variables & Age & Measurement & Description & Reference \\
\hline \multicolumn{5}{|l|}{ Study V } \\
\hline $\begin{array}{l}\text { Bender Neuropsycho- } \\
\text { logical scores } \\
\text { (The ABC scoring) }\end{array}$ & $51 / 2$ & $\begin{array}{l}\text { Bender Visual } \\
\text { Motor Gestalt } \\
\text { Test. }\end{array}$ & $\begin{array}{l}\text { Scoring developed } \\
\text { to measure neuro- } \\
\text { psychological fea- } \\
\text { tures in Bender } \\
\text { drawings }\end{array}$ & $\begin{array}{l}\text { (Böhm et al., } \\
\text { 2010). }\end{array}$ \\
\hline EF $51 / 2$ & $51 / 2$ & & See study IV. & \\
\hline EF 18 & 18 & & See study IV. & \\
\hline Parental education & $\begin{array}{l}\text { At } \\
\text { birth }\end{array}$ & & See study IV. & \\
\hline Medical risks & $\begin{array}{l}\text { At } \\
\text { birth }\end{array}$ & & See study II. & \\
\hline Birth-weight ratio & $\begin{array}{l}\text { At } \\
\text { birth }\end{array}$ & & See study II. & \\
\hline
\end{tabular}




\section{Results}

\section{At $5 \frac{1}{2}$ years of age}

\section{Study I}

\section{Comparisons between the preterm and the term groups}

The results of the Bender Visual Motor Gestalt test showed a clear advantage for the children born at term; this was evident with all three scoring systems that were applied. The largest group differences were found in the ABC Neuropsychological Scoring system developed by our group and, within this system, the scores for the specific features were also significant (see Table 2). 
Table 2. Bender results according to the Brannigan \& Decker, Koppitz and $A B C$ Neuropsychological Scoring systems; comparison between children born preterm and at term.

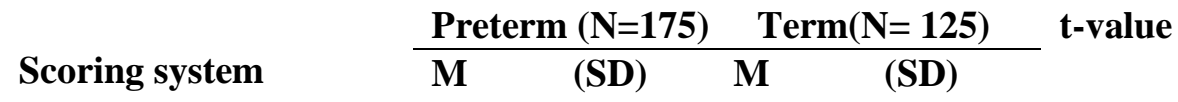

\begin{tabular}{|c|c|c|c|c|c|}
\hline Brannigan \& Decker ${ }^{\text {pos }}$ & 6.92 & $(4.97)$ & 10.62 & $(5.22)$ & $6.18 * * *$ \\
\hline Koppitz ${ }^{\text {neg }}$ & 16.41 & $(5.04)$ & 12.37 & $(4.10)$ & $-7.63^{* * *}$ \\
\hline ABC Neuropsych. Score neg & 11.68 & $(5.65)$ & 7.26 & $(3.53)$ & $-8.31 * * *$ \\
\hline Specific features & & & & & \\
\hline Planning & 1.99 & $(1.52)$ & 1.46 & $(1.07)$ & $-2.68 * *$ \\
\hline Perseveration & 2.74 & $(1.65)$ & 1.73 & $(1.22)$ & $-6.12 * * *$ \\
\hline Rotation & 3.74 & $(1.96)$ & 2.50 & $(1.50)$ & $-6.20 * * *$ \\
\hline Closure & 3.31 & $(1.28)$ & 2.54 & $(1.32)$ & $-5.10 * * *$ \\
\hline Expansion & 17 & & 0 & & \\
\hline
\end{tabular}

(Number of children)

Significant difference, ${ }^{*} \mathrm{p}<0.05, * * \mathrm{p}<0.01$, *** $\mathrm{p}<0.001$, between Pre-term and Term children.

${ }^{\mathrm{Pos}}=$ high score indicates superior performance. ${ }^{\mathrm{Neg}}=$ high score indicates inferior performance.

\section{Relation to gender}

Preterm girls were clearly superior to preterm boys in their Bender performance; however, in the group born at term, the girls scored significantly better than boys only for the ABC neuropsychological system overall, and for the specific feature related to planning. For the remaining Bender scores, there was merely a non-significant tendency for the term girls to do better than term boys. The interaction effect gender $\times$ group, tested by ANOVA, was not statistically significant $(\mathrm{p}<0.09)$. 


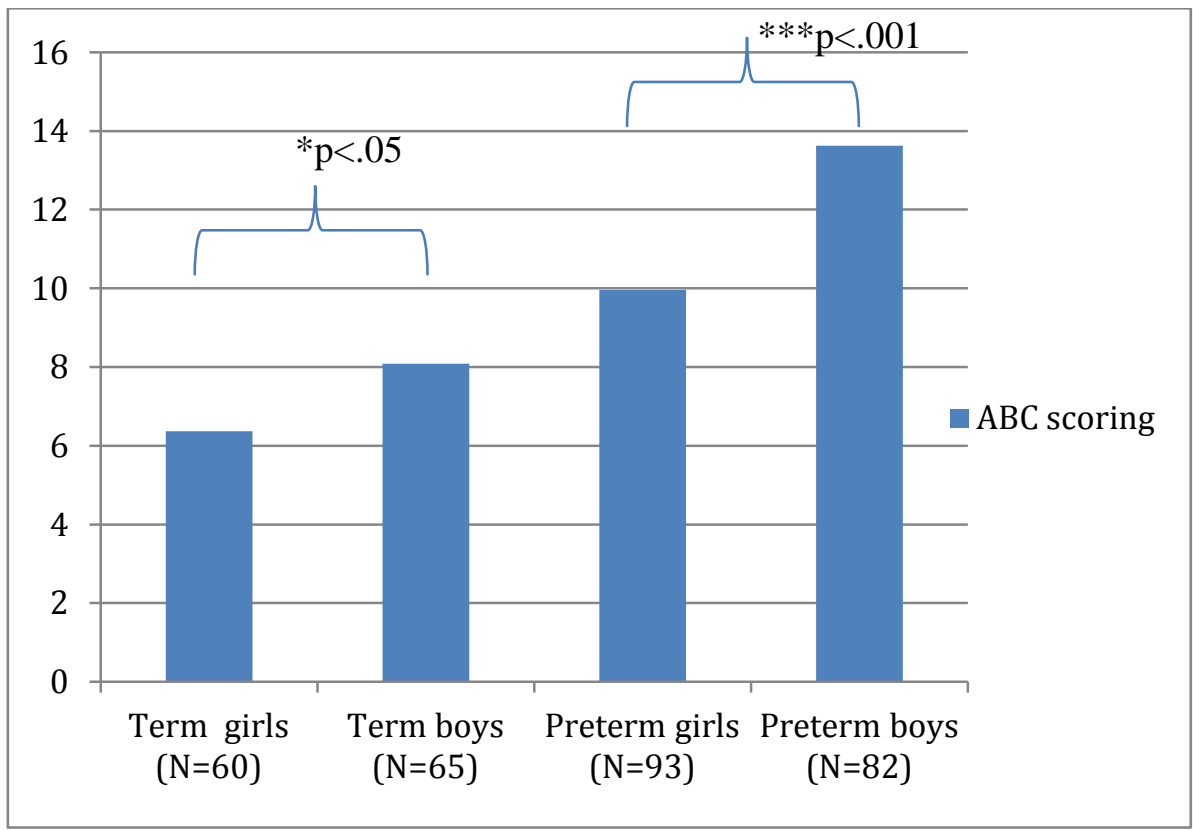

Figure 6. Bender results by gender, according to the ABC neuropsychological scoring system; a high score indicates inferior performance on this scale.

\section{The Bender results in relation to general intelligence and neuropsychological functions}

For the total group of children we obtained strong Pearson correlations between WPPSI-R performance IQ (PIQ), Visual-Motor Integration (VMI), the three Bender scores (B\&D, Koppitz and ABC neuropsychological score) and a NEPSY EF score comprised of four subtests (NEPSY-4). The three Bender scores were highly interrelated $(0.86,0.84,0.79)$, and similarly related to PIQ (0.52-0.65.). As expected, VMI correlated strongly with the Bender scores (-0.67 to -0.71$)$ and with PIQ (0.76). The NEPSY -4 score correlated significantly, but moderately well, with the other measures, giving values of around 0.30 , with the highest correlation coefficient found relative to the ABC neuropsychological score (with a value of -0.33). Regression analysis using WPPSI-R PIQ and the three Bender scores as predictors with the NEPSY-4 as the dependent variable, resulted in a model that explained 14 percent of variance in NEPSY -4 , with PIQ $(\beta=0.18, p<0.05)$ and the Bender $\mathrm{ABC}$ score $(\beta=-0.25, \mathrm{p}<0.05)$ as significant contributors. 


\section{Study II}

\section{Individual neuropsychological profiles at $5 \frac{1}{2} 2$ years of age}

\section{Comparisons between the preterm and the term groups}

Neuropsychological profiles typical of preterm children and control children, respectively, were identified by cluster analysis, and included NEPSY subtests that fulfilled the assumption of normality and represented the domains Attention, Memory, Sensory-Motor, Verbal, and Visuo-Spatial functions. Ztransformations were performed for the selected subtests based on the total sample $(N=262)$, after which subtest $z$ scores were summed within each domain, and the $z$ sum for each domain was again transformed into a domain $z$ score. Ward's cluster analysis, which is a hierarchical agglomerative method, was used for preterm children and term children separately, based on the five NEPSY domain $z$ scores. The agglomerative method starts by assuming each individual case to be a cluster and, at each step, the two clusters that have the most similar profiles are fused. The number of clusters was chosen based on a pronounced drop in the explained error sum of squares (EESS), occurring when a solution with one less cluster was extracted. Also, the theoretical meaningfulness of the cluster solution was considered.

The cluster analyses identified five neuropsychological clusters in the preterm group (Figure 7) and the term group (Figure 8), respectively. The explained variance was 55.8 percent in the preterm group and 57.1percent in the term group. Overall, the clusters in the preterm group reflected a generally lower level of performance than that of the term group. 


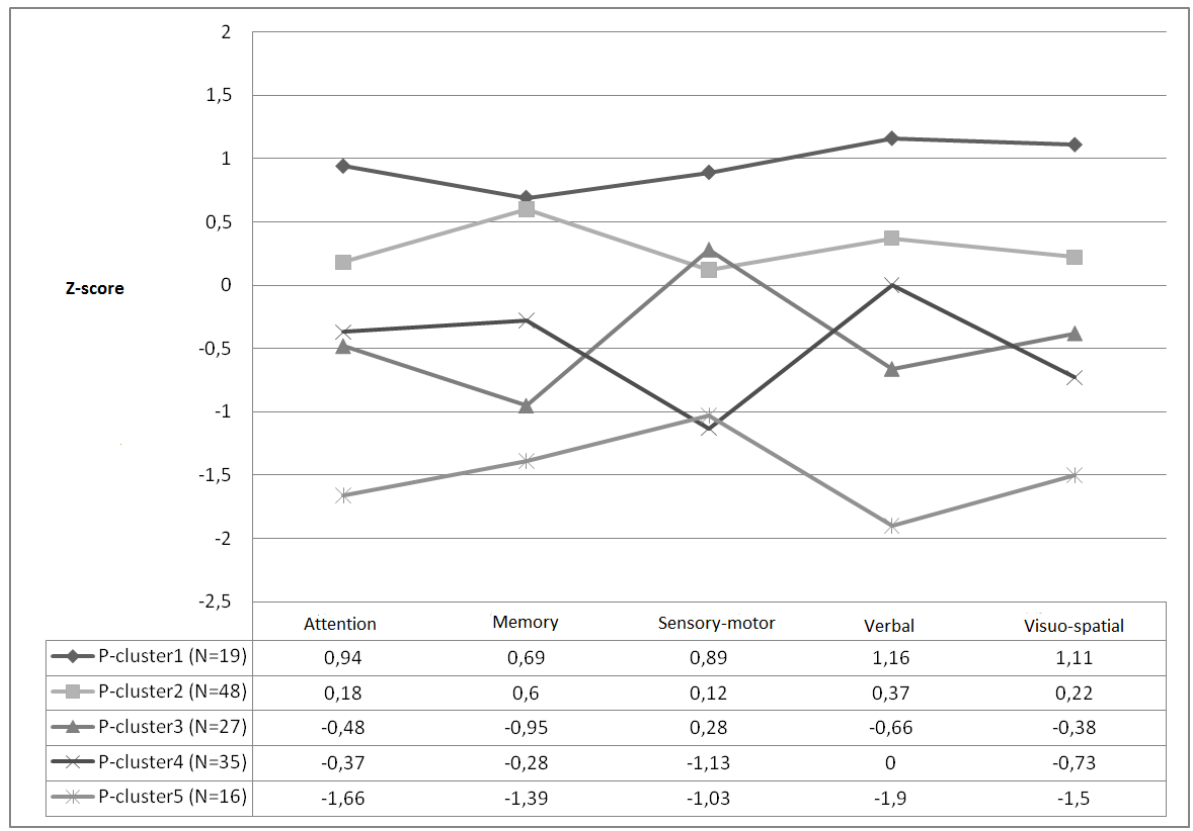

Figure 7 Clusters of neuropsychological profiles identified by five NEPSY domains for children born preterm.

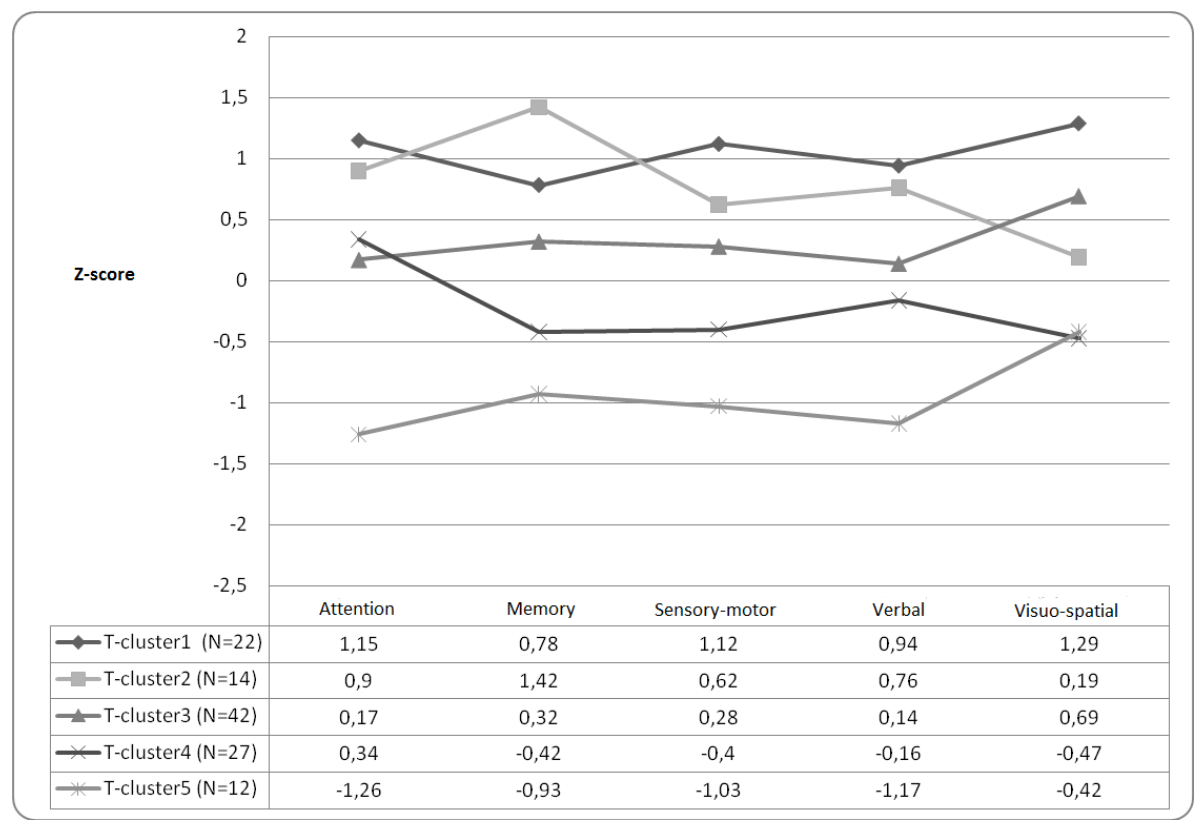

Figure 8. Clusters of neuropsychological profiles identified by five NEPSY domains for children born at term. 
Fifty-four percent of the preterm children belonged to one of three clusters with below zero z-scores in at least four of the five domains. The three low functioning clusters for the preterm-born children also had more uneven profiles, reflecting a substantial intra-individual variability in the neuropsychological functioning of the children belonging to these clusters. By comparison, 33 percent of term-born children belonged to one of two low functioning term clusters, distinguished by a relatively even, but below average performance. In fact, the profiles of all of the clusters for the term-born children were primarily defined by the overall level of performance. Interestingly, the two clusters for the high functioning preterm children, had even profiles, similar to those of the clusters for the term-born individuals.

\section{Neuropsychological profiles in relation to intelligence and motor functions}

According to a series of one-way ANOVAs, general intelligence differed significantly between clusters. The overall levels of neuropsychological performance corresponded well with the level of verbal, performance and fullscale IQ measures, in the groups comprised of preterm and term-born youngsters, alike. The overall levels of neuropsychological performance also corresponded well with the children's motor functions, defined by the Movement ABC, according to one-way ANOVAs. Motor functions were less favorable in preterm children, even in those with high functioning profiles.

\section{Neuropsychological profiles in relation to birth-weight and medical complications}

Extremely low birth-weight children $(<1000 \mathrm{~g}$; ELBW) might be slightly overrepresented in the two lowest functioning clusters (P-4 and P-5), but no significant trend was found (Pearson Chi-square, $\mathrm{P}=0.44$ ). We could not identify any associations between specific perinatal medical complications and neuropsychological profiles. Slightly more children with a high level of medical complications belonged to the clusters with problematic neuropsychological profiles, but the observation was not statistically significant (Pearson Chi-square, $p=0.55$ ). It was noteworthy that children with an uncomplicated medical history were found in all clusters, and that there were children who had suffered multiple complications who belonged to a high functioning cluster (see Figure 7). 


\section{Neuropsychological profiles in relation gender}

A Pearson Chi-square test was conducted to investigate possible genderrelated differences between clusters, in preterm and term-born children, respectively. We could only identify a gender-related effect in the term clusters $(\mathrm{p}=0.04)$. Two of five clusters of term-born children (T-1 and T-2), signified by strengths in the verbal domain, were dominated by girls; two of five term clusters (T-3 and T-5), signified by strengths in the visuo-spatial domain, were dominated by boys (Chi-square $\mathrm{p}<0.001$ ).

\section{Neuropsychological profiles in relation maternal education}

The preterm and control groups were well-matched as far as maternal education was concerned: One-way ANOVA showed that maternal education was related to the overall level of the neuropsychological profiles in both groups, but the relationship was strongest in the group comprised of children who were born at term.

\section{At 18 years of age}

\section{Study III}

\section{Cognitive and executive functioning in adolescence}

For the analysis, the participants who were born preterm were divided into three groups by their gestational age at the time of birth: Extremely Preterm (EPT; 23-27 wks), Very Preterm (VPT; 28-31 wks) and moderately preterm (PT; 32-36 wks). As a result of our second inclusion criteria, having a birthweight of $<1500 \mathrm{~g}$, the majority of those included in the PT group had suffered from Intrauterine growth retardation (IUGR), with 67percent fulfilling a diagnosis of small for gestational age (SGA), meaning that their weight fell below -2SD of the expected birth-weight. ANOVA showed that there were significant group differences between the gestational groups. Post-hoc analyses showed that youngsters who had been born EPT consistently exhibited a lower performance than those in any other group. In contrast, the cognitive outcome of VPT youngsters did not differ from that of controls born at term. The PT group comprised of those who were moderately preterm, but with a subnormal birth-weight, showed a less favorable cognitive outcome than either the VPT or control groups (see Table 3 and figure 9). 
Table 3. Results on tests of general intelligence, memory, language, and visuo-motor skills, by gestational age group, analyzed with ANOVA and post hoc t-tests.

$\begin{array}{llllll}\text { I } & \text { II } & \text { III } & \text { IV } & \text { F-value } & \text { Post-hoc } \\ \text { EPT } & \text { VPT } & \text { PT } & \text { Term } & \\ 23-27 w & 28-31 w & 32-36 w & >37 w & \\ \text { N=73 } & \text { N=36 } & \text { N=25 } & \text { N=94 } & \\ \text { Mean }(S D) & \text { Mean }(S D) & \text { Mean }(S D) & \text { Mean }(S D) & \\ & & & & \\ \end{array}$

\section{Intelligence}

FIQ

$84.3(21.8)$

95.9 (15.8)

$87.0(23.2)$

$97.2(17.2)$

$7.18^{* * *}$

I \& II,

I \& IV

$V I Q$

$90.8(18.3)$

100.1(14.4)

$91.7(18.0)$

$99.4(14.8)$

$5.18^{* *}$

I \& II,

I \& IV

$P I Q$

$$
80.6 \text { (23.9) }
$$

92.5 (17.5)

$84.4(25.3)$

$95.7(20.0)$

$7.48^{* * *}$

I \& II,

I \& IV

\section{Episodic}

memory

Face
recognition
RAVL lear
RAVL re
Verbal
function

WISC VCI

$96.9(22.0)$

$104.9(19.2)$

$92.7(21.1)$

$101.9(17.9)$

$2.7^{*}$

D-KEFS

$7.7(4.1)$

$9.7(2.7)$

$8.0(4.0)$

$9.0(3.5)$

3.1

I \& II

Proverb

Boston Naming

48.4 (5.9)

$49.2(5.2)$

47.1 (7.4)

$49.1(4.8)$

1.0

Naming speed

43.3 (17.5)

$34.6(10.1)$

$38.4(11.1)$

$38.4(13.5)$

$3.3^{*}$

I \& II

(Sec)

Visuo- motor

function

Trail Making A

$7.8(3.7)$

8.7 (2.9)

$9.6(2.9)$

$9.6(2.9)$

$5.3^{* *}$

I \& IV

VMI

$19.4(4.0) \quad 20.8(3.4)$

$20.0(3.5)$

21.9 (2.9)

$7.5 * *$

I \& IV 


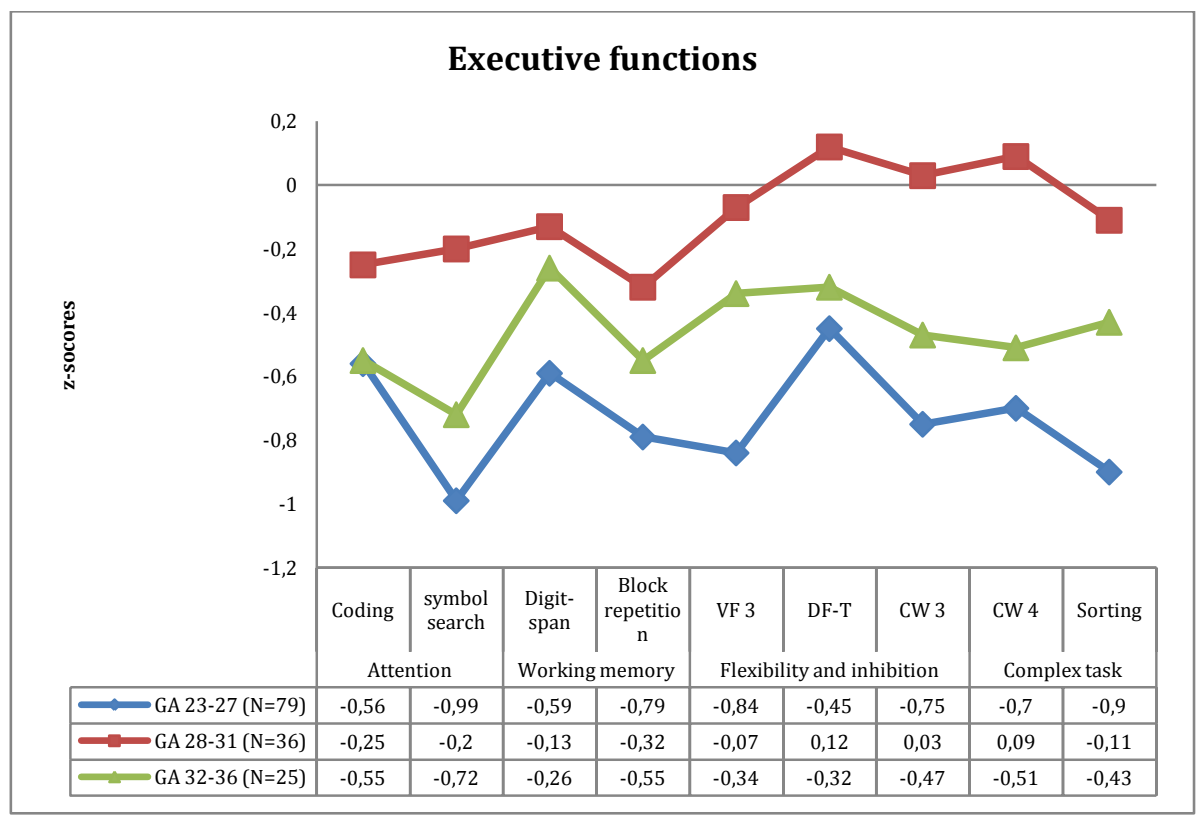

Figure 9. Mean z-scores on EF subtests for the three preterm gestational age groups; z-scores are calculated using the means and $S D$ for the control group of term born adolescents ( $n=94)$. VF=Verbal Fluency, DF-T=Design Fuency total Score, $\mathrm{CW}=$ Color Word.

\section{Outcome among adolescents born extremely preterm in relation to medical risks}

About half of the extremely preterm born adolescents had experienced at least one of the following medical complications, known to pose a risk for cognitive outcome: Intraventricular hemorrhage (IVH) grade III-V, periventricular leukomalacia, (PVL) grade III-IV, chronic lung disease (CLD), or retinopathy of prematurity (ROP) grade 3+. A series of t-tests were performed to investigate differences between EPT adolescents with $(n=35)$ and without $(n=38)$ such medical risks. The group results only differed significantly in terms of general intelligence and for two of the EF domains: those relating to flexibility and inhibition, and to the performance of complex tasks. On these measures, EPT adolescents without medical risks demonstrated a superior performance compared to those who had been identified as having at least one high medical risk. Only minor differences, that did not attain statistical significance, were found between high and low risk EPT adolescents for the EFs of attention, speed and, working memory, and for episodic memory, language and visuo-motor tasks. 
Figure 10 illustrates differences in performance between EPT with $(\mathrm{N}=35)$ and without $(\mathrm{N}=38)$ medical risks, VPT $(\mathrm{N}=36)$ and term $(\mathrm{N}=94)$ groups on three EF sub-tests. ANOVAs showed a main effect for group on all three measures (TMT A; F=5.3, $\mathrm{p}<0.001$ Verbal fluency; $\mathrm{F}=8.8$, $\mathrm{p}<0.001$; Color word; $\mathrm{F}=8.5, \mathrm{P}<0.001)$. Post hoc tests revealed that the EPT group with medical complications had consistently inferior results compared to VPT and controls, also on a simple EF tasks (TMT A). It is noteworthy that on most measures even the low-risk EPT group had lower results than the VPT group and term-born controls

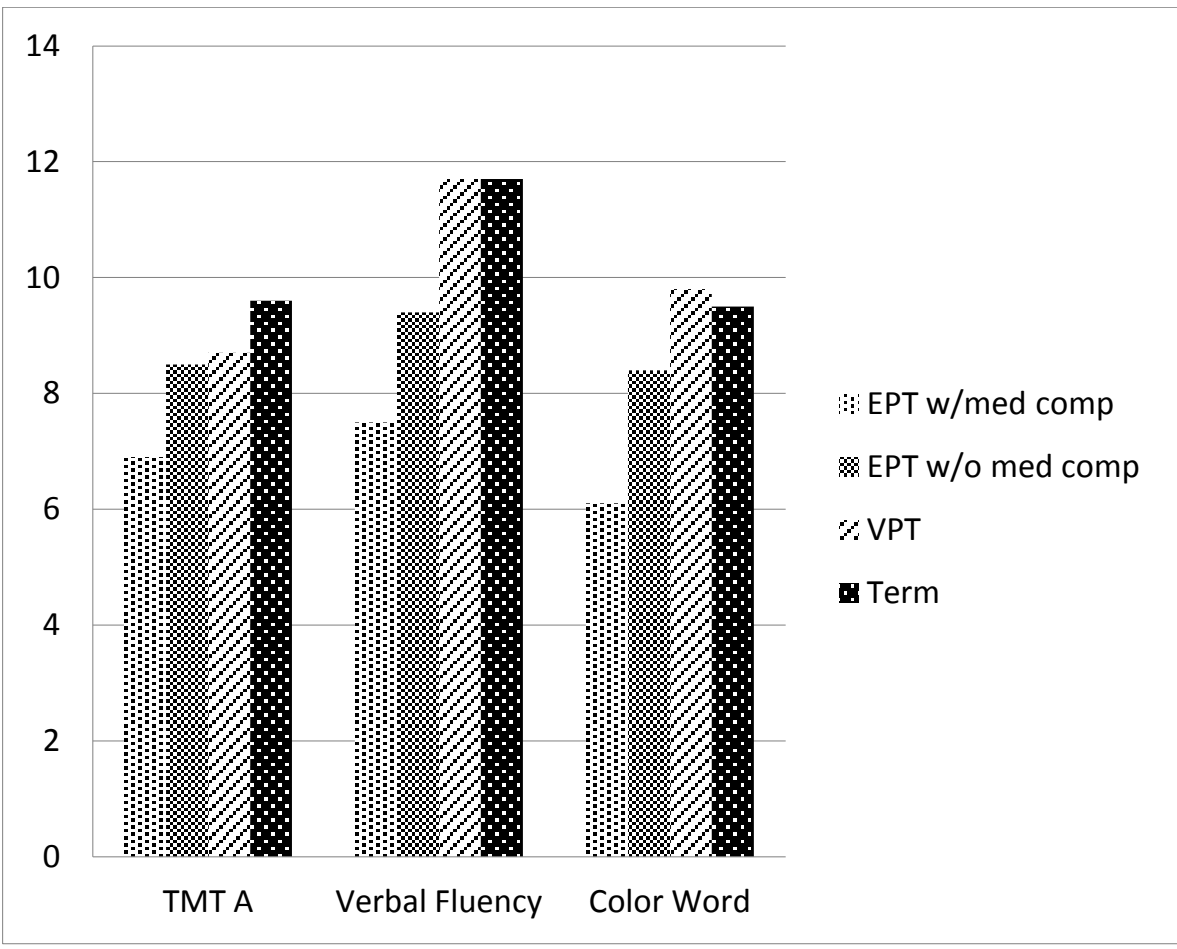

Figure 10. Results on three measures of executive functions, for term-born controls $(N=94)$, very preterm-born $(V P T ; N=36)$, and extremely pretermborn $(E P T)$ adolescents with $(N=35)$ and without $(N=38)$ developmental risks associated with perinatal medical complications. 


\section{Gender related differences at the age of 18 years}

There was an overall gender effect in that girls had superior performance compared to boys. As demonstrated above, there was also a consistent and strong group effect in favor of controls. Although there was no significant interaction effect between group and gender on cognitive outcome, t-tests revealed that gender effects had a slightly different pattern in the preterm as compared to the control group born at term. In the term group, genderrelated differences were found for just three of the sub-tests: RAVL learning $\&$ retention, D-KEFS Sorting and WISC-III Coding. Females performed better than males in each of these three tests $(\mathrm{p}<0.001, \mathrm{p}<0.01, \mathrm{p}<0.05$ respectively).

On the other hand, in the preterm group, the females performed better than the males on four D-KEFS subtests (TMT, VF , DF and Sorting; $p<0.01$ ), VMI ( $p<0.01$ ), WAIS-R Block Repetition, WISC-III Speed Index, and Face Recognition (all three $\mathrm{p}<0.05$ ).

\section{Predicting the developmental outcome from $5 \frac{1}{2}$ to 18 years of age}

\section{Study IV}

\section{Stability and prediction of outcome from preschool through adolescence}

\section{General intelligence}

The correlation between the WPPSI-R Full-scale IQ at the age of $51 / 2$ and the WISC-III Full-scale IQ at the age of 18 was $r=0.78(p<0.001)$ for the whole group, $r=0.84(\mathrm{p}<0.001)$ for the preterm group and $\mathrm{r}=0.61(\mathrm{p}<$ 0.001 ) for the controls (Figure 11). 


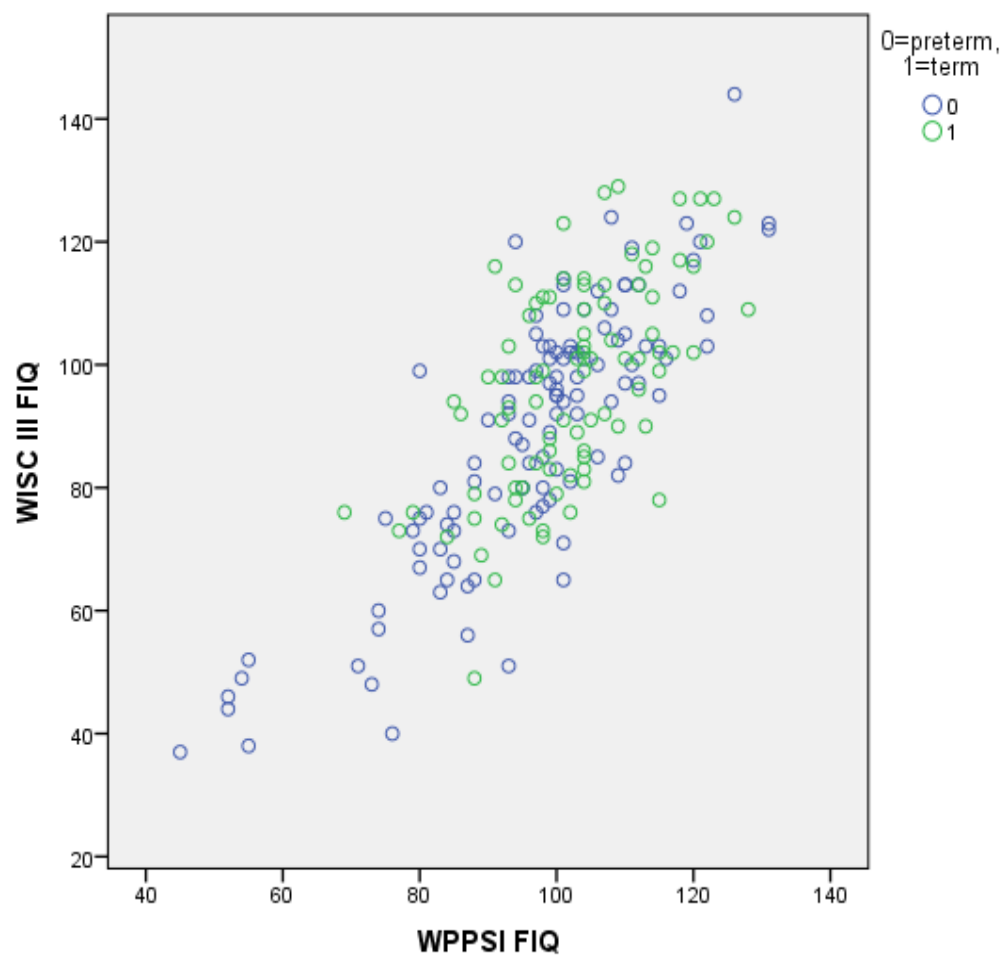

Figure 11. Relationship between Full-scale IQs (FIQ) at $51 / 2$ and 18 years of age, for preterm and term born adolescents.

\section{Executive functions}

The correlation between composite measures of EF at age $51 / 2$ years and those conducted at the age of 18 years was $r=0.65(p<0.001)$ for the group as a whole, $r=0.64(\mathrm{p}<0.001)$ for the preterm group and $\mathrm{r}=0.53(\mathrm{p}<$ $0.001)$ for the controls. 


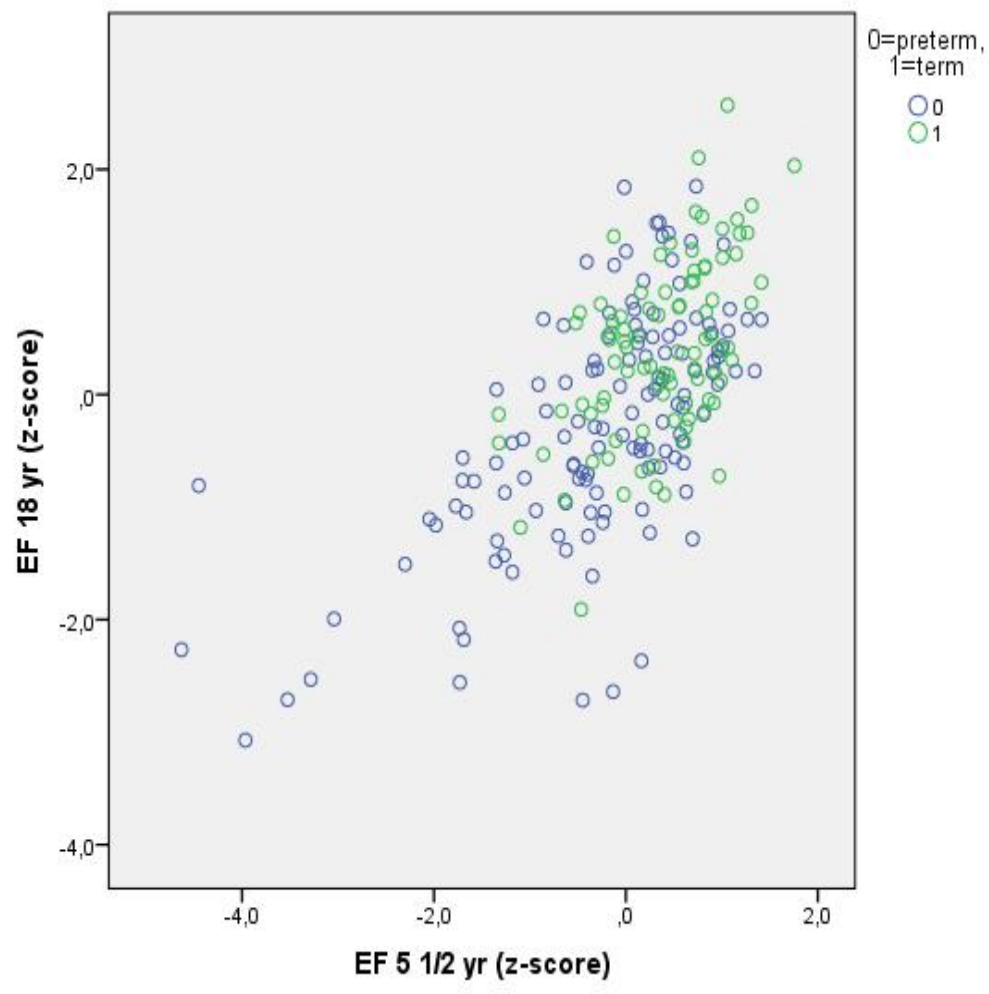

Figure 12. Relationship between composite measures of EF at $51 / 2$ and 18 years of age, for preterm and term born adolescents.

\section{Developmental predictors}

Stepwise multiple regression analyses were performed for the preterm and control groups separately using FIQ and EF at 18 years as dependent variables. For both groups, the EF at $51 / 2$ years, parental education and gender were assigned as independent variables, and perinatal medical risks and birth-weight ratio were also included for the preterm group.

The EFs at $51 / 2$ years were significant predictors of both FIQ and EF at 18 years of age in both the preterm and the term-born groups. Likewise, parental education significantly predicted FIQ in both groups. However, EF at 18 years of age was predicted significantly by parental education level only in the control group. In the preterm group, medical risks contributed significantly to variance in outcome with respect to EF and FIQ at 18 years, whereas birth-weight ratio only predicted the FIQ at 18 years of age. 
Table 5. Preterm group: Results of stepwise multiple regression analysis with EFs at $51 / 2$ years, parental education, gender, medical risks and birthweight ratio as predictors of FIQ and EF at 18 years.

\begin{tabular}{|c|c|c|c|c|c|}
\hline $\begin{array}{l}\text { Outcomes } \\
\text { at } 18 \text { years }\end{array}$ & Predictor & $\beta$ & SE of $\beta$ & $p$-value for $\beta$ & $\% \mathrm{EV}^{*}$ \\
\hline \multirow[t]{4}{*}{ WISC-III FIQ } & EFs $51 / 2$ years & 0.61 & 1.25 & $<0.001$ & 44.9 \\
\hline & Parental education & 0.15 & 0.57 & 0.02 & 1.6 \\
\hline & Medical risks & -0.18 & 2.10 & 0.01 & 1.8 \\
\hline & Birth-weight ratio & 0.16 & 0.07 & 0.01 & 2.5 \\
\hline \multirow[t]{2}{*}{ D-KEFS EF } & EF $51 / 2$ years & 0.60 & 0.06 & $<0.001$ & 40.3 \\
\hline & Medical risks & -0.18 & 0.11 & 0.01 & 2.9 \\
\hline
\end{tabular}

Table 6. Term group: Results of stepwise multiple regression analysis with EFs at $51 / 2$ years, parental education, and gender as predictors of FIQ and EF at 18 years.

\begin{tabular}{lllllr}
\hline $\begin{array}{l}\text { Outcomes } \\
\text { at 18 years }\end{array}$ & Predictor & $\beta$ & SE of $\beta$ & p-value for $\beta$ & \% EV* \\
\hline WISC-III FIQ & EF 5 1/2 years & 0.35 & 2.57 & $<0.001$ & 18.5 \\
& Parental education & 0.29 & 0.67 & 0.01 & 7.7 \\
& & & & & \\
D-KEFS EF & EF 5 1/2 years & 0.48 & 0.12 & $<0.001$ & 28.8 \\
& Parental education & 0.20 & 0.03 & 0.03 & 3.7 \\
\hline
\end{tabular}

$\mathrm{SE}=$ standard error, $* \mathrm{EV}=$ explained variance; FIQ: adjusted $\mathrm{R}^{2}=0.26$; $\mathrm{EF}$ : adjusted $\mathrm{R}^{2}=0.33$ 


\section{Study V}

\section{The Bender test with the ABC Neuropsychological Scoring System as a developmental predictor}

Stepwise multiple regression analysis was performed to investigate to what extent cognitive outcome at 18 years age was predicted by the Bender ABC Neuropsychological Scoring at $51 \frac{1}{2}, \mathrm{EF}$ at $5 \frac{1}{2}$, gender, parental education, perinatal medical risks, and birth-weight ratio. Although EF at $51 / 2$ years was the strongest predictor, the Bender ABC Neuropsychological Scoring System significantly contributed to the prediction of IQ and EF at 18 years, in both the preterm and the control group (see table 7).

Table 7. Preterm group: Stepwise multiple regression analysis with Bender $A B C$ Neuropsychological scoring system, EF at 5 1/2 years, parental education, gender, medical risks and birth-weight ratio as predictors.

\begin{tabular}{llcccr}
\hline $\begin{array}{l}\text { Outcomes } \\
\text { At 18 years }\end{array}$ & Predictor & $\beta$ & SE of $\beta$ & p-value for $\beta$ & $\% \mathrm{EV}^{*}$ \\
\hline WISC-III FIQ & EFs 5 1/2 years & 0.50 & 1.54 & $<0.001$ & 42.7 \\
& Bender ABC & -0.28 & 0.34 & $<0.001$ & 4.0 \\
& Gender & -0.14 & 2.76 & 0.03 & 2.0 \\
& Parental education & 0.13 & 0.56 & 0.04 & 1.7
\end{tabular}

\begin{tabular}{llrrrr} 
D-KEFS EF 18 & EFs 5 1/2 years & 0.43 & 0.08 & $<0.001$ & 36.5 \\
& Bender ABC & -0.25 & 0.02 & 0.01 & 5.2 \\
& Medical risks & 0.11 & -0.14 & 0.05 & 1.9 \\
\hline
\end{tabular}

$\mathrm{SE}=$ standard error, $* \mathrm{EV}=$ explained variance; FIQ: adjusted $\mathrm{R}^{2}=0.50$; EF: adjusted $R^{2}=0.44$ 
Table 8. Term group: Stepwise multiple regression analysis performed with the Bender ABC Neuropsychological scoring systems, the EF at $51 / 2$ years, parental education and gender as predictors.

\begin{tabular}{|c|c|c|c|c|c|}
\hline $\begin{array}{l}\text { Outcomes } \\
\text { at } 18 \text { years }\end{array}$ & Predictor & $\beta$ & SE of $\beta$ & $p$-value for $\beta$ & $\% \mathrm{EV}^{*}$ \\
\hline \multirow{3}{*}{ WISC-III FIQ } & NEPSY EF $51 / 2$ yrs & 0.32 & 2.50 & 0.001 & 18.5 \\
\hline & Bender ABC & -0.26 & 0.52 & 0.05 & 10.0 \\
\hline & Parental education & 0.21 & 0.68 & 0.04 & 3.5 \\
\hline \multirow{2}{*}{ D-KEFS EF } & NEPSY EF 5 1/2 yrs & 0.46 & 0.11 & $<0.001$ & 28.8 \\
\hline & Bender ABC & -0.38 & 0.02 & $<0.001$ & 13.9 \\
\hline
\end{tabular}

\section{Concurrent validity}

The ability of the Bender ABC Neuropsychological Scoring System to correctly distinguish between children with and without concurrent EF dysfunctions at $5 \frac{1}{2}$ years of age was tested by ROC-analysis. EF dysfunction was defined as having a composite EF $51 / 2$ z-score of $\leq-1$, based on NEPSY data from the total group of term-born and preterm youngster, who participated in the assessments both at $51 / 2$ and 18 years of age $(n=228)$. The cutoff defines the lower 15 percent of EF $5 \frac{1}{2} 2$ scores in our sample. With this definition 28 children were identified as having an EF dysfunction at age 5 $1 / 2$ (=positive), whereas 198 fell within the normal variation for EF 5 1/2 (=negative), and two participants could not be classified due to missing data.

The area under the ROC curve (AUC) was 0.84 , and the AUC was significantly different from the area under the reference line $(\mathrm{p}<0.001)$.

According to our analysis of the sensitivity and specificity of the Bender ABC Neuropsychological Score, an optimal cut off point would be a score of around 8.5 points, above which EF dysfunction becomes increasingly likely and further assessment might be recommended. With this cut-off, 89.3 percent of children with EF dysfunctions are correctly classified (positive actual state) and 65.7 percent of children without EF dysfunctions are also correctly classified (negative actual state). This also means that 34.3 percent of the individuals without EF dysfunction are incorrectly classified (false positive), which would become evident from further assessment, and that 10.7 percent of individuals with EF dysfunctions are missed (false negative). 


\section{Predictive validity}

The ability of the Bender ABC neuropsychological scoring system applied at $5 \frac{1}{2}$ years of age to correctly distinguish between individuals with and without EF dysfunctions at 18 years of age was also tested with ROC-analysis and it is presented in figure 13. Here, EF dysfunction was defined as having a composite EF $\mathrm{z}$-score of $\leq-1$, based on D-KEFS data from the total group of term and preterm adolescents, equivalent to the lower 15 percent of our sample. With this definition, 30 adolescents were identified as having an EF dysfunction (=positive), whereas 190 fell within the normal variation for EF (=negative), and eight participants could not be classified due to missing data. The area under the ROC curve was also 0.84. The AUC was significantly different from the area under the reference line $(\mathrm{p}<0.001)$.

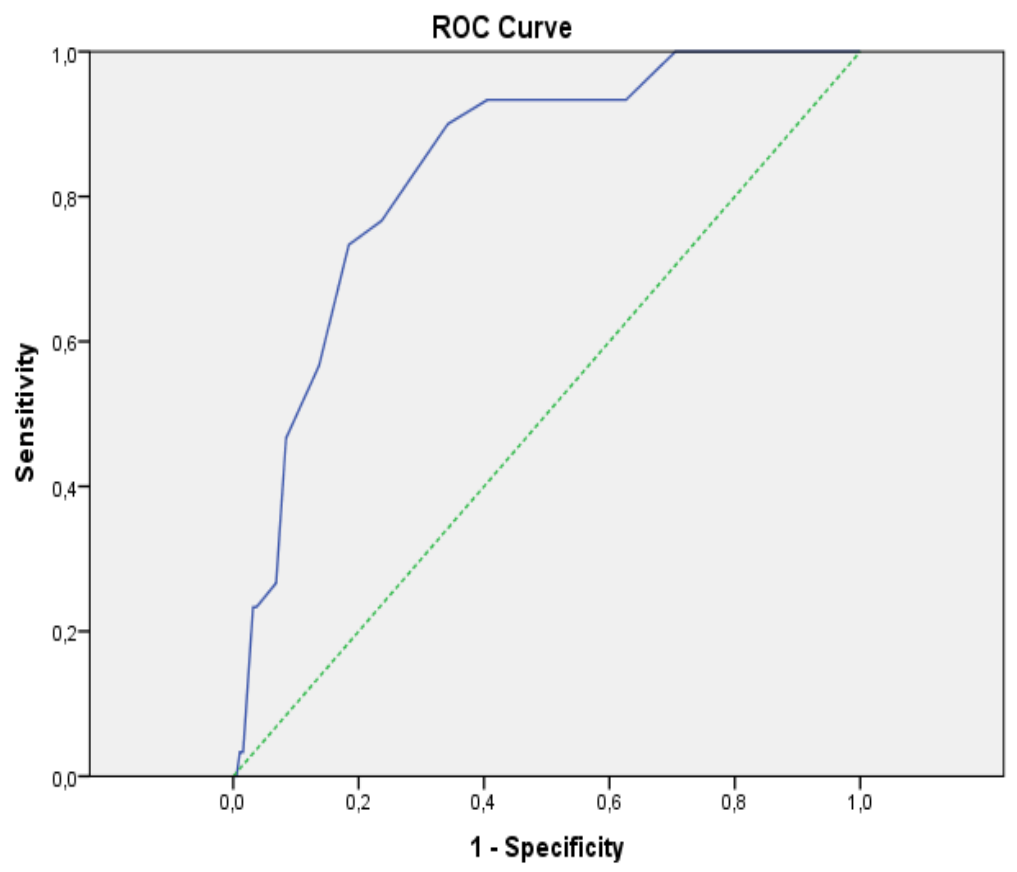

Figure 13. ROC-curve for the Bender ABC scoring system when it was used to identify Predictive EF dysfunctions at $51 / 2$ years of age. 


\section{Discussion}

The overall aim of this thesis was to explore the diversity of preterm children's development from preschool through adolescence and to consider the relation between this development and their degree of prematurity, birthweight, gender, medical risks and environmental factors, with special focus on the attainment of executive functions.

The results showed that on a group level, preterm children were at higher risk than controls of exhibiting executive dysfunctions even when their IQs lay within the normal range. This tendency did not change from preschool age to adolescence. Nevertheless, the diversity of developmental outcome was higher in the preterm group. Presumably, their individual development is determined by a more complex set of factors, in interaction: biological, environmental as well as factors relating to preterm birth.

\section{Group differences: preterm vs term}

In our sample, 68 percent of preterm-born and 81percent of term-born adolescents had IQ-scores above 85 (> -1SD) compared to the Swedish norm group for WISC-III (Wechsler, 1999). We conclude that most preterm-born children have a general intelligence within the normal range, and that this is also the case in adolescence. However, the IQ scores of the preterm group were significantly lower and exhibited higher rates of sub-average IQ $(<85)$ than the term-born group, thereby revealing that the distribution was skewed.

Poor visuo-motor skills in children born preterm are among the problems most frequently reported at a young age (Goyen et al., 2006; Sommerfelt, Markestad, \& Ellertsen, 1998). In fact, according to an early report from the SNP, eye-hand coordination at 10 months was the single area in which even low risk preterm children exhibited a significant weakness (Gerner et al., 1997).

Likewise, SNP results from preschool age (study I) showed that preterm children have less well-developed visuo-motor skills than term-born peers, and that visuo-motor skills are related to general cognitive ability $(r=0.65$, 
$\mathrm{p}<0.001)$ and executive functions $(\mathrm{r}=0.32, \mathrm{p}<0.001)$. In adolescence, weakness in visuo-motor functions persisted among individuals who were born extremely preterm (EPT). Moreover, the overall lower results of the preterm group cannot be attributed to single risk factors or to obvious impairments.

Verbal functions were revealed to be a relative strength in preterm individuals, both at a preschool age (study II) and in adolescence (study III). At the preschool age, most preterm children displayed a verbal ability on a par with the controls. In adolescence, no group differences were identified in the results obtained from a simple verbal task test, such as the Boston Naming Test. However, the speed of word mobilization was significantly slower in the EPT group.

According to a study by Briscoe and colleagues (2001), memory functions at a preschool age are closely linked to receptive language ability, but not to general cognitive ability, in preterm and term children alike (Briscoe et al., 2001). This appeared to be verified by our sample (study II). In adolescents, only the EPT group performed significantly worse on episodic memory, measured by face recognition and therefore of visuo-spatial nature. Likewise, slight difficulties in a verbal learning task were identified in the EPT group, however these differences were not statistically significant for a retention-based task, indicating that once new material has been acquired verbal episodic memory is functioning well.

An earlier report from the SNP follow-up conducted at $5 \frac{1}{2}$ years of age showed that EF were a specific weakness among preterm children, especially regarding impulse control and working memory (Böhm et al., 2004). This tendency persisted in adolescence (study III). According to our results, the preterm population exhibits, at least, subtle deficits across all EF domains, indicating a rather global dysfunction. This is supported by the fact that principle component analysis showed that EF data from each of the two assessments ( $51 / 2$ and 18 years) identified only two EF factors (information processing, and other EFs), in each data set. Moreover, in the age 18 data half of the sub-tests loaded on both factors. This was the reason that we have chosen to use composite EF measures in the regression analyses rather than theoretically derived sub-domains. Nevertheless, one should be aware that, by forming an EF composite measure, potentially significant dimensions of the EF might have been overshadowed. In fact, some EF subtests, such as the Verbal Fluency test and the Color-Word test that require more complex processing seem to be more sensitive measures for differentiating between individuals with and without general cognitive deficits. To be more precise, among preterm children, degree of prematurity, medical complications, birth-weight ratio, and male gender appear to have some impact on all EF measures, but 
the degree of the impact seems to differ by what might be interpreted as executive sub-domains. With reference to Anderson's model (2002), the two domains of Attentional Control and Information Processing appear to be generally negatively affected in the EPT group. By comparison, Cognitive Flexibility and Goal Setting appear to be associated with more general cognitive deficits seen in children who have suffered medical complications and intrauterine growth retardation (figure 12).

Our data does not support either of the theoretical formulations that working memory (Baddeley, 2000) or inhibition (Barkeley, 1996) would be keys to executive functioning. As mentioned above, all EF measures were highly correlated in our sample, but it is difficult to identify the reason for this; it might be because all components were interrelated as suggested by Anderson's model (2002) or that they had a common underlying mechanism, as in Miyake's model (2000). Another alternative is that the assessments used to measure EF do not always measure a single aspect or rather, that any EF model might look different for different populations, such as healthy controls, preterm children, and children with autism or ADHD. Population differences might also be one of the reasons that as of yet no single EF theory has been uniformly accepted.

In summary, EF dysfunction persisted into adolescence among those who had been born preterm. On a group level, EF dysfunction seems to be global rather than specific, however the degree of impact on different domains of EF seem to differ in connection with biological and medical factors. Further studies are necessary to explore the EF development of individual preterm children before we can finally conclude whether and to what extent EF dysfunctions are global or specific, or a combination of the two. 


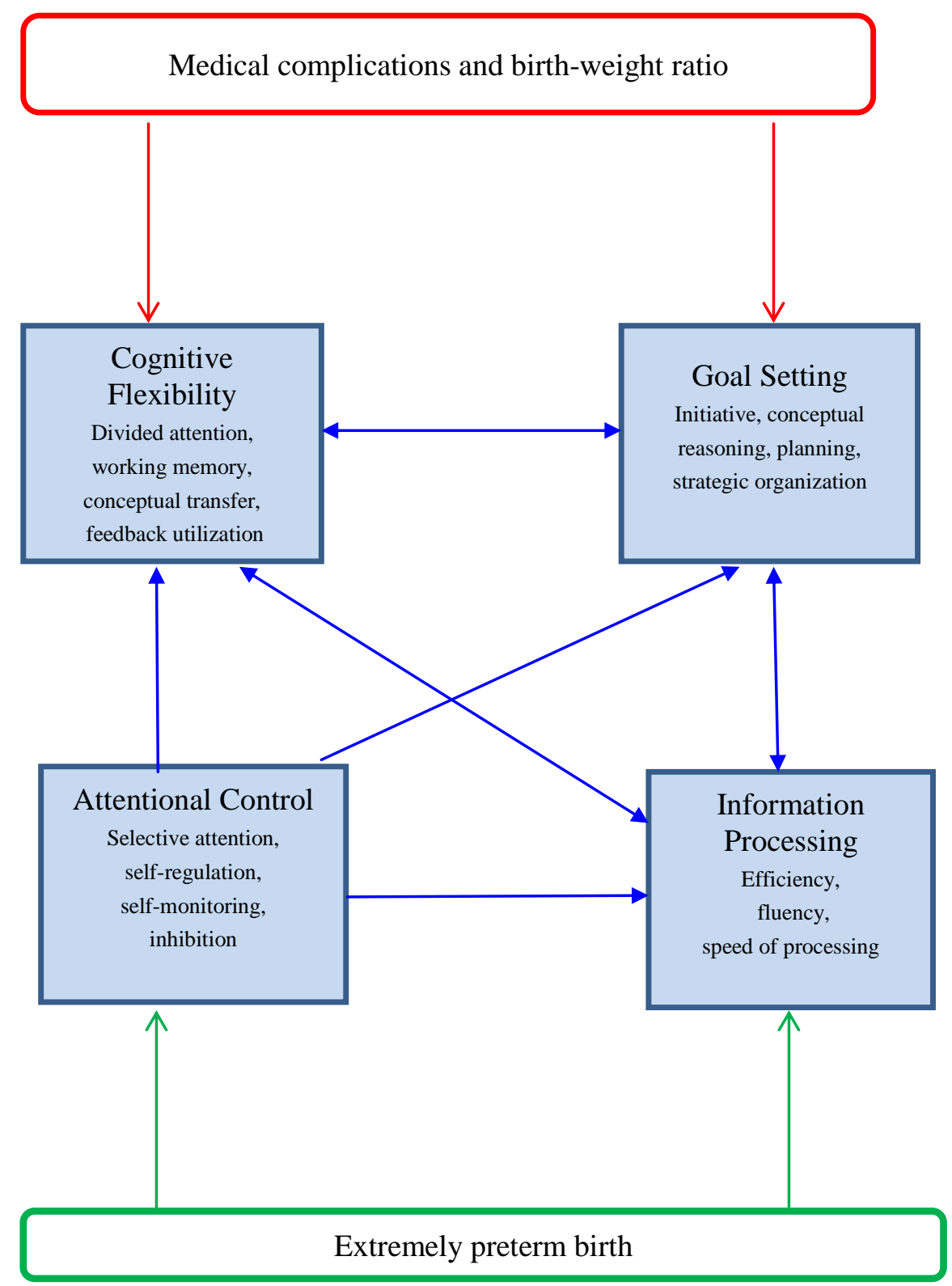

Figure 14. The model of executive control system by P. Anderson (2002), and how it may be applied to our results. 


\section{Individual differences at $51 / 2$ years}

Overall, $5 \frac{1}{2} 2$ years old preterm children tended to have lower neuropsychological profiles across all domains. Even at that, more than 46 percent of preterm children belonged to well-functioning clusters, characterized by an even functional development, that is, they were strong in all neuropsychological domains and seemed to have a problem-free cognitive development.

On the other hand, those who belonged to lower clusters typically exhibited uneven functional development, with deficits in at least one domain, which did not preclude that they revealed relative strengths and therefore approached average performance in other domains. This provides a striking illustration of the diversity of cognitive outcome in preterm children. It also means that preterm children exhibiting uneven development have a range of variability in their functioning, which, because of their relative strengths, might lead to their difficulties being misinterpreted as laziness or lack of motivation where academic performance is concerned. This, in turn, could prevent these children from receiving appropriate interventions. Another problem can be that the weakness in certain functions, e.g. working memory, may compromise performance also in areas of relative strengths, e.g. verbal learning. Moreover, uneven development might make children more frustrated than children with a generally low level of performance. The provision of appropriate psychological support for these children is therefore highly recommended.

Medical risks and birth-weight have some negative impact on different aspects of neuropsychological development, but this is limited in extent and we cannot explain neuropsychological profiles by medical complications or birth-weight alone. Some of the preterm children who had experienced serious medical problems belonged to the high-performing clusters, while other preterm children with no obvious medical disadvantages had low functional profiles. This illustrates that a follow-up assessment of preterm children should not be determined by medical factors alone, or by any other singular perinatal circumstance. Even healthy preterm babies need a follow-up assessment in the form of developmental screening, which we suggest in study $\mathrm{V}$, and this recommendation is also supported by at least one other study (Dall'oglio et al., 2010).

Term-born children's profiles were not only higher, but also more even than those of the preterm group, meaning that the profiles of the term-born children were determined primarily by their overall cognitive level. Two of five term-born clusters signified by strength in the verbal domain, were dominated by girls; two of five clusters, signified by strengths in the visuo-spatial domain, were dominated by boys. Interestingly, profiles typical of gender 
were identified only among children that had been born at term, indicating that preterm birth and its consequences may overshadow other biological and psychosocial mechanisms that contribute to gender related effects on neurocognitive profiles.

\section{Factors influencing development}

\section{Gender}

Although no profiles typical of gender were identified in the preterm group at age $51 / 2$ years, preterm girls as compared to preterm boys showed an overall advantage in terms of cognitive outcome, a finding that is in agreement with other studies (Goddeeris et al., 2010; Hack et al., 2002; Kesler et al., 2008; Reiss et al., 2004). Girls were ahead of boys in terms of visuo-motor development at a preschool age, but this was consistently significant only for preterm children and the effect was relatively weak among the controls, indicating a specific vulnerability for preterm-born boys.

Earlier studies from SNP showed that visual impairments and gender were significantly related to the EF results, with the girls' performance being superior to that of the boys (Böhm et al., 2004), but gender per se neither predicted general intelligence, nor EF at 18 years of age in either group in the research presented here. Nevertheless, an analysis of group differences by gender showed that male preterm born individuals are at higher risk of experiencing executive dysfunctions than females born preterm, and this trend is still evident in adolescence. This tendency could not be identified in the group of term-born youngsters. These results may partly, but not entirely, be explained by the fact that morbidity after preterm birth is higher in males (Cartlidge \& Stewart, 1997; Ingemarsson, 2003).

\section{Parental education}

It is well established knowledge that parental education has an impact on children's cognitive development. A previous study from SNP showed that parental education was the single most important predictor of intelligence at $51 / 2$ years (Böhm, 2002). Not surprisingly, neuropsychological profiles at 5 $1 / 2$ in study II were associated with maternal education, in both groups. This is nonetheless quite interesting since gender effects on neuropsychological profiles at age $5 \frac{1}{2}$ were overshadowed by other factors in the preterm group, whereas parental educational levels were not. In adolescence, too, parental 
education predicted general intelligence in both groups. Parental education was associated with the children's general intelligence, but, this effect was stronger in term-born children. Despite these findings, parental education predicted development in executive functions from age $5 \frac{1}{2}$ to 18 years only in the term group, whereas medical complications/history predicted the preterm children's EF. This means that parental education has a continued significant impact on the development of EFs after $5 \frac{1 / 2}{2}$ years of age in the group comprised of children born at term, whereas medical factors continued to play a significant detrimental role for the preterm group.

In an early study of Scottish low birth-weight children, Drillien and colleagues (1980) reported that the combination of low socioeconomic status and preterm birth has a dramatic negative impact on intellectual performance (Botvinick \& Watanabe, 2007). Our studies so far have not addressed whether this is also the case in a Swedish population of children born preterm in the early 1990s, where there has been universal access to maternal health and perinatal care of high quality. Our data might be limited by restriction of range, but the question as such merits further investigation.

\section{Degree of prematurity}

One of the most positive results from our study is that adolescents born after 28 weeks of gestation, or later, with a normal birth-weight and no perinatal complications do not have an elevated risk of developing cognitive deficits at the age of 18. In other words, VPT adolescents performed as well as controls in all cognitive domains. This result might not be universal, but indicates that, if children are born very preterm in a country with a similar standard of medical resources to that in Sweden, their long-term cognitive outcome can be expected to be essentially problem-free. By contrast, the results revealed that extremely preterm birth per se poses a risk for the child's longterm cognitive outcome, and particularly for his or her EF. The elevated risk for EPT children is in agreement with the findings of other studies (Hintz, Kendrick, Stoll, et al., 2005; Leversen et al., 2011; Washburn et al., 2007).

\section{Birth-weight}

Our study population is defined not only by being born preterm, at $<37$ weeks of gestation, but also by the infant having a very low birth-weight $<1500 \mathrm{~g}$. As a result, we have a clear overrepresentation of growth-retarded children in the moderately preterm group (PT). A low gestational birth age should be distinguished from intrauterine growth retardation (IUGR) since the risk mechanisms and their impact on cognitive outcome differ (Johansson \& Cnattigius, 2010). Our PT group, dominated by SGA adoles- 
cents because of IUGR, had sub-average cognitive outcomes, particularly on complex cognitive measures. In addition, VPT adolescents who were born earlier but had not suffered IUGR performed significantly better in all domains. This tendency was already seen at $5 \frac{1}{2}$ years of age. (Böhm et al., 2002).The result might indicate that, if the moderately premature fetus is poorly nourished, it may be better for the child to be delivered than to stay in the mothers' womb. Before we get to the final conclusions, however, we need to pursue studies of other aspects of the children's development and, in particular, their socio-emotional outcome.

\section{Medical complications}

Perinatal medical complications affect cognitive outcome, but to a limited extent. Study III showed that extremely preterm children are at risk of having long-term cognitive deficits, particularly in their EF and this may be exacerbated by medical complications. Study IV also demonstrated that such complications continue to have a negative impact on cognitive development beyond the preschool years. Still, Study II found that individual neuropsychological profiles identified at preschool age were not determined by medical risks to a statistically significant degree. Obviously, individual development after preterm birth is determined by multiple factors in interaction.

\section{Developmental changes}

The stability in general intelligence between $5 \frac{1}{2}$ years and 18 years was high $(r=0.78, p<0.001$ in the whole group, $r=0.84, p<0.001$ in the preterm group and $r=0.61 p<.001$ in the term group). Likewise, the stability of EF development was high, but not quite as high. $(r=0.65, p<0.001$ in the whole group, $r=0.64, p<.001$ in the preterm group and $r=0.53 p<0.001$ in the term group). The higher stability in IQ for the preterm group is at least partly attributable to the larger variance among children born preterm, on both occasions. Another explanation is that environmental factors, namely parental education, appear to have a stronger influence on the cognitive development of term-born children, whereas medical risks continue to exert a negative impact among the preterm born. From these results, we conclude that, on a group level, general catch-up effects could not be identified. Indeed, rather than catching up on their peers, a slight decline relative to controls could be identified in the EF of preterm adolescents. A practical implication of this result might be that preterm children who display executive dysfunctions at a preschool age may benefit from identification through early assessments and educational interventions. However, when we look at the results at an individual level, there are individuals who caught up, and there are also examples of youngsters who showed further decline relative to the 
performance of their peers. A multiple case study might be useful to investigate these individuals with the intention of identifying the keys to positive and negative development throughout childhood.

\section{Bender as a screening test}

The finding that EF dysfunction at a preschool age tends to persist into adolescence points to the need for early identification of such problems, in order to prevent school failure. Since our studies showed that even some of the healthy preterm children are at risk of exhibiting EF dysfunctions, a followup assessment of preterm children should not be determined on the basis of medical history alone. However, the administration of a neuropsychological assessment battery is a time-consuming task, and it is not feasible to offer this to all preterm-born children at an early age, which would be required for the identification of developmental deficits with the intention of providing an early intervention. Thus, a simple, but reliable and valid screening test that is sensitive to EF is required, to enable correct and early identification of children with executive deficits.

The results of Studies I and V showed that the Bender test with the ABC Neuropsychological Score was sensitive for identifying children with a delay in $\mathrm{EF}$ and general psychological development, in preterm and term-born children. These findings speak in favor of using it as a tool in developmental screening. In addition to visuo-motor skills, the Bender test reflects EF, such as planning and impulse control, since all nine figures included in the test should be copied and placed on one sheet of paper. The ABC neuropsychological score appeared to be sensitive to these important EF. Moreover, the ABC Neuropsychological Score predicted developmental outcome in adolescence. From the point of view of being able to offer a psychological screening, it is vital to note that instead of the several hours required to use a neuropsychological battery, administration of the Bender and the ABC Neuropsychological Scoring System takes only about 15 minutes per individual. Besides, to most preschool children drawing is a commonplace and natural activity. We recommend that the Bender test with the ABC Neuropsychological Scoring be further tested in developmental screening at a preschool age. 


\section{Summary of the present state of knowledge arising from the research}

In Figure 15, our findings are summarized and placed in the conceptual framework outlined in Figure 4.

\section{Biological factor / Gender}

\section{Controls}

Gender differences decreased from preschool through adolescence.

Gendered cognitive profiles identified.

\section{Preterm}

Girls showed a cognitive advantage.

Boys were at higher risk for EF deficits.

No gendered cognitive profiles identified.

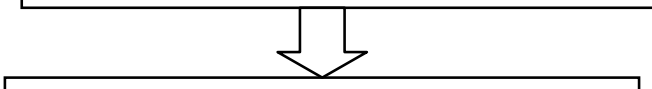

\section{Developmental changes}

Controls and preterm

IQ and EF development were relatively stable from preschool through adolescence in both groups.

\section{Preterm}

Most of preterm youngsters had an IQ within the normal range but there was a higher rate of sub-average IQs.

EF weakness persisted into adolescence.

Uneven cognitive profiles were seen among children with lower performance.

Diversity of outcome was higher among preterm children.

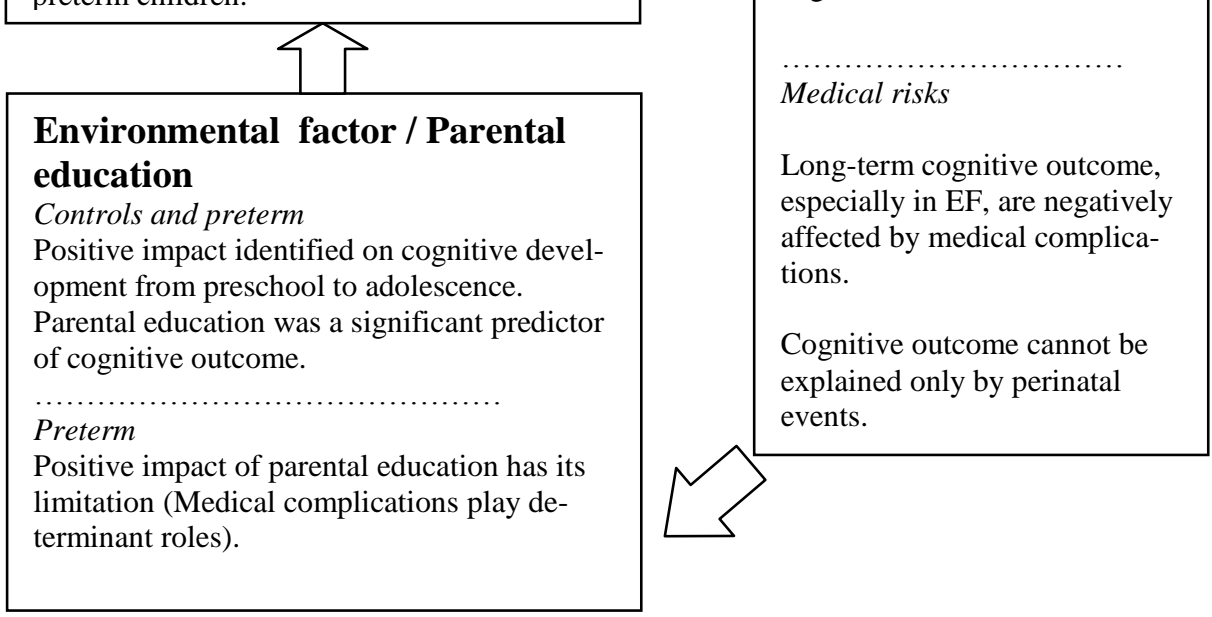

Figure 15. Summary of the present state of knowledge. 


\section{Methodological strengths and challenges}

The Stockholm Neonatal Project (SNP) is a longitudinal and population based study of a cohort of children who have been followed prospectively since birth. The longitudinal design makes it possible to investigate children's individual development, which is something that cannot be done by either register or crossover studies. This thesis is the first report from SNP on cognitive developmental outcome at age 18 , and its predictors.

Since we have a fairly large sample, it was possible to investigate profiles on individual levels as well as the impact of gestational age, birth-weight, medical complications, gender, and parental education on cognitive outcomes. By international standards, the socioeconomic characteristics are satisfactory and high quality care is universally available in Sweden. Furthermore, alcohol or drug abuse during pregnancy is relatively rare (Gäddlin, 2011).These factors make it possible to investigate the impact of premature birth per se on cognitive development.

However, the closer we look at the development of preterm born youngsters, the greater the complexity appears to be. Not surprisingly, single factors cannot explain the complexity of human development.

Our results indicate that there is relative stability in individual cognitive development from preschool through adolescence (18 years). However, this might be too bold a conclusion, given that we lack assessment data from middle childhood. Lack of resources have prevented a follow-up study from that period, which could otherwise have provided important information about "transition to efficient brain collaboration" (Luna \& Sweeney, 2004, p. $305)$ and how this might differ between groups. Moreover, we did not utilize developmental assessment data from infancy in this study. Further investigation is needed to see if there are catch-up effects before age of $5 \frac{1 / 2}{2}$ years.

In this thesis, Anderson's model of executive control was applied as a way to highlight EF mechanisms. However, the neuropsychological batteries chosen were not based on his model, but rather on what previous studies, including our own, have found to be psychometrically sound and diagnostically useful. If I could add more tests, the measurement of information processing speed without visual stimuli would be a priority, since preterm children tend to have problem in visual processing. At age 18, I would also include specific tests of goal setting ability. We did include a relatively complex Sorting test (D-KEFS), but a purer measure of goal setting would be valuable. These additions would open up for a better test of our data against Anderson's model. Afterthought is intrinsic to longitudinal studies; as knowledge expands the included variables tend to appear less than ideal. 
The present studies have only utilized some of the variables from the SNP's large database. Environmental aspects were represented by parental educational level only. Undoubtedly it has a significant influence, but, parental education is certainly not the only environmental factor that will affect children's development. The relation between cognitive outcome and other environmental factors, such as, family interaction and structure, disease which is not related to preterm birth, economic resources, and community factors would be interesting to investigate. Moreover, for the ecological validity, to compare our cognitive test result to school attainment will give us a more complete picture of the development of the SNP cohort.

Although the time gap between assessments was quite long, drop-out rate was only 25 percent. This indicates that the participants have a high interest in SNP. However, children of parents with lower education were slightly less likely to participate, in both groups. We cannot preclude that the drop-outs differ in their developmental trajectories, and it remains a challenge to keep attrition at a minimum and unsystematic.

The preterm group had inferior results on EF measures, even when controlling for IQ. However, following the critical appraisal of Dennis and colleagues (2009), in the analyses of EF outcome presented here, we have not used IQ as a covariate. As Dennis and colleagues have pointed out, "the covariate should not be an outcome of the dependent variable or of the independent variable” (p. 334). Executive dysfunctions often lead to lower IQ, and low IQ may in itself be an effect of preterm birth. By using IQ as a covariate, the dynamics of cognitive outcome will be minimized. obscuring true developmental patterns (Dennis et al., 2009).

Finally, as in all longitudinal studies, we should not forget the cohort's effect. It is necessary to compare results with studies from other cohorts in different countries, as well as newer cohorts from Sweden.

\section{Suggestions for further research}

In this thesis, I have investigated the effect of some biological and environmental factors on cognitive outcome, after preterm birth. Further investigations of the combined impact of biological and environmental factors, in interaction, on cognitive outcome would be the next step in the search to comprehend different developmental trajectories. In addition, it is known from former studies that preterm children are at higher risk for developing psychiatric problems, such as anxiety, depression and other internalizing problems. However, psychosocial problems have a strong relation to the environment and, since Sweden is a country where the general welfare system, including medical care, is relatively good, the psychosocial outcome of 
children who were born preterm might be more positive than in many other countries. These aspects have not yet been analyzed in SNP, and is not taken into account in the studies presented here. Nevertheless, some relevant data have been collected, also including family aspects such as parental stress and socio-economic status.

We have reported results for the cognitive outcomes at 18 years of age on a group level only. However the diversity of individual outcomes in adolescents with developmental problems and EF deficits will give important information of use in planning appropriate interventions for future generations of preterm children. Thus the data from age 18 should be analyzed applying a person-oriented method to identify individual neuropsychological profiles among adolescents, and to examine the relationship between the cognitive profiles and perinatal medical complications, brain structure and environmental factors.

One challenge for the future would be to identify the optimal timing for interventions since very little is known about this aspect. In the some upcoming SNP studies, the interaction between cognitive/psychosocial outcomes, biological factors (DNA, MRI) and environmental factors will be investigated. 


\section{Conclusions}

Most of the individuals who are born preterm have a general intelligence level within the normal range, at preschool age and in adolescence, However, a weakness in the EFs is seen in the preterm group, even in adolescence, and no general catch-up effect could be identified.

EF dysfunctions are related to the degree of prematurity and to medical complications suffered in the perinatal period. Furthermore, a tendency for preterm boys to exhibit a special vulnerability to develop EF deficits was identified.

A low birth-weight in moderately preterm children who had experienced intrauterine growth retardation, seems to have a negative impact on general cognitive development, and especially on the ability to perform complex tasks, more than on basic EFs. Our combined findings indicate that moderately preterm children who are also SGA are at risk of developing general cognitive deficits, whereas EPT children are at risk of having EF dysfunctions.

One of the most positive findings of our results is that VPT children with no obvious medical complications performed as well as their term-born peers in all cognitive domains. A future study should investigate their psycho-social development as well.

A second positive finding is that EPT adolescents' ability to retain verbal material was as good as that of their term born peers. This might imply that EPT children require more time to learn than others, but that their relative capacity to retain the acquired knowledge is on the same level as that of other individuals. Special pedagogy for children with EF deficits might be developed, inspired by this finding.

Another finding is that also for preterm children, parental education has a positive impact on children's development. This indicates the importance of environmental as well as biological factors.

Based on individual neuropsychological profiles, we could identify typical outcomes for preterm and term-born children, respectively. Diversity in developmental outcome is highest among preterm children, who more often than term-born children displayed weakness in at least one domain. The profiles obtained in our group could not be explained by either birth-weight, or medical history. This illustrates the complexity of development and of its interaction with biological and environmental factors. 
Cognitive outcome after preterm birth cannot be sufficiently explained by birth-weight, gestational age or medical risks, and it would be ideal to assess all preterm children with a valid screening test. We have shown that the Bender gestalt test with the ABC Neuropsychological Scoring System is a promising screening instrument for identifying executive dysfunction before school start, in preterm children as well as term children. 


\section{Acknowledgements}

I am deeply grateful to have had the opportunity to explore interesting and important questions during my PhD studies. First and foremost I would like to thank all the children and their parents in SNP for participating in our studies and sharing their life experiences with us.

This work could not have been done by a single person. I would like to express my deepest gratitude to all those who have supported me.

I gratefully acknowledge financial support from the Swedish Council for Working Life and Social Research (FAS), the Vårdal Foundation, and Olle Engkvist stiftelsen.

I sincerely thank:

my main supervisor Professor Ann-Charlotte Smedler who is not only the world's best scientific supervisor but also a wonderful role model for life. There are no words that can express how grateful I am for the opportunity to work with you! My warmest thank for all your support and patience.

my co-supervisor Dr. Birgitta Böhm, a great and experienced clinical neuropsychologist with one of the world's warmest hearts, who was responsible for the successful follow-up study at $51 / 2$ years. Many thanks for all your support and for freely sharing your ideas and experiences. My greatest aspiration is to one day become a clinician like you!

To Stockholm Neonatal Project collaborators:

Professor Hugo Lagercrantz, founder of SNP. Your humanistic perspective on scientific work in preterm children inspired not only me but also continues to inspire many researchers all over the world.

Professor Hans Forssberg, founder of SNP. I am truly grateful for your guidance which always reflected your broad knowledge in science and medicine. Your supervision always inspired me to see the facts from many different angles. 
Associate professor Miriam Katz Salamon, who for many years served as the SNP project coordinator and created the original data base. Your hard work and generosity has laid the ground for all our continued efforts.

Associate professor Pia Risholm-Mothander, a wonderful psychologist and psychotherapist. It was nothing but joy to spend time with you. Thank you for supporting me when I needed it the most.

Associate professor Brigitte Vollmer, an excellent scientist and child neurologist, and Dr. Gustaf Mortenson, a great MR-physicist - a big thank you for guiding me through the field of MRI. Associate professor Rochellys Diaz Heijtz, thank you so much for teaching me about DNA. I am looking forward to further collaboration with all of you!

To the psychologists who tested children at Astrid Lindgren Children's Hospital, Linn Almström, Per Aschan, Wilhelm Behrman, Helena Bohlin, Maria Breide, Marie Bremberg, Hans-Martin Engström, Sally Fogelberg, Lena Järvtass, Märit Larsson, Sofia Lindström, Moa Manneberg, Anna Råde, Diana Sezgin, Erika Sterner and Åsa Södergren - it was great to work with you!

To my "doctoral sibling “ Jannica Stålnacke who is a wonderful friend and room-mate at both Karolinska Institutet and Stockholm University. Thank you for sharing great times, many laughs and interesting discussions with me!

Thanks also to the developmental psychology seminar group at Stockholm university, Lilianne Eninger, Laura Ferrer Wreder, Pehr Granqvist, Hanna Ginner Hau, Stephan Hau, Lotta Reuterskiöld, and Kristina Bergström for sharing knowledge and ideas and being so supportive.

To my colleagues and friends at Astrid Lindgren Children's Hospital and Stockholm university, Lea, Nelli, Ann-Marie, Sermin, Johan, Momin, Linda, Elena, Ann-Christin, Lena, Miyabi, Catherine, Marianne, Malena, Gergör, Niklas ... and many more, thanks for all the joy and interesting discussions. Special thanks to None-Marie and Mikael for administrative and technical support!

Special thanks to:

the external readers, Professor Philip Hwang and Professor Ove Almkvist for valuable feedback to improve my thesis and to Suzy Lindström for brushing up my English with interesting and humorous comments. 
my family and friends in Japan, especially to my parents Yoshikazu and Yoshiko Kawanaka for the support from far away and inspiring my interest in research.

my family and friends in Sweden, especially to my parents in Sweden, Rune and Agneta Lundequist, for believing in me and for all practical support that I needed to accomplish this work.

And at last but not least, a very special thanks to my dearest family, Tomas, Mikaela and Erika for love, support, patience and encouragement. You mean everything to me!

Aiko Lundequist

Stockholm, August 2012 


\section{References}

Allin, M., Henderson, M., Suckling, J., Nosarti, C., Rushe, T., Fearon, P., . . Murray, R. (2004). Effects of very low birthweight on brain structure in adulthood. Dev Med Child Neurol, 46(1), 46-53.

Allin, M., Rooney, M., Griffiths, T., Cuddy, M., Wyatt, J., Rifkin, L., \& Murray, R. (2006). Neurological abnormalities in young adults born preterm. J Neurol Neurosurg Psychiatry, 77(4), 495-499.

Alloway, T. P., Gathercole, S. E., \& Pickering, S. J. (2006). Verbal and visuospatial short-term and working memory in children: are they separable? Child Dev, 77(6), 1698-1716.

Anderson, P. (2002). Assessment and development of executive function (EF) during childhood. Child Neuropsychol, 8(2), 71-82.

Anderson, P., \& Doyle, L. W. (2004). Executive functioning in school-aged children who were born very preterm or with extremely low birth weight in the 1990s. Pediatrics, 114(1), 50-57.

Anderson, P. J., \& Doyle, L. W. (2008). Cognitive and educational deficits in children born extremely preterm. Semin Perinatol, 32(1), 51-58.

Anderson, V. (2002). Executive function in children: introduction. Child Neuropsychol, 8(2), 69-70.

Anderson, V., Jacobs, R., \& Anderson, P. J. (2008). Executive functions and the frontal lobes; A lifespan perspective. New York, London: Taylor $\&$ Francis.

Anderson, V., Jacobs, R., Spencer-Smith, M., Coleman, L., Anderson, P., Williams, J., . . Leventer, R. (2010). Does early age at brain insult predict worse outcome? Neuropsychological implications. J Pediatr Psychol, 35(7), 716-727.

Anderson, V., Northam, E., Hendy, J., \& Wrennal, J. (2001). Developmental Neuropsychology. A Clinical Approach Hove and New York: Taylor $\&$ Francis group.

Anderson, V., Spencer-Smith, M., Coleman, L., Anderson, P., Williams, J., Greenham, M., . . . Jacobs, R. (2010). Children's executive functions: are they poorer after very early brain insult. Neuropsychologia, 48(7), 2041-2050.

Anderson, V., Spencer-Smith, M., \& Wood, A. (2011). Do children really recover better? Neurobehavioural plasticity after early brain insult. Brain, 134(Pt 8), 2197-2221.

Andrews, W. W., Hauth, J. C., \& Goldenberg, R. L. (2000). Infection and preterm birth. Am J Perinatol, 17(7), 357-365. 
Archibald, L. M., \& Gathercole, S. E. (2006). Short-term and working memory in specific language impairment. Int $J$ Lang Commun Disord, 41(6), 675-693.

Arpino, C., Compagnone, E., Montanaro, M. L., Cacciatore, D., De Luca, A., Cerulli, A., . . . Curatolo, P. (2010). Preterm birth and neurodevelopmental outcome: a review. Childs Nerv Syst, 26(9), 1139-1149.

Baddeley, A. (2000). The episodic buffer: A new component of working memory? Trend in cognitive Sciences, 4, 417-423.

Baddeley, A., \& Hitch, G. (1974). Working memory. In G. A. Gower (Ed.), The psychology of learning and motivation (pp. 47-89). New York: Academic Press.

Barker, D. J. (1995). Fetal origins of coronary heart disease. BMJ, 311(6998), 171-174.

Barkley, R. A. (1996). Linkages between attention and executive functions. In G. R. Lyon \& N. A. Krasnegor (Eds.), Attention, memory, and executive function (pp. 307-325). Baltimore: Paul H. Brookes Publishing.

Bayless, S., \& Stevenson, J. (2007). Executive functions in school-age children born very prematurely. Early Hum Dev, 83(4), 247-254.

Beery, K. E., \& Berry, N. A. (2004). Beery-Buktenica test of visual-motor integration (VIM). Administration, scoring and teaching manual. Minneapolis: MN:NCS Pearson, Inc.

Bhutta, A. T., Cleves, M. A., Casey, P. H., Cradock, M. M., \& Anand, K. J. (2002). Cognitive and behavioral outcomes of school-aged children who were born preterm: a meta-analysis. JAMA, 288(6), 728-737.

Blondel, B., Macfarlane, A., Gissler, M., Breart, G., \& Zeitlin, J. (2006). Preterm birth and multiple pregnancy in European countries participating in the PERISTAT project. BJOG, 113(5), 528-535.

Botting, N., Powls, A., Cooke, R. W., \& Marlow, N. (1998). Cognitive and educational outcome of very-low-birthweight children in early adolescence. Dev Med Child Neurol, 40(10), 652-660.

Botvinick, M., \& Watanabe, T. (2007). From numerosity to ordinal rank: a gain-field model of serial order representation in cortical working memory. J Neurosci, 27(32), 8636-8642.

Bowen, J. R., Gibson, F. L., \& Hand, P. J. (2002). Educational outcome at 8 years for children who were born extremely prematurely: a controlled study. J Paediatr Child Health, 38(5), 438-444.

Boyle, M. H., Miskovic, V., Van Lieshout, R., Duncan, L., Schmidt, L. A., Hoult, L., . . . Saigal, S. (2011). Psychopathology in young adults born at extremely low birth weight. Psychol Med, 41(8), 1763-1774.

Brannigan, G. G., \& Decker, S. L. (2003). Bender visual-motor gestalt test. Examiner's manual. Itasca: Riverside Publishing.

Briscoe, J., Gathercole, S. E., \& Marlow, N. (2001). Everyday memory and cognitive ability in children born very prematurely. J Child Psychol Psychiatry, 42(6), 749-754. 
Brocki, K. C. (2007). Executive control processes : Dementions. Development and ADHD. Uppsala: Acta Universitatis Upsalienseis.

Brocki, K. C., \& Bohlin, G. (2004). Executive functions in children aged 6 to 13: a dimensional and developmental study. Dev Neuropsychol, 26(2), 571-593.

Brodd, K. S. (2011). Delayed development of visualmotor capacity in very preterm infants. Uppsala: Acta universitatis upsaliensis uppsala.

Butcher, P. R., van Braeckel, K., Bouma, A., Einspieler, C., Stremmelaar, E. F., \& Bos, A. F. (2009). The quality of preterm infants' spontaneous movements: an early indicator of intelligence and behaviour at school age. J Child Psychol Psychiatry, 50(8), 920-930.

Böhm, B., Katz-Salamon, M., Smedler, A. C., Lagercrantz, H., \& Forssberg, H. (2002). Developmental risks and protective factors for influencing cognitive outcome at $51 / 2$ years of age in very-lowbirthweight children. Dev Med Child Neurol, 44(8), 508-516.

Böhm, B., Lundequist, A., \& Smedler, A. C. (2010). Visual-motor and executive functions in children born preterm: The Bender Visual Motor Gestalt Test revisited. Scand J Psychol.

Böhm, B., Smedler, A. C., \& Forssberg, H. (2004). Impulse control, working memory and other executive functions in preterm children when starting school. Acta Paediatr, 93(10), 1363-1371.

Cartlidge, P. H., \& Stewart, J. H. (1997). Survival of very low birthweight and very preterm infants in a geographically defined population. Acta Paediatr, 86(1), 105-110.

Chaudhari, S., Otiv, M., Chitale, A., Pandit, A., \& Hoge, M. (2004). Pune low birth weight study--cognitive abilities and educational performance at twelve years. Indian Pediatr, 41(2), 121-128.

Chen, H. J., Fan, X. F., Gao, X. R., Liu, X. H., Wu, B. Q., Wu, G. Q., \& Zhou, C. L. (2009). Multicenter follow-up report of 147 premature infants with brain injuries from 6 hospitals in China. Zhongguo Dang Dai Er Ke Za Zhi, 11(3), 166-172.

Cioni, G., Fazzi, B., Coluccini, M., Bartalena, L., Boldrini, A., \& van Hofvan Duin, J. (1997). Cerebral visual impairment in preterm infants with periventricular leukomalacia. Pediatr Neurol, 17(4), 331-338.

Colvin, M., McGuire, W., \& Fowlie, P. W. (2004). Neurodevelopmental outcomes after preterm birth. Bmj, 329(7479), 1390-1393.

Copper, R. L., Goldenberg, R. L., Das, A., Elder, N., Swain, M., Norman, G., . . Meier, A. M. (1996). The preterm prediction study: maternal stress is associated with spontaneous preterm birth at less than thirty-five weeks' gestation. National Institute of Child Health and Human Development Maternal-Fetal Medicine Units Network. Am J Obstet Gynecol, 175(5), 1286-1292.

Cornforth, C. M., Thompson, J. M., Robinson, E., Waldie, K. E., Pryor, J. E., Clark, P., . . . Mitchell, E. A. (2011). Children born small for gestational age are not at special risk for preschool emotion and behaviour problems. Early Hum Dev. 
Dall'oglio, A. M., Rossiello, B., Coletti, M. F., Bultrini, M., C, D. E. M., Rava, L., . . . Cuttini, M. (2010). Do healthy preterm children need neuropsychological follow-up? Preschool outcomes compared with term peers. Dev Med Child Neurol, 52(10), 955-961.

Davis-Kean, P. E. (2005). The influence of parent education and family income on child achievement: the indirect role of parental expectations and the home environment. J Fam Psychol, 19(2), 294304.

De Groote, I., Roeyers, H., \& Warreyn, P. (2006). Social -communicative ablities in young high-risk preterm children. $J$ clin Exp Neuropsychol, 19(2), 261-274.

de Kieviet, J. F., Zoetebier, L., Van Elburg, R. M., Vermeulen, R. J., \& Oosterlaan, J. (2012). Brain development of very preterm and very low-birthweight children in childhood and adolescence: a metaanalysis. Dev Med Child Neurol, 54(4), 313-323.

De Luca, C. R., \& Leventer, R. J. (2008). Developmental trajectories of executive functions across the lifespan. In V. Anderson, R. Jacobs \& A. P. (Eds.), Executive Functions and the Frontal Lobes. A Lifespan Perspective (pp. 23-46). Hove, East Sussex och New York: Taylor \& Francis Group.

Delis, D. C., Kaplan, E., \& Kramer, J. H. (2001). Delis-Kaplan Executive Function System (D-KEFS). Examiner's manual. San Antonio, TX: The Psychological Corporation.

Deng, W., Pleasure, J., \& Pleasure, D. (2008). Progress in periventricular leukomalacia. Arch Neurol, 65(10), 1291-1295.

Dennis, M., Francis, D. J., Cirino, P. T., Schachar, R., Barnes, M. A., \& Fletcher, J. M. (2009). Why IQ is not a covariate in cognitive studies of neurodevelopmental disorders. J Int Neuropsychol Soc, 15(3), 331-343.

Diamond, A., \& Goldman-Rakic, P. S. (1989). Comparison of human infants and rhesus monkeys on Piaget's AB task: evidence for dependence on dorsolateral prefrontal cortex. Exp Brain Res, 74(1), 24-40.

Donders, J. (1997).Short form of the WISC-III for clinical use. Psychological assesment, 9(1), 15-20.

Drews-Botsch, C., Schieve, L. A., Kable, J., \& Coles, C. (2011). Socioeconomic differences and the impact of being small for gestational age on neurodevelopment among preschool-aged children. Rev Environ Health, 26(3), 221-229.

Drillien, C. M., Thomson, A. J., \& Burgoyne, K. (1980). Low-birthweight children at early school-age: a longitudinal study. Developmental Medicine and Child Neurology, 22(1), 26-47.

Erikson, C., Allert, C., Carlberg, E. B., \& Katz-Salamon, M. (2003). Stability of longitudinal motor development in very low birthweight infants from 5 months to 5.5 years. Acta Paediatr, 92(2), 197-203.

Erikson, E. H. (1950). Childhood and society. New York: Norton. 
Eslinger, P., Biddle, K., Pennington, B., \& Page, R. (1999). Cognitive and behavioral development up to 4 years after right frontal lobe lesion. Developmental neuropsychology, 15, 157-191.

Espy, K. A. (2004). Using developmental, cognitive, and neuroscience approaches to understand executive control in young children. Dev Neuropsychol, 26(1), 379-384.

EXPRESS. (2010). Incidence of and risk factors for neonatal morbidity after active perinatal care: extremely preterm infants study in Sweden (EXPRESS). Acta Paediatr, 99(7), 978-992.

Fellman, V., Hellstrom-Westas, L., Norman, M., Westgren, M., Kallen, K., Lagercrantz, H., . . . Wennergren, M. (2009). One-year survival of extremely preterm infants after active perinatal care in Sweden. Jama, 301(21), 2225-2233.

Foster-Cohen, S., Edgin, J. O., Champion, P. R., \& Woodward, L. J. (2007). Early delayed language development in very preterm infants: evidence from the MacArthur-Bates CDI. J Child Lang, 34(3), 655675.

Freud, S. (1973). An outline of psychoanalysis. London: Hograth.

Garth, J., Anderson, V., \& Wrennall, J. (1997). Executive functions following moderate to severe frontal lobe injury: impact of injury and age at injury. Pediatr Rehabil, 1(2), 99-108.

Gathercole, S. E., Pickering, S. J., Ambridge, B., \& Wearing, H. (2004). The structure of working memory from 4 to 15 years of age. Dev Psychol, 40(2), 177-190.

Gerner, E.(1999). Emotional interaction in a group of preterm infants at 3 and 6 months of corrected age. Infant and child development, 8,117128.

Gerner, E. M., Katz-Salamon, M., Hesser, U., Soderman, E., \& Forssberg, H. (1997). Psychomotor development at 10 months as related to neonatal health status: the Stockholm Neonatal Project. Acta Paediatr Suppl, 419, 37-43.

Gisselmann, M., Koupil, I., \& De Stavola, B. L. (2010). The combined influence of parental education and preterm birth on school performance. J Epidemiol Community Health, 65(9), 764-769.

Goddeeris, J. H., Saigal, S., Boyle, M. H., Paneth, N., Streiner, D. L., \& Stoskopf, B. (2010). Economic outcomes in young adulthood for extremely low birth weight survivors. Pediatrics, 126(5), e11021108 .

Goyen, T. A., Todd, D. A., Veddovi, M., Wright, A. L., Flaherty, M., \& Kennedy, J. (2006). Eye-hand co-ordination skills in very preterm infants <29 weeks gestation at 3 years: Effects of preterm birth and retinopathy of prematurity. Early Hum Dev, 82(11), 739-745.

Groen, S. E., de Blecourt, A. C., Postema, K., \& Hadders-Algra, M. (2005). General movements in early infancy predict neuromotor development at 9 to 12 years of age. Dev Med Child Neurol, 47(11), 731-738. 
Grunau, R. E., Whitfield, M. F., Petrie-Thomas, J., Synnes, A. R., Cepeda, I. L., Keidar, A., . . . Johannesen, D. (2009). Neonatal pain, parenting stress and interaction, in relation to cognitive and motor development at 8 and 18 months in preterm infants. Pain, 143(1-2), 138-146.

Gäddlin, P. O. (2011). Follow-up studies of very low birthweight children in Sweden. Acta Paediatr, 100(7), 940-949.

Hack, M., Flannery, D. J., Schluchter, M., Cartar, L., Borawski, E., \& Klein, N. (2002). Outcomes in young adulthood for very-low-birth-weight infants. N Engl J Med, 346(3), 149-157.

Hack, M., \& Taylor, H. G. (2000). Perinatal brain injury in preterm infants and later neurobehavioral function. Jama, 284(15), 1973-1974.

Hack, M., Taylor, H. G., Drotar, D., Schluchter, M., Cartar, L., WilsonCostello, D., . . . Morrow, M. (2005). Poor predictive validity of the Bayley Scales of Infant Development for cognitive function of extremely low birth weight children at school age. Pediatrics, 116(2), 333-341.

Hallin, A. L., Hellström-Westas, L., \& Stjernqvist, K. (2010). Follow-up of adolescents born extremely preterm: cognitive function and health at 18 years of age. Acta Paediatr, 99(9), 1401-1406.

Hallin, A. L., \& Stjernqvist, K. (2011a). Adolescents born extremely preterm: behavioral outcomes and quality of life. Scand J Psychol, 52(3), 251-256.

Hallin, A. L., \& Stjernqvist, K. (2011b). Follow-up of adolescents born extremely preterm: self-perceived mental health, social and relational outcomes. Acta Paediatr, 100(2), 279-283.

Harris, M., \& Butterworth, G. (2002). Developmental psychology. New York: Psychology Press.

Heineman, K. R., La Bastide-Van Gemert, S., Fidler, V., Middelburg, K. J., Bos, A. F., \& Hadders-Algra, M. (2010). Construct validity of the Infant Motor Profile: relation with prenatal, perinatal, and neonatal risk factors. Dev Med Child Neurol, 52(9), e209-215.

Henderson, S. E., \& Sugden, D.A. (1992). Movement assessment battery for children. London: Psychological Corportation.

Hintz, S. R., Kendrick, D. E., Wilson-Costello, D. E., Das, A., Bell, E. F., Vohr, B. R., \& Higgins, R. D. (2011). Early-childhood neurodevelopmental outcomes are not improving for infants born at $<25$ weeks' gestational age. Pediatrics, 127(1), 62-70.

Hintz, S. R., Kendrick, D. E., Vohr, B. R., Poole, W. K., \& Higgins, R. D. (2005). Changes in neurodevelopmental outcomes at 18 to 22 months' corrected age among infants of less than 25 weeks' gestational age born in 1993-1999. Pediatrics, 115(6), 1645-1651.

Hoff Esbjørn, B., Hansen, B. M., Greisen, G., \& Mortensen, E. L. (2006). Intellectual development in a Danish cohort of prematurely born preschool children: specific or general difficulties? J Dev Behav Pediatr, 27(6), 477-484. 
Hoffman, M. C., Jeffers, S., Carter, J., Duthely, L., Cotter, A., \& GonzalezQuintero, V. H. (2007). Pregnancy at or beyond age 40 years is associated with an increased risk of fetal death and other adverse outcomes. Am J Obstet Gynecol, 196(5), e11-13.

Howard, K., Anderson, P. J., \& Taylor, H. G. (2008). Executive functioning and attention in children born preterm. In V. Anderson, Jacobs, R.,\& Anderson, P.J. (Ed.), Executive functions and frontal lobes (Vol. Eds). London: Taylor \& Francis.

Hutton, J. L., Pharoah, P. O., Cooke, R. W., \& Stevenson, R. C. (1997). Differential effects of preterm birth and small gestational age on cognitive and motor development.. Arch Dis Child Fetal Neonatal Ed, 76(2), F75-81.

Indredavik, M. S., Vik, T., Heyerdahl, S., Kulseng, S., Fayers, P., \& Brubakk, A. M. (2004). Psychiatric symptoms and disorders in adolescents with low birth weight. Arch Dis Child Fetal Neonatal $E d, 89(5)$, F445-450.

Ingemarsson, I. (2003). Gender aspects of preterm birth. Bjog, 110 Suppl 20, 34-38.

Jacobson, L., Lundin, S., Flodmark, O., \& Ellstrom, K. G. (1998). Periventricular leukomalacia causes visual impairment in preterm children. A study on the aetiologies of visual impairment in a population-based group of preterm children born 1989-95 in the county of Varmland, Sweden. Acta Ophthalmol Scand, 76(5), 593598.

Johansson, J., \& Cnattigius, S. (2010). Epidemiology of preterm birth. In C. Nosarti, R. M. Murray \& M. Hack (Eds.), Neurodevelopmental Outcomes of Preterm Birth (pp. 1-16). New York: Cambridge university press.

Johnson, M. H. (2005). Developmental cognitive neuroscience (2 nd ed.): Blackwell Publishing.

Kaplan, E., Goodglass, H., \& Weintraub, S. (1983). Boston Naming Test. Philadelphia: Lee \& Febiger.

Katz-Salamon, M., Gerner, E. M., Jonsson, B., \& Lagercrantz, H. (2000). Early motor and mental development in very preterm infants with chronic lung disease. Arch Dis Child Fetal Neonatal Ed, 83(1), F16.

Kesler, S. R., Reiss, A. L., Vohr, B., Watson, C., Schneider, K. C., Katz, K. H., . . Ment, L. R. (2008). Brain volume reductions within multiple cognitive systems in male preterm children at age twelve. $J$ Pediatr, 152(4), 513-520, 520 e 511.

Kolb, B., \& Wishaw, Q. (1996). Fundamentals of human neuropsychology. New York: W.H. Freeman.

Koppitz, E. M. (1964). The Bender gestalt test for young children. New York,: Grune \& Stratton.

Koppitz, E. M. (1975). The Bender gestalt test for young children. Volume II: Resarch andapprication, 1963-1973. Orlando: Grune \& Stratton. 
Korkman, M. (Ed.). (1990). NEPSY, Neuropsychological Assesment 4-7 years. Swedish Version. Stockholm: Psykologiförlaget AB.

Kyrklund-Blomberg, N. B., \& Cnattingius, S. (1998). Preterm birth and maternal smoking: risks related to gestational age and onset of delivery. Am J Obstet Gynecol, 179(4), 1051-1055.

Lagercrantz, H., Katz-Salamon, M., \& Forssberg, H. (1997). The Stockholm Neonatal Project: neonatal mortality and morbidity at the Children's Centre, Karolinska Hospital. Acta Paediatr Suppl, 419, 11-15.

Landry, S. H., Densen, S. E., \& Swank, P. R. (1997). Effects of medical risk and socioeconomic status on the rate of change in cognitive and social development for low birth weight children. J clin Exp Neuropsychol, 19(2), 261-274.

Larroque, B., Ancel, P. Y., Marchand-Martin, L., Cambonie, G., Fresson, J., Pierrat, V., . . . Marret, S. (2011). Special care and school difficulties in 8-year-old very preterm children: the Epipage cohort study. PLoS One, 6(7), e21361.

Lemons, J. A., Bauer, C. R., Oh, W., Korones, S. B., Papile, L. A., Stoll, B. J., . . Stevenson, D. K. (2001). Very low birth weight outcomes of the National Institute of Child health and human development neonatal research network, January 1995 through December 1996. NICHD Neonatal Research Network. Pediatrics, 107(1), E1.

Leon-Carrion, J., Garcia-Orza, J., \& Perez-Santamaria, F. J. (2004). Development of the inhibitory component of the executive functions in children and adolescents. Int J Neurosci, 114(10), 1291-1311.

Leversen, K. T., Sommerfelt, K., Ronnestad, A., Kaaresen, P. I., Farstad, T., Skranes, J., . . . Markestad, T. (2011). Prediction of neurodevelopmental and sensory outcome at 5 years in Norwegian children born extremely preterm. Pediatrics, 127(3), e630-638.

Lezak, M. D. (1995). Neuropsychological Assesment. New York: Oxford University Press.

Lind, A., Korkman, M., Lehtonen, L., Lapinleimu, H., Parkkola, R., Matomaki, J., \& Haataja, L. (2011). Cognitive and neuropsychological outcomes at 5 years of age in preterm children born in the 2000s. Dev Med Child Neurol, 53(3), 256-262.

Lindström, K., Winbladh, B., Haglund, B., \& Hjern, A. (2007). Preterm infants as young adults: a Swedish national cohort study. Pediatrics, 120(1), 70-77.

Luciana, M., \& Nelson, C. A. (2002). Assessment of neuropsychological function through use of the Cambridge Neuropsychological Testing Automated Battery: performance in 4- to 12-year-old children. Dev Neuropsychol, 22(3), 595-624.

Luna, B., \& Sweeney, J. A. (2004). The emergence of collaborative brain function: FMRI studies of the development of response inhibition. Ann N Y Acad Sci, 1021, 296-309. doi: 10.1196/annals.1308.035

Luria, A.R. (1973). The working brain: an introduction to neuropsychology; New York: Basic Book Inc. 
Luu, T. M., Ment, L., Allan, W., Schneider, K., \& Vohr, B. R. (2011). Executive and memory function in adolescents born very preterm. Pediatrics, 127(3), e639-646.

McNeal, R. B. (2001). Differential effects of parental involvement on cognitive and behavioral outcomes by socioeconomic status. J Socio Econ, 30, 171-179.

Mikkola, K., Ritari, N., Tommiska, V., Salokorpi, T., Lehtonen, L., Tammela, O., . . . Fellman, V. (2005). Neurodevelopmental outcome at 5 years of age of a national cohort of extremely low birth weight infants who were born in 1996-1997. Pediatrics, 116(6), 1391-1400.

Miyake, A., Friedman, N. P., Emerson, M. J., Witzki, A. H., Howerter, A., \& Wager, T. D. (2000). The unity and diversity of executive functions and their contributions to complex "Frontal Lobe" tasks: a latent variable analysis. Cogn Psychol, 41(1), 49-100.

Moster, D., Lie, R. T., \& Markestad, T. (2008). Long-term medical and social consequences of preterm birth. N Engl J Med, 359(3), 262273.

Nagy, Z., Ashburner, J., Andersson, J., Jbabdi, S., Draganski, B., Skare, S., . . . Lagercrantz, H. (2009). Structural correlates of preterm birth in the adolescent brain. Pediatrics, 124(5), e964-972.

Nagy, Z., Westerberg, H., Skare, S., Andersson, J. L., Lilja, A., Flodmark, O., . . . Klingberg, T. (2003). Preterm children have disturbances of white matter at 11 years of age as shown by diffusion tensor imaging. Pediatr Res, 54(5), 672-679.

Nosarti, C., Giouroukou, E., Healy, E., Rifkin, L., Walshe, M., Reichenberg, A., ... Murray, R. M. (2008). Grey and white matter distribution in very preterm adolescents mediates neurodevelopmental outcome. Brain, 131(Pt 1), 205-217.

Nosarti, C., Giouroukou, E., Healy, E., Rifkin, L., Walshe, M., Williams, S. C. R., \& Murray, R. M. (2007). Abnormalities of grey and white matter distribution in adolescents who were born very pre term and relationship with neurodevelopmental outcome. Acta Paediatrica, 96, 204-204.

Nosarti, C., Giouroukou, E., Micali, N., Rifkin, L., Morris, R. G., \& Murray, R. M. (2007). Impaired executive functioning in young adults born very preterm. J Int Neuropsychol Soc, 13(4), 571-581.

Nosarti, C., Murray, R., \& Hack, M. (2010). Neurodevelopmental outcomes of preterm birth : from childhood to adult life. Cambridge ; New York: Cambridge University Press.

Olausson, P. O., Cnattingius, S., \& Haglund, B. (1999). Teenage pregnancies and risk of late fetal death and infant mortality. $\mathrm{Br} J$ Obstet Gynaecol, 106(2), 116-121.

Ornstein, M., Ohlsson, A., Edmonds, J., \& Asztalos, E. (1991). Neonatal follow-up of very low birthweight/extremely low birthweight infants to school age: a critical overview. Acta Paediatr Scand, 80(8-9), 741-748. 
Papalia, D., \& Olds, S. (1992). Human development. New York: McGrawHill.

Pascanu, R., \& Jaeger, H. (2011). A neurodynamical model for working memory. Neural Netw, 24(2), 199-207.

Paus, T., Keshavan, M., \& Giedd, J. N. (2008). Why do many psychiatric disorders emerge during adolescence? Nat Rev Neurosci, 9(12), 947957.

Philbin, M. K., Ballweg, D. D., \& Gray, L. (1994). The effect of an intensive care unit sound environment on the development of habituation in healthy avian neonates. Dev Psychobiol, 27(1), 11-21.

Piaget, J. (1971). Biology and knowledge. Chicago: University of Chicago Press.

Pritchard, V. E., Clark, C. A., Liberty, K., Champion, P. R., Wilson, K., \& Woodward, L. J. (2009). Early school-based learning difficulties in children born very preterm. Early Hum Dev, 85(4), 215-224.

Pyhala, R., Lahti, J., Heinonen, K., Pesonen, A. K., Strang-Karlsson, S., Hovi, P., . . . Raikkonen, K. (2011). Neurocognitive abilities in young adults with very low birth weight. Neurology, 77(23), 20522060.

Reiss, A. L., Kesler, S. R., Vohr, B., Duncan, C. C., Katz, K. H., Pajot, S., . . . Ment, L. R. (2004). Sex differences in cerebral volumes of 8-yearolds born preterm. J Pediatr, 145(2), 242-249.

Rey, A. (1964). L'examen clinique en psychologie. Paris: Presses Universitaires de France.

Riley, K., Roth, S., Sellwood, M., \& Wyatt, J. S. (2008). Survival and neurodevelopmental morbidity at 1 year of age following extremely preterm delivery over a 20-year period: a single centre cohort study. Acta Paediatr, 97(2), 159-165.

Roberts, G., Lim, J., Doyle, L. W., \& Anderson, P. J. (2011). High rates of school readiness difficulties at 5 years of age in very preterm infants compared with term controls. J Dev Behav Pediatr, 32(2), 117-124.

Rose, S. A., \& Feldman, J. F. (1996). Memory and processing speed in preterm children at eleven years: a comparison with full-terms. Child Dev, 67(5), 2005-2021.

Rose, S. A., Feldman, J. F., \& Jankowski, J. J. (2009). Information Processing in Toddlers: Continuity from Infancy and Persistence of Preterm Deficits. Intelligence, 37(3), 311-320.

Rushe, T. M., Rifkin, L., Stewart, A. L., Townsend, J. P., Roth, S. C., Wyatt, J. S., \& Murray, R. M. (2001). Neuropsychological outcome at adolescence of very preterm birth and its relation to brain structure. Dev Med Child Neurol, 43(4), 226-233.

Saavalainen, P., Luoma, L., Bowler, D., Maatta, S., Kiviniemi, V., Laukkanen, E., \& Herrgard, E. (2007). Spatial span in very prematurely born adolescents. Dev Neuropsychol, 32(3), 769-785.

Saigal, S., Hoult, L. A., Streiner, D. L., Stoskopf, B. L., \& Rosenbaum, P. L. (2000). School difficulties at adolescence in a regional cohort of 
children who were extremely low birth weight. Pediatrics, 105(2), 325-331.

Saigal, S., \& O'Brodovich, H. (1987). Long-term outcome of preterm infants with respiratory disease. Clin Perinatol, 14(3), 635-650.

Saigal, S., Pinelli, J., Hoult, L., Kim, M. M., \& Boyle, M. (2003). Psychopathology and social competencies of adolescents who were extremely low birth weight. Pediatrics, 111(5 Pt 1), 969-975.

Satz, P. (1993). Brain reserve capacity on symptom onset after brain injury: a formulation and review of evidence for threshold theory. Neuropsychology, 7, 273-295.

Schafer, R. J., Lacadie, C., Vohr, B., Kesler, S. R., Katz, K. H., Schneider, K. C., . . . Ment, L. R. (2009). Alterations in functional connectivity for language in prematurely born adolescents. Brain, 132(Pt 3), 661670.

Schmidt, M. (1996). Rey Auditory and Verbal Learning Test: A handbook. Los Angelse, CA: Western Psychological Services.

Shah, D. K., Doyle, L. W., Anderson, P. J., Bear, M., Daley, A. J., Hunt, R. W., \& Inder, T. E. (2008). Adverse neurodevelopment in preterm infants with postnatal sepsis or necrotizing enterocolitis is mediated by white matter abnormalities on magnetic resonance imaging at term. J Pediatr, 153(2), 170-175, 175 e171.

Shaywitz, B. A., Shaywitz, S. E., Pugh, K. R., Constable, R. T., Skudlarski, P., Fulbright, R. K., . . . et al. (1995). Sex differences in the functional organization of the brain for language. Nature, 373(6515), 607-609.

Skranes, J., Lohaugen, G. C., Evensen, K. A., Indredavik, M. S., Haraldseth, O., Dale, A. M., . . . Martinussen, M. (2012). Entorhinal cortical thinning affects perceptual and cognitive functions in adolescents born preterm with very low birth weight (VLBW). Early Hum Dev, 88(2), 103-109.

Skranes, J., Lohaugen, G. C., Martinussen, M., Indredavik, M. S., Dale, A. M., Haraldseth, O., . . . Brubakk, A. M. (2009). White matter abnormalities and executive function in children with very low birth weight. Neuroreport, 20(3), 263-266.

Sommerfelt, K., Markestad, T., \& Ellertsen, B. (1998). Neuropsychological performance in low birth weight preschoolers: a population-based, controlled study. European Journal of Pediatrics, 157(1), 53-58.

Stanley,F., Blair,B., \& Alberman, E.(2000) Cerebral palsies: epidemiology \& causal pathways. Clinics in Developmental Medicin, 151 Mac Keith press.Cambridge university Press.

Stephens, B. E., \& Vohr, B. R. (2009). Neurodevelopmental outcome of the premature infant. Pediatr Clin North Am, 56(3), 631-646, Table of Contents.

Stoll, B. J., Hansen, N. I., Adams-Chapman, I., Fanaroff, A. A., Hintz, S. R., Vohr, B., \& Higgins, R. D. (2004). Neurodevelopmental and growth impairment among extremely low-birth-weight infants with neonatal infection. JAMA, 292(19), 2357-2365. 
Strand-Brodd, K., Ewald, U., Gronqvist, H., Holmstrom, G., Stromberg, B., Gronqvist, E., . . . Rosander, K. (2011). Development of smooth pursuit eye movements in very preterm infants: 1 . General aspects. Acta Paediatrica, 100(7), 983-991.

Stjernqvist, K., \& Svenningsen, N. W. (1999). Ten-year follow-up of children born before 29 gestational weeks: health, cognitive development, behaviour and school achievement. Acta Paediatr, 88(5), 557-562.

Strauss, E., Wada, J., \& Hunter, M. (1992). Sex-related differences in the cognitive consequences of early left-hemisphere lesions. J Clin Exp Neuropsychol, 14(5), 738-748.

Strauss, R. S. (2000). Adult functional outcome of those born small for gestational age: twenty-six-year follow-up of the 1970 British Birth Cohort. JAMA, 283(5), 625-632.

Stuss, D. T., \& Alexander, M. P. (2000). Executive functions and the frontal lobes: a conceptual view. Psychol Res, 63(3-4), 289-298.

Takashima, S., \& Tanaka, K. (1978). Development of cerebrovascular architecture and its relationship to periventricular leukomalacia. Arch Neurol, 35(1), 11-16.

Taylor, H. G., Minich, N., Bangert, B., Filipek, P. A., \& Hack, M. (2004). Long-term neuropsychological outcomes of very low birth weight: associations with early risks for periventricular brain insults. $J$ Int Neuropsychol Soc, 10(7), 987-1004.

Taylor, L. C., Clayton, J. D., \& Rowley, S. J. (2004). Academic socialization: Understanding parental influences on chilren's schoolrelated development in the early years. Review of General Psychology, 8(3), 163-178.

Vohr, B. R., Wright, L. L., Dusick, A. M., Perritt, R., Poole, W. K., Tyson, J. E., . . . Mayes, L. C. (2004). Center differences and outcomes of extremely low birth weight infants.Pediatrics, 113(4), 781-789.

Vohr, B. R., Wright, L. L., Poole, W. K., \& McDonald, S. A. (2005). Neurodevelopmental outcomes of extremely low birth weight infants <32 weeks' gestation between 1993 and 1998. Pediatrics, 116(3), 635-643.

Volpe, J. (Ed.). (2008). Neurology of the Newborn. Philadelpia: Saunders Elsevier.

Vygotsky, L. S. (1978). Mind in society: The development of higher mental process. Cambridge, MA: Harvard University Press.

Wallace, I. F., Rose, S. A., McCarton, C. M., Kurtzberg, D., \& Vaughan, H. G., Jr. (1995). Relations between infant neurobehavioral performance and cognitive outcome in very low birth weight preterm infants. J Dev Behav Pediatr, 16(5), 309-317.

van Wassenaer, A. (2005). Neurodevelopmental consequences of being born SGA. Pediatr Endocrinol Rev, 2(3), 372-377.

Washburn, L. K., Dillard, R. G., Goldstein, D. J., Klinepeter, K. L., deRegnier, R. A., \& O'Shea, T. M. (2007). Survival and major 
neurodevelopmental impairment in extremely low gestational age newborns born 1990-2000: a retrospective cohort study. BMC Pediatr, 7, 20.

Wechsler, D. (1991). Wechsler Intelligence Scale for Children: WISC-III. Stockholm: Psykologiförlaget AB.

Wechsler, D. (1997) Wechsler Adult Intelligence Scale- third edition. San Antonio, TX: The psychological corporation.

Wechsler, D. (1999). Wechsler preschool and primary scale of intelligencerevised. Swedish version. Stockholm: Psykologiförlaget AB.

Westrup, B., Kleberg, A., von Eichwald, K., Stjernqvist, K., \& Lagercrantz, H. (2000). A randomized, controlled trial to evaluate the effects of the newborn individualized developmental care and assessment program in a Swedish setting. Pediatrics, 105(1 Pt 1), 66-72.

Wharton, K. N., Pinar, H., Stonestreet, B. S., Tucker, R., McLean, K. R., Wallach, M., \& Vohr, B. R. (2004). Severe umbilical cord inflammation-a predictor of periventricular leukomalacia in very low birth weight infants. Early Hum Dev, 77(1-2), 77-87.

Wilcox, T., Nadel, L., \& Rosser, R. (1996). Location Memory in Healthy Preterm and Full-Term Infants. Infant behavior and development, 19(3), 309-323.

Wilson-Costello, D., Friedman, H., Minich, N., Fanaroff, A. A., \& Hack, M. (2005). Improved survival rates with increased neurodevelopmental disability for extremely low birth weight infants in the 1990s. Pediatrics, 115(4), 997-1003. Viggedal, G., Lundalv, E., Carlsson, G., \& Kjellmer, I. (2004). Neuropsychological follow-up into young adulthood of term infants born small for gestational age. Med Sci Monit, 10(1), CR8-16.

Wolke, D., \& Meyer, R. (1999). Cognitive status, language attainment, and prereading skills of 6-year-old very preterm children and their peers: the Bavarian Longitudinal Study. Dev Med Child Neurol, 41(2), 94109.

Woodward, L. J., Edgin, J. O., Thompson, D., \& Inder, T. E. (2005). Object working memory deficits predicted by early brain injury and development in the preterm infant. Brain, 128(Pt 11), 2578-2587.

Yeh, T. F., Lin, Y. J., Lin, H. C., Huang, C. C., Hsieh, W. S., Lin, C. H., \& Tsai, C. H. (2004). Outcomes at school age after postnatal dexamethasone therapy for lung disease of prematurity. $N$ Engl $J$ Med, 350(13), 1304-1313. 